\title{
Redundant Information and Predictable Returns
}

\begin{abstract}
How well do investors distinguish information that already is priced from genuinely novel and exclusive private information? This paper examines whether investors misweight information that already is in stock prices ("redundant information") in making their trading decisions. I extend the Kyle (1985) model to allow for nonBayesian updating and transaction costs. The model predicts that price changes exhibit a state space process, in which the parameter for investors' non-Bayesian weighting of redundant information is estimable distinctly from information asymmetry, transaction costs, and serial correlation in liquidity trader demand. Using this model, I estimate a firm-quarter measure of investors' misweighting of redundant information. I find that, on average, investors behave as if over 47 percent of the information content in the immediately prior price change is private information. Overall, these results suggest one way that momentum and mean reversion in stock price returns could result from investors' misuse of information.
\end{abstract}




\section{Introduction}

A number of predictable patterns in stock price returns suggest that investors misperceive the amount of information already incorporated into stock prices. For example, extensive survey evidence documents that investors form expectations of future returns by extrapolating from past returns (e.g., Malmendier and Nagel, 2011, Amromin and Sharpe, 2014, Greenwood and Shleifer, 2014, Hoffmann and Post, 2015). These extrapolation-driven beliefs, in combination with frictions to arbitrage, could contribute to momentum in the returns of individual equities, industries, mutual funds, and country-wide equity indices (e.g., Jegadeesh and Titman, 1993, 2001, Carhart, 1997, Asness, Moskowitz, and Pedersen, 2013, Géczy and Samonov, 2015, 2016).

Explanations for this seeming violation of the efficient markets hypothesis are varied (see Harvey, Liu, and Zhu, 2016 and Novy-Marx and Velikov, 2016, for recent reviews). Daniel and Hirshleifer [2015] argue that psychological biases constrain investors' ability to form unbiased expectations of future returns. Banerjee, Kaniel, and Kremer [2009], Banerjee [2011], and others argue that investors overreact to their own private information and dismiss the information in prices as noise. Abreu and Brunnermeier [2002, 2003] suggest why this misuse of information can persist. They argue that frictions to arbitrage, such as capital constraints, could encourage arbitrageurs to delay exploiting mispricing or even trade in the same direction as, rather than against, mispricing.

In prior work, empirical identification of non-Bayesian investor behavior has proven difficult. Models of non-Bayesian weighting of information signals and models of information asymmetry or trading costs often yield the same empirical predictions about stock price behavior. For example, Daniel, Hirshleifer, and Subrahmanyam [1998] and Odean [1998] present models of non-Bayesian behavior and show that excessive weighting of private information leads to higher stock price volatility and greater trading volume. In a rational expectations setting, Kim and Verrecchia [1997] show that greater dispersion in investors' information precision also leads to greater price volatility and trading volume. Information asymmetry not only generates similar stock price behavior as information processing biases do, but also can facilitate higher equilibrium levels of information processing biases. Fischer and Verrecchia [1999] show that, if given the choice, privately informed investors would trade as if their private signals were more informative than the signals really are. They find that this exaggeration of information precision is increasingly profitable as information asymmetry increases.

To ascertain the information mechanisms that underlie predictable stock price returns, and distinguish the misweighting of information from information precision, I present an analytical model and structural estimation that identify investors' misweighting of information that is already priced. I label information that is already priced as "redundant information." I choose the term "redundant information" to indicate formerly private information that 
is impounded into the stock price and no longer could provide an investor with an information advantage. ${ }^{1}$

I extend the standard Kyle [1985] model to allow for trading costs and the possibility that informed investors overreact or under-react to their private signals about the value of a risky asset. Specifically, I assume that informed investors observe a private signal that comprises some private information and some public information, but behave as if the private signal has greater or less private information than the signal truly has. If informed investors exaggerate the novelty and exclusivity of their private signal, they would tend to trade in the same direction as prior informed investors did, and subsequent price changes could exhibit momentum. If informed investors under-react to the novelty and exclusivity of their private signal, they would tend to trade in the opposite direction of prior informed investors, and subsequent price changes would exhibit mean-reversion.

The analytical model predicts that price changes exhibit a state space process in which investors' misweighting redundant information is identifiable separately and distinctly from information asymmetry and trading costs. I estimate the parameters of this price change process by maximum likelihood by firm-quarter. This estimation yields a firm-quarter measure of informed investors' misweighting of redundant information.

I find that informed investors overweight redundant information more often than not. Investors weight redundant information excessively in 72 percent of the 107,850 firm-quarter estimations on five-minute returns (65 percent of the estimations at the 5 percent statistical significance level). Investors weight redundant information excessively in 79 percent of the 136,500 firm-quarter estimations on 12-minute returns (72 percent of the estimations at the 5 percent statistical significance level). Investors weight redundant information excessively in 82 percent of the 160,700 firm-quarter estimations on 30-minute returns (65 percent of the estimations at the 5 percent statistical significance level). In sum, investors appear to behave as if information content in the immediately prior price change contains novel private information.

To validate that the estimated measure reflects investors' misweighting of information, I conduct three studies. First, the analytical model predicts that trading on redundant information reduces informed investors' expected profits from trading on genuine private information, but would not completely negate informed investors' expected profits if the misweighting is not too egregious. I estimate that the magnitude of trading on redundant information would not wipe out informed investors' expected profits for at minimum 93 percent of firm-quarters. Second, the analytical model shows that rational arbitrageurs who weight redundant information fairly can profit from informed investors' misweighting of redundant information. These rational arbitrageurs are likely to correct extreme levels of

\footnotetext{
${ }^{1}$ Alternatively, Tetlock [2011] defines "stale news" as the similarity of a news story to prior news stories about the same firm. In this sense, the term "stale news" emphasizes the repetition of public information by information intermediaries. In examining "redundant information," I do not distinguish between news that information intermediaries repeated, news that investors accessed repeatedly, etc.
} 
misweighting with some delay (Abreu and Brunnermeier, 2002). Consistent with this prediction, I find evidence that investors' misweighting of redundant information mean reverts almost entirely over the next two quarters. Third, the analytical model predicts that trading volume is proportional to a linear function of the estimated parameters. I find empirical evidence consistent with this prediction.

Regarding policy implications, this paper addresses how market microstructure frictions affect the expected profits of investors who misweight information. Misweighting information monotonically decreases investors' expected profits. As shown in Appendix A.25, the expected profits of investors who misweight information increase as transaction costs decrease when transaction costs are already low, and increase as transaction costs increase when transaction costs are already high. This U-shaped function appears because high transaction costs discourage trading altogether, low transaction costs limit the price impact of trading of redundant information, and moderate transaction costs encourage trading that incurs a moderate price impact. The empirically estimated mean and median ratios of transaction costs to information asymmetry are near the point at which investors' misweighting of redundant information most harms investors' expected profits.

The paper proceeds as follows. Section 2 reviews the precedent literature. Section 3 presents the analytical model. Section 4 presents the estimation of the model and its results. Section 5 provides the construct validity tests. Section 6 concludes.

\section{Literature review}

\subsection{Empirical evidence of predictable returns}

A sufficient condition for market efficiency is that existing information cannot be used to predict future securities returns. Empirical evidence suggests, however, that securities returns can be predictable. De Bondt and Thaler [1985] provide evidence that stock prices mean-revert over consecutive three-year windows. French and Roll [1986] find that individual stocks exhibit negative autocorrelation in returns over two- to 12-day horizons. In addition, over consecutive days, stocks in the smallest quintile by market value of equity exhibit negative autocorrelation in returns, while those in the largest quintile by market value of equity exhibit positive autocorrelation in returns. Jegadeesh and Titman [1993] find that a zero-cost portfolio strategies that buys the stocks with the highest relative returns over the prior one to four quarters, sells the stocks in the lowest relative returns over the prior one to four quarters, and holds these stocks for one to four quarters consistently outperform. Investment strategies that seek to exploit this tendency have become known as relative strength strategies or momentum strategies. Subsequent research has documented profitable relative strength strategies across asset classes, geographies, and time. Carhart 
[1997] demonstrates that momentum in stock returns accounts for the persistence in mutual fund performance. Asness, Moskowitz, and Pedersen [2013] present evidence of momentum in individual stocks in the United States, the United Kingdom, continental Europe, and Japan, as well as country-wide equity index futures, government bonds, currencies, and commodity futures. Géczy and Samonov [2016] combine databases of U.S. stock price returns from 1800 to 2012, and document that relative strength strategies would have been profitable throughout these 212 years. Moskowitz, Ooi, and Pedersen [2012] document that country equity indexes, currencies, commodities, and sovereign bonds also exhibit momentum with respect to their own trailing 12-month returns. Heston, Korajczyk, and Sadka [2010] document similar predictable patterns in intraday returns.

\subsection{Explanations for predictable returns}

The origins of these predictable patterns in returns remain debated. Behavioral economists argue that psychological biases constrain investors' ability to form unbiased beliefs about the distribution of future returns (Daniel and Hirshleifer, 2015, Thaler, 2016). Among possible psychological biases, survey evidence documents that investors form expectations of future returns by extrapolating from past returns during salient periods (e.g., Malmendier and Nagel, 2011, Greenwood and Shleifer, 2014, Hoffmann and Post, 2015). DeLong et al. [1990], Barberis and Shleifer [2003], Barberis et al. [2015], and others present theoretical models in which certain investors hold extrapolative beliefs - expectations of future returns that extrapolate from recent past returns. In Barberis et al. [2015], for example, "extrapolators" believe that mean future returns are a weighted average of recent past returns. Their model predicts that the dividend-to-price ratio predicts stock price returns, which is consistent with empirical evidence. Their model, however, also predicts that price changes exhibit negative autocorrelation at all horizons, which is not consistent with empirical evidence. Theoretical models that allow investors to hold extrapolation-driven beliefs generally find that, although such investors lose money on average, they can survive long enough to affect securities returns (e.g., Kogan et al., 2006, Yan, 2008).

Behavioral economists also have documented that investors overestimate their information precision, using survey evidence (e.g., Ben-David, Graham, and Harvey, 2013, Glaser, Langer, and Weber, 2013) and proprietary data on investor attributes as proxies for cross-sectional variation in investors' embellishment of their own information precision (e.g., Barber and Odean, 2001, Grinblatt and Keloharju, 2009, Døskeland and Hvide, 2011). Kyle and Wang [1997] and Fischer and Verrecchia [1999] present theoretical models in which informed investors could exaggerate the precision of their private information. Extending the Kyle [1985] framework, the authors assume that two or more informed investors may behave as if the precision of their private signals is greater or less than it truly is. The authors show that, given the choice, exaggerating one's precision could be an informed investor's optimal strategy. 
Informed investors who exaggerate their information precision ("heuristic investors") essentially are committed to trading aggressively, which leads investors who weight their private information fairly ("Bayesian investors") to trade less aggressively. As a result, heuristic investors could earn higher expected profits than Bayesian investors would earn. Fischer and Verrecchia [1999] show that, if few heuristic investors are present, an informed investor might choose to behave as if his private signal has greater precision than the signal really has. Further, Kyle and Wang [1997] show that, if two investment funds must decide whether to hire a heuristic investor or a Bayesian investor as portfolio manager, these funds face a prisoner's dilemma in which hiring a heuristic investor is the Nash dominant strategy, even though each fund would earn higher expected profits if both hired Bayesian portfolio managers.

As an alternative explanation for predictable returns, the functional fixation hypothesis conjectures that investors with limited attention exaggerate the precision of easily accessible information in forming their beliefs about the value of risky assets (Watts and Zimmerman, 1986). In theoretical models, Hirshleifer and Teoh [2003] and Hirshleifer, Lim, and Teoh [2011] consider environments in which some investors have limited attention and can overweight certain signals. They demonstrate that this misweighting of signals can affect prices. Empirical studies of functional fixation often hypothesize that investors overemphasize reported earnings and underweight other accounting information, such as operating cash flows (e.g., Sloan, 1996) or interim reports of capital structure transactions (e.g., Hand, 1990). These studies often assume that some investors act on miscalibrated beliefs at one information event and correct their beliefs at another information event (e.g., sequential quarterly earnings announcements).

Other work considers the possibility that investors dismiss the information content of other investors' trading activity and misunderstand the informativeness of stock prices. Varian [1989] labeled circumstances in which agents know one another's beliefs but regard others' beliefs as lacking information content as "differences of opinion." Harrison and Kreps [1978] present a "differences of opinion" environment in which investors have heterogeneous, subjective beliefs about the value of a risky asset and the risky asset cannot be sold short. In such an environment, investors who value the risky asset the highest acquire the asset. The price of the asset tends toward the highest subjective belief and speculative bubbles can occur. Xiong [2013] reviews numerous theoretical models with differences of opinion and short sale constraints that predict speculative bubbles. Banerjee [2011] and Banerjee and Green [2015] posit "differences of opinion" environments in which informed investors behave as if other informed investors' private signals are noise or are uncertain of the quality of other informed investors' private signals. These models yield empirical predictions of how stock price volatility and trading volume vary with investors' dispersion in beliefs.

Frictions to arbitrage - such as short sale restrictions and capital constraints - can explain the persistence of predictable patterns in returns, but not their origins. Shleifer and Vishny [1997] explain that real-world arbitrage opportunities typically require traders to post collateral and expose traders to short-term volatility in prices. If traders 
face potential capital constraints or collateral shortfalls, they must be selective in which arbitrage opportunities they attempt to exploit (Amihud and Mendelson, 1980). Shleifer and Vishny [1997] show that, when arbitrageurs' access to capital covaries with their immediate past performance on a mark-to-market basis, arbitrageurs lose the capacity to exploit arbitrage opportunities as their expected returns increase. In addition, as the counter-cyclicality between arbitrageurs' access to capital and expected returns increases, the persistence of mispricing increases. Abreu and Brunnermeier [2002] show that in these circumstances arbitrageurs would delay attempting to exploit a mispricing until they believe that a critical mass of other arbitrageurs have become aware of the mispricing. The authors label this coordination problem as "synchronization risk." Abreu and Brunnermeier [2003] show that rational arbitrageurs might even trade in the same direction as, rather than against, the mispricing until they believe that enough other arbitrageurs have become aware of the mispricing and gathered to exploit it.

\subsection{Complications in identifying non-Bayesian investor behavior}

Theoretical models of non-Bayesian weighting of information signals often yield the same predictions regarding observable trading activity as theoretical models of information asymmetry or trading costs yield. The similarity of these comparative statics has impeded identifying non-Bayesian investor behavior empirically. Fischer and Verrecchia [1999] recognize this challenge:

Our comparative static results provide explicit predictions regarding the extent of heuristic behavior.

Direct tests of these predictions, however, are likely to be difficult because doing so would require a good proxy for heuristic trade. We are reluctant to suggest such a proxy. (p. 104)

Nevertheless, some authors have suggested empirical proxies for non-Bayesian investor behavior. For example, Gervais and Odean [2001] argue that investors are prone to overestimate their information processing ability due to self-serving attribution bias. They predict that, following positive portfolio returns, investors behave like their information precision is greater and trade more aggressively. As evidence of this prediction, Statman, Thorley, and Vorkink [2006] and Griffin, Nardari, and Stulz [2007] find that trading volume in individual stocks increases after positive market returns. Trading volume also could have increased, however, due to a change in the heterogeneity in investors' information precision (Kim and Verrecchia, 1997). Consistent with an information asymmetry explanation, Griffin, Nardari, and Stulz [2007] find that this increase in trading volume is greater in countries with greater corruption, short sale constraints, and market volatility. Similarly, Huddart, Lang, and Yetman [2009] find that trading volume is higher after a stock crosses through its 52-week high or 52-week low. This increase in trading volume around highs and lows appears stronger when information asymmetry is likely to be higher - for small, young, and volatile firms and when institutional investor holdings are low. 
Similarly, recent empirical literature questions whether "home bias" actually reflects an information advantage. French and Poterba [1991] first documented that U.S. investors hold excessively large portfolio allocations in U.S. assets relative to an efficient frontier portfolio that includes international assets. Coval and Moskowitz [1999] document that mutual fund managers tend to hold large positions in firms whose headquarters are closer geographically. More recently authors have questioned whether this seeming under-diversification puzzle reflects an information advantage. Coval and Moskowitz [2001] and Baik, Kang, and Kim [2010] argue that investors exhibit an advantage in gathering and processing information on geographically close firms, and document that institutional investors in the U.S. appear to earn excess profits on their holdings in local firms. Internationally, evidence is mixed. For example, Choe et al. [2001] using Korean data, Hau [2001] using German data, Dvořák [2005] using Indonesian data, and Choi et al. [2017] using a cross section of 72 countries find that investors who hold larger concentrations of their portfolios in domestic firms earn higher risk-adjusted returns. In contrast, Grinblatt and Keloharju [2000] using Finnish data and Froot and Ramadorai [2008] using a cross section of 25 countries find that foreigners outperform local investors. Kang and Stulz [1997] using Japanese data find no difference in the performance of domestic and foreign investors. Further, Graham, Harvey, and Huang [2009] document that investors who feel more competent tend to allocate their investments more internationally. This finding suggests, counterintuitively, that investors tend to under-diversify due to risk aversion. Finally, Giannetti and Laeven [2012] document a "flight home bias" in which syndicated lenders exhibit a tendency to concentrate their lending to local firms when market-wide costs of capital increase. In sum, extant research has not been able to identify definitively whether investors' portfolio concentration in geographically local firms reflects an information advantage or a bias in risk preferences.

Market-making activities and other market microstructure institutions also confound empirical identification of whether investors process information efficiently. Ho and Stoll [1981] show that, if trading costs are positive and the distribution of investors' demand for shares is symmetric (e.g., given an initial bid-ask spread, the probability of a buy order for a certain number of shares equals the probability of a sell order for that number of shares), price changes will exhibit negative serial covariance. Roll [1984] provides a simple example to illustrate this result. Suppose that the expected terminal value of a risky asset, $v_{t}$, follows a random walk over three rounds of trade, $t=1,2,3$. A competitive market maker in the risky asset faces a transaction cost, $w$, and passes this cost through to investors by increasing the market-clearing price if net order flow is to buy or lowering the market-clearing price if net order flow is to sell. That is, in each round the market maker sets the bid price to $p_{B, t}=v_{t}-w$ and the ask price to $p_{A, t}=v_{t}+w$. Roll labels this adjustment to the market-clearing price as the effective bid-ask spread. Suppose the probability of a buy order, event $b$, or sell order, event $s$, for one share in each period is equal to $\frac{1}{2}$, and orders are independent over time. The serial covariance in price changes over the three rounds of trade is $\operatorname{Cov}\left(p_{3}-p_{2}, p_{2}-p_{1}\right)=-w^{2}$. Stoll [1989] extends this illustrative example to allow for inventory holding costs and 
information-driven trading. He shows that in the presence of inventory holding costs not only do transaction price changes exhibit negative serial correlation, but also bid price changes and ask price changes exhibit negative serial correlation as well. In sum, market makers' variable costs give rise to mean reversion in prices.

The analytical model below extends the single period model in Kyle [1985] to allow for transaction costs - as in Roll [1984] - and the possibility that investors misuse their private information signals. The private information signal and misweighting structure extends those postulated in Kyle and Wang [1997] and Fischer and Verrecchia [1999]. The analytical model also allows for serial correlation in liquidity trader demand, as conjectured in Dontoh, Ronen, and Sarath [2003]. The combination of transaction costs, serial correlation in liquidity trader demand, and investors' misuse of their private signal in a Kyle [1985] environment yields a structural estimation specification with identified parameters for these constructs.

\section{Analytical model}

\subsection{Setup}

The following model extends Kyle [1985] to allow for the possibility that informed investors misweight redundant information. Informed investors, liquidity traders, a market maker, and rational arbitrageurs trade a single, risky asset and a numeraire asset. The risky asset has terminal value $\tilde{V}=\sum_{t=1}^{T} \tilde{v}_{t}$, where $\tilde{v}_{t}$ are independently distributed on $\mathcal{N}\left(0, \sigma_{v, t}^{2}\right) .^{2}$ At the end of period $T, V$ reveals publicly. One informed investor, one liquidity trader, and $M \geq 0$ rational arbitrageurs arrive in each in period, $t=1, \ldots, T$, to trade the risky asset with the market maker.

The market maker clears the market by taking the order imbalance, $D_{t}$, into his inventory. The market maker cannot distinguish the trading of the informed investors or rational arbitrageurs from the trading of liquidity traders; that is, the market maker observes the order imbalance as an aggregate. The market maker sets price, $P_{t}$, according to the expected value of the risky asset conditional on the order imbalance, the set of public information, denoted $H_{t-1}$, and a private transaction cost, $\rho\left|D_{t}\right|$, where $\rho \geq 0$. The parameter $\rho$ conflates the market maker's operating costs (such as interest on margin debt and capital requirements), quasi-rents for supplying liquidity, and risk aversion. The market maker passes this transaction cost through to investors by increasing the trade price by $\rho D_{t}$ if the net demand is positive or lowering the trade price by $-\rho D_{t}$ if the net demand is negative.

\footnotetext{
${ }^{2}$ Tilde accent marks distinguish random variables from their realizations.
} 
Formally, the market maker sets price by

$$
P_{t}=\mathrm{E}\left[\tilde{V} \mid D_{t}, H_{t-1}\right]+\rho D_{t}
$$

where $\mathrm{E}\left[\tilde{V} \mid D_{t}, H_{t-1}\right]=\mathrm{E}\left[\tilde{V} \mid H_{t}\right]$ denotes the expected value of the risky asset given all available public information at the end of period $t$. Within the context of the model, the public information set at the end of period $t$ comprises the history of order flow: $H_{t}=\left\{D_{1}, \ldots, D_{t}\right\}$.

In an informationally efficient market, investors gather and process information signals to gain an information advantage over other investors (e.g., Verrecchia, 1982). These information signals could include mandatory and voluntary disclosures, reports from analysts and the mass media, public information from regulators, etc. Since these information signals are public, some of their information content would be impounded into prices immediately. To obtain private information from these public signals and gain an information advantage, an investor must separate these public signals into that which is already priced and that which has not been priced. I examine an environment in which some informed investors might behave like information that is already priced is novel and exclusive insight into the value of a firm. I label information that already is priced as "redundant information" and novel, exclusive insight as "private information."

All informed investors are risk neutral. ${ }^{3}$ The informed investor in period $t$ may trade in period $t$ only. The informed investor in period $t$ observes the public information set, $H_{t-1}$, and infers the expected value of the risky asset given public information, $\mathrm{E}\left[\tilde{V} \mid H_{t-1}\right]$.

The informed investor in period $t$ also observes a private signal. The private signal comprises incremental private information and redundant information,

$$
s_{t}=v_{t}+\alpha u_{t-1}
$$

where $u_{t-1}=\mathrm{E}\left[\tilde{v}_{t-1} \mid H_{t-1}\right]$ denotes the information about $v_{t-1}$ that was priced in period $t-1$ and $\alpha$ is an exogenous scalar. The information $u_{t-1}$ is redundant because it is already known publicly and is impounded into price. Although $u_{t-1}$ is endogenous to the model, this assumption offers a straightforward way to describe information that already is public and priced.

Since $v_{t}$ is independent of all prior signals, the Bayesian updating process is simply additive. If the informed investor

\footnotetext{
${ }^{3}$ In the present model, the risky asset has a known liquidation date. As the liquidation date approaches, the remaining risk decreases. If informed investors were risk averse, the risk premium they would demand would decrease as the liquidation date approaches. As a result, prices could exhibit positive returns drift due to risk aversion, but not negative returns drift. Prior empirical literature, however, documents that securities exhibit positive and negative returns drift. The present model can predict momentum in positive returns and negative returns.
} 
in period $t$ updated his beliefs according to Bayes's rule, he would calculate the expected value of the risky asset by

$$
\mathrm{E}\left[\tilde{V} \mid s_{t}, H_{t-1}\right]=\left(s_{t}-\alpha u_{t-1}\right)+\mathrm{E}\left[\tilde{V} \mid H_{t-1}\right]=v_{t}+\mathrm{E}\left[\tilde{V} \mid H_{t-1}\right]
$$

Instead, the informed investor acts as if the private signal comprises only private information; that is, as if $\alpha u_{t-1}$ was private information. In neglecting to back out the redundant information from the private signal, the informed investor in effect chooses how much to trade using the belief

$$
v_{t}+\alpha u_{t-1}+\mathrm{E}\left[\tilde{V} \mid H_{t-1}\right]
$$

The parameter $\alpha$ represents the extent to which informed investors misweight the redundant information content in their private signals. If informed investors backed out redundant information perfectly, $\alpha=0$. If informed investors behave like their private signals have more private information and less redundant information than the signals truly have, $\alpha>0$. If informed investors understate the novelty of their private signals and overstate the extent to which their private signals already have been priced, $\alpha<0$. Using this miscalibrated belief, the informed investor in $t$ submits a market order, $x_{t}$, to maximize his perceived expected profit. ${ }^{45}$

Liquidity traders demand a random number of shares for reasons unrelated to the value of the risky asset. Black [1986] describes liquidity traders as investors who receive a signal that is "noise" relative to the value of a risky asset - i.e., independent of the value of a risky asset. Similarly, Grossman [1995] states:

Reasons for these noninformational trades include cross-sectional changes in wealth, risk preferences, liquidity needs, unanticipated investment opportunities, and all factors that do not directly relate to the payoffs on the securities being traded. (p. 775)

Many theoretical models of the price impact of information asymmetry assume that liquidity trader demand arrives randomly and independently over time (e.g., Kyle, 1985, Glosten and Milgrom, 1985). Dontoh, Ronen, and Sarath [2003] consider a rational expectations equilibrium setting in which the supply of the risky asset - which functions as noise trader demand - exhibits serial correlation over time. In practice, liquidity trader demand could be correlated across investors due investors' year-end tax-loss selling, mutual fund managers' quarterly window dressing, or hedge

\footnotetext{
${ }^{4}$ Although I construct this theoretical model using a single informed investor, an alternative would be to introduce multiple informed investors with heterogenous misweightings of redundant information. Since the market maker observes net demand as an aggregate, only the average level of informed investors' misweighting would affect prices. In my empirical estimation, the estimated $\alpha$ parameters represent the average misweighting of redundant information within each estimation.

${ }^{5}$ While I do not specify the utility function of the informed investor, one could be constructed such that the informed investor faces a private cost to minimizing $|\alpha|$ or receives private, non-monetary utility from having $\alpha \neq 0$.
} 
funds' restricted windows on redemptions and new investments (e.g., He, Ng, and Wang, 2004, Ng and Wang, 2004, Sadka, 2010). These examples suggest that non-informational trading may have a tendency to cluster in time. Formally, I allow liquidity trader demand to be serially correlated by assuming that the liquidity trader in period $t$ submits a random market order,

$$
\tilde{z_{t}}=\phi z_{t-1}+\tilde{\zeta} t
$$

where $\tilde{\zeta}_{t} \sim \mathcal{N}\left(0, \sigma_{\zeta, t}^{2}\right), \tilde{\zeta}_{t}$ are serially independent and independent of $\tilde{v}_{t}$, and $\phi$ is an exogenous scalar. Since unexpected liquidity trader demand is independent of fundamental information flows, the assumption that liquidity trader demand is serially correlated does not affect the precision of public information.

The combination of the market maker's transaction cost and either predictable informed investor demand or predictable liquidity trader demand could induce a situation in which a rational investor could earn positive expected profits by trading only on public information. The possibility of arbitrage in this manner suggests that rational arbitrageurs could be present in this market. I assume that $M \geq 0$ rational arbitrageurs participate in this market to exploit the arbitrage opportunity. Each risk-neutral rational arbitrageur is identical, has no private information, holds his trades until the terminal date, and submits a market order, $y_{t}$. Each arbitrageur knows that the informed investor is misweighting information, the time series properties of liquidity trader demand, and the market maker's transaction cost parameter. Meanwhile, the informed investor anticipates the arbitrageurs' demand in choosing his own demand. Since the informed investor behaves as if his private signal is correct, he treats the rational arbitrageurs' demand as additional liquidity.

To allow for heteroscedasticity in stock price returns, I assume that the variance of liquidity trade and the variance of private information vary over time. Extensive finance literature documents that securities returns do not exhibit constant volatility over time (See Engle, 2001 for a review). In the present model, the volatility of returns comprises a weighted average of the variance of liquidity trade and the variance of private information flows. Nevertheless, to make information asymmetry constant over time, I assume that the ratio of the variance of private information to the variance of liquidity trade is constant over time. If liquidity traders have partial discretion over the timing over their trades, they would choose to trade when many other liquidity traders also are trading. Informed investors also want to trade when liquidity is the greatest (Admati and Pfleiderer, 1988). As a result, information asymmetry is likely to be constant over short time horizons. If information asymmetry varied over short time horizons, an informed investor or a liquidity trader with discretion could reduce the price impact of his trades by choosing to trade during a period with lower information asymmetry. Formally, I assume that

$$
\frac{\sigma_{v, t}^{2}}{\sigma_{\zeta, t}^{2}} \equiv \bar{\sigma}
$$


is constant over time.

\subsection{Equilibrium characterization}

I focus on recursive equilibria, which are equilibria in which price and informed demand are of the following linear

forms. As in a standard Kyle [1985] framework, I restrict attention to linear demand and pricing functions. Price satisfies

$$
P_{t}=\left(\lambda_{d}+\rho\right) D_{t}+\lambda_{u} u_{t-1}+\lambda_{\phi} \mathrm{E}\left[\tilde{z}_{t-1} \mid H_{t-1}\right]+\lambda_{E} \mathrm{E}\left[\tilde{V} \mid H_{t-1}\right]
$$

Informed demand satisfies

$$
x_{t}=\kappa_{d} v_{t}+\kappa_{u} u_{t-1}+\kappa_{\phi} \mathrm{E}\left[\tilde{z}_{t-1} \mid H_{t-1}\right]+\kappa_{E} \mathrm{E}\left[\tilde{V} \mid H_{t-1}\right]
$$

Each rational arbitrageur's demand satisfies

$$
y_{t}=\gamma_{u} u_{t-1}+\gamma_{\phi} \mathrm{E}\left[\tilde{z}_{t-1} \mid H_{t-1}\right]+\gamma_{E} \mathrm{E}\left[\tilde{V} \mid H_{t-1}\right]
$$

\subsubsection{Informed demand}

In any recursive equilibrium, the informed investor in period $t$ chooses his demand, $x_{t}$, to maximize his perceived expected profit, as follows:

$$
\begin{gathered}
\max _{x_{t}}\left\{x_{t}\left(s_{t}+\mathrm{E}\left[\tilde{V} \mid H_{t-1}\right]-\mathrm{E}\left[\tilde{P}_{t} \mid x_{t}, H_{t-1}\right]\right)\right\} \\
=\max _{x_{t}}\left\{x _ { t } \left(v_{t}+\alpha u_{t-1}+\mathrm{E}\left[\tilde{V} \mid H_{t-1}\right]\right.\right. \\
-\left(\lambda_{d}+\rho\right)\left(x_{t}+M\left(\gamma_{u} u_{t-1}+\gamma_{\phi} \mathrm{E}\left[\tilde{z}_{t-1} \mid H_{t-1}\right]+\gamma_{E} \mathrm{E}\left[\tilde{V} \mid H_{t-1}\right]\right)+\phi \mathrm{E}\left[\tilde{z}_{t-1} \mid H_{t-1}\right]\right) \\
\left.\left.-\left(\lambda_{u} u_{t-1}+\lambda_{\phi} \mathrm{E}\left[\tilde{z}_{t-1} \mid H_{t-1}\right]+\lambda_{E} \mathrm{E}\left[\tilde{V} \mid H_{t-1}\right]\right)\right)\right\}
\end{gathered}
$$

Maximization of this objective function yields demand of the form:

$$
\begin{aligned}
x_{t}= & \frac{1}{2\left(\lambda_{d}+\rho\right)} v_{t}+\frac{\alpha-\left(\lambda_{d}+\rho\right) M \gamma_{u}-\lambda_{u}}{2\left(\lambda_{d}+\rho\right)} u_{t-1} \\
& +\frac{-\left(\lambda_{d}+\rho\right)\left(M \gamma_{\phi}+\phi\right)-\lambda_{\phi}}{2\left(\lambda_{d}+\rho\right)} \mathrm{E}\left[\tilde{z}_{t-1} \mid H_{t-1}\right]+\frac{1-\left(\lambda_{d}+\rho\right) M \gamma_{E}-\lambda_{E}}{2\left(\lambda_{d}+\rho\right)} \mathrm{E}\left[\tilde{V} \mid H_{t-1}\right]
\end{aligned}
$$


It follows that, in any recursive equilibrium, the coefficients of the informed demand function must satisfy:

$$
\begin{gathered}
\kappa_{d}=\frac{1}{2\left(\lambda_{d}+\rho\right)} \\
\kappa_{u}=\frac{\alpha-\left(\lambda_{d}+\rho\right) M \gamma_{u}-\lambda_{u}}{2\left(\lambda_{d}+\rho\right)} \\
\kappa_{\phi}=\frac{-\left(\lambda_{d}+\rho\right)\left(M \gamma_{\phi}+\phi\right)-\lambda_{\phi}}{2\left(\lambda_{d}+\rho\right)} \\
\kappa_{E}=\frac{1-\left(\lambda_{d}+\rho\right) M \gamma_{E}-\lambda_{E}}{2\left(\lambda_{d}+\rho\right)}
\end{gathered}
$$

Since $\tilde{v_{t}}$ has a mean of zero, $\kappa_{d}$ is the response coefficient of unexpected demand to informed investor $t$ 's observation of $v_{t}$. The coefficient $\kappa_{d}$ is the standard demand response for a Kyle [1985] model with transaction costs. The coefficient $\kappa_{u}$ is informed investor $t$ 's response to misweighted redundant information. The coefficient $\kappa_{\phi}$ is informed investor $t$ 's response to expected liquidity trade. The coefficient $\kappa_{E}$ is informed investor $t$ 's response to the mean of $\tilde{V}$ conditional on public information.

\subsubsection{Rational arbitrage demand}

In any recursive equilibrium, each rational arbitrageur, $j$, in period $t$ chooses his demand $y_{j, t}$ to maximize his perceived expected profit, which is:

$$
\begin{gathered}
\max _{y_{j, t}}\left\{y_{j, t}\left(\mathrm{E}\left[\tilde{V}-\tilde{P}_{t} \mid y_{j, t}, H_{t-1}\right]\right)\right\} \\
=\max _{y_{j, t}}\left\{y _ { j , t } \left(\mathrm{E}\left[\tilde{V} \mid H_{t-1}\right]\right.\right. \\
-\left(\lambda_{d}+\rho\right)\left(\kappa_{u} u_{t-1}+\left(\kappa_{\phi}+\phi\right) \mathrm{E}\left[\tilde{z}_{t-1} \mid H_{t-1}\right]+\kappa_{E} \mathrm{E}\left[\tilde{V} \mid H_{t-1}\right]+y_{j, t}+(M-1) y_{-j, t}\right) \\
\left.\left.-\lambda_{u} u_{t-1}-\lambda_{\phi} \mathrm{E}\left[\tilde{z}_{t-1} \mid H_{t-1}\right]-\lambda_{E} \mathrm{E}\left[\tilde{V} \mid H_{t-1}\right]\right)\right\}
\end{gathered}
$$

where $y_{-j, t}$ denotes the demand from each of the remaining $M-1$ identical rational arbitrageurs.

Maximization of this objective function yields demand of the form:

$$
\begin{aligned}
y_{t}= & -\frac{\left(\lambda_{d}+\rho\right) \kappa_{u}+\lambda_{u}}{2\left(\lambda_{d}+\rho\right)} u_{t-1}-\frac{\left(\lambda_{d}+\rho\right)\left(\kappa_{\phi}+\phi\right)+\lambda_{\phi}}{2\left(\lambda_{d}+\rho\right)} \mathrm{E}\left[\tilde{z}_{t-1} \mid H_{t-1}\right] \\
& +\frac{1-\left(\lambda_{d}+\rho\right) \kappa_{E}-\lambda_{E}}{2\left(\lambda_{d}+\rho\right)} \mathrm{E}\left[\tilde{V} \mid H_{t-1}\right]-\frac{1}{2}(M-1) y_{-j, t}
\end{aligned}
$$


Since all rational arbitrageurs are identical, each chooses demand of the form

$$
\begin{aligned}
y_{t}= & -\frac{\left(\lambda_{d}+\rho\right) \kappa_{u}+\lambda_{u}}{(M+1)\left(\lambda_{d}+\rho\right)} u_{t-1}-\frac{\left(\lambda_{d}+\rho\right)\left(\kappa_{\phi}+\phi\right)+\lambda_{\phi}}{(M+1)\left(\lambda_{d}+\rho\right)} \mathrm{E}\left[\tilde{z}_{t-1} \mid H_{t-1}\right] \\
& +\frac{1-\left(\lambda_{d}+\rho\right) \kappa_{E}-\lambda_{E}}{(M+1)\left(\lambda_{d}+\rho\right)} \mathrm{E}\left[\tilde{V} \mid H_{t-1}\right]
\end{aligned}
$$

It follows that, in any recursive equilibrium, the coefficients of the rational arbitrage demand function must satisfy:

$$
\begin{gathered}
\gamma_{u}=-\frac{\left(\lambda_{d}+\rho\right) \kappa_{u}+\lambda_{u}}{(M+1)\left(\lambda_{d}+\rho\right)} \\
\gamma_{\phi}=-\frac{\left(\lambda_{d}+\rho\right)\left(\kappa_{\phi}+\phi\right)+\lambda_{\phi}}{(M+1)\left(\lambda_{d}+\rho\right)} \\
\gamma_{E}=\frac{1-\left(\lambda_{d}+\rho\right) \kappa_{E}-\lambda_{E}}{(M+1)\left(\lambda_{d}+\rho\right)}
\end{gathered}
$$

The coefficient $\gamma_{u}$ is each rational arbitrageur's response to the informed investor's demand due to the misweighting of redundant information. The coefficient $\gamma_{\phi}$ is each rational arbitrageur's response to expected liquidity trade. The coefficient $\gamma_{E}$ is each rational arbitrageur's response to the mean of $\tilde{V}$ conditional on public information.

\subsubsection{Market maker pricing}

The market maker sets the market-clearing price to satisfy

$$
P_{t}=\mathrm{E}\left[\tilde{V} \mid D_{t}, H_{t-1}\right]+\rho D_{t}
$$

Since $v_{t}$ is independent of all prior signals, the Bayesian updating process of $\mathrm{E}\left[\tilde{V} \mid D_{t}, H_{t-1}\right]$ is simply additive:

$$
\mathrm{E}\left[\tilde{V} \mid D_{t}, H_{t-1}\right]=\mathrm{E}\left[\tilde{v}_{t} \mid D_{t}, H_{t-1}\right]+\mathrm{E}\left[\tilde{V} \mid H_{t-1}\right]
$$

The market maker sets price

$$
P_{t}=\mathrm{E}\left[\tilde{v}_{t} \mid D_{t}, H_{t-1}\right]+\mathrm{E}\left[\tilde{V} \mid H_{t-1}\right]+\rho D_{t}
$$


where

$$
\begin{aligned}
\mathrm{E}\left[\tilde{v}_{t} \mid D_{t}, H_{t-1}\right] & =\mathrm{E}\left[\tilde{v}_{t} \mid H_{t-1}\right]+\frac{\operatorname{Cov}\left(\tilde{v}_{t}, \tilde{D}_{t}\right)}{\operatorname{Var}\left(\tilde{D}_{t}\right)}\left(D_{t}-\mathrm{E}\left[\tilde{D}_{t} \mid H_{t-1}\right]\right) \\
& =\frac{\left(\kappa_{d}\right) \sigma_{v, t}^{2}}{\left(\kappa_{d}\right)^{2} \sigma_{v, t}^{2}+\sigma_{\zeta, t}^{2}}\left(D_{t}-\mathrm{E}\left[\tilde{D}_{t} \mid H_{t-1}\right]\right)
\end{aligned}
$$

and

$$
\mathrm{E}\left[\tilde{D}_{t} \mid H_{t-1}\right]=\left(\kappa_{u}+M \gamma_{u}\right) u_{t-1}+\left(\kappa_{\phi}+\phi+M \gamma_{\phi}\right) \mathrm{E}\left[\tilde{z}_{t-1} \mid H_{t-1}\right]+\left(\kappa_{E}+M \gamma_{E}\right) \mathrm{E}\left[\tilde{V} \mid H_{t-1}\right]
$$

Given the informed investor's and the rational arbitrageurs' linear demand functions, the coefficients of the market maker's pricing function satisfy:

$$
\begin{gathered}
\lambda_{d}=\frac{\left(\kappa_{d}\right) \sigma_{v, t}^{2}}{\left(\kappa_{d}\right)^{2} \sigma_{v, t}^{2}+\sigma_{\zeta, t}^{2}} \\
\lambda_{u}=-\lambda_{d}\left(\kappa_{u}+M \gamma_{u}\right) \\
\lambda_{\phi}=-\lambda_{d}\left(\kappa_{\phi}+\phi+M \gamma_{\phi}\right) \\
\lambda_{E}=1-\lambda_{d}\left(\kappa_{E}+M \gamma_{E}\right)
\end{gathered}
$$

The coefficient $\lambda_{d}$ is the standard single-period Kyle's lambda. The coefficient $\lambda_{u}$ is the market maker's adjustment to net demand related to informed investor t's misweighting of redundant information. The coefficient $\lambda_{\phi}$ is the market maker's adjustment to net demand related to expected liquidity trade. The coefficient $\lambda_{E}$ is the market maker's response to the mean of $\tilde{V}$ conditional on public information.

\subsection{Equilibrium}

Characterizing a recursive equilibrium entails identifying the set

$$
\left\{\lambda_{d}, \lambda_{u}, \lambda_{\phi}, \lambda_{E}, \kappa_{d}, \kappa_{u}, \kappa_{\phi}, \kappa_{E}, \gamma_{u}, \gamma_{\phi}, \gamma_{E}\right\}
$$

that satisfy Equations (3.12), (3.13), (3.14), (3.15), (3.20), (3.21), (3.22), (3.27), (3.28), (3.29), and (3.30), and a specification of the conditional expectation of $\tilde{V}$ as a function of past demands. Observation 1, which is proven in Appendix A.1, characterizes the recursive equilibrium. 
Observation 1: In every period, there exists a unique equilibrium in which:

1. $\lambda_{d}$ is the unique solution of $\lambda_{d}^{3}+2 \rho \lambda_{d}^{2}+\left(\rho^{2}-\frac{1}{4} \bar{\sigma}\right) \lambda_{d}-\frac{1}{2} \bar{\sigma} \rho=0$ in which $\lambda_{d}>-\rho$;

2. $\lambda_{u}=\frac{-\alpha \lambda_{d}}{\lambda_{d}+(M+2) \rho}$;

3. $\lambda_{\phi}=\frac{-\lambda_{d}\left(\lambda_{d}+\rho\right) \phi}{\lambda_{d}+(M+2) \rho}$; and,

4. $\lambda_{E}=1$.

In summary, the market maker sets price using the strategy

$$
P_{t}=\lambda_{d}\left(D_{t}-\frac{\alpha}{\lambda_{d}+(M+2) \rho} u_{t-1}-\frac{\left(\lambda_{d}+\rho\right) \phi}{\lambda_{d}+(M+2) \rho} \mathrm{E}\left[\tilde{z}_{t-1} \mid H_{t-1}\right]\right)+\mathrm{E}\left[\tilde{V} \mid H_{t-1}\right]+\rho D_{t}
$$

where $\lambda_{d}$ is the unique real root of

$$
\lambda_{d}^{3}+2 \rho \lambda_{d}^{2}+\left(\rho^{2}-\frac{1}{4} \bar{\sigma}\right) \lambda_{d}-\frac{1}{2} \bar{\sigma} \rho=0
$$

in which $\lambda_{d}>0 \geq-\rho$.

Each informed investor chooses his demand according to:

$$
x_{t}=\frac{1}{2\left(\lambda_{d}+\rho\right)} v_{t}+\frac{\alpha\left(\lambda_{d}+(M+1) \rho\right)}{\left(\lambda_{d}+\rho\right)\left(\lambda_{d}+(M+2) \rho\right)} u_{t-1}-\frac{\phi \rho}{\lambda_{d}+(M+2) \rho} \mathrm{E}\left[\tilde{z}_{t-1} \mid H_{t-1}\right]
$$

Each rational arbitrageur each chooses his demand according to:

$$
y_{t}=-\frac{\alpha \rho}{\left(\lambda_{d}+\rho\right)\left(\lambda_{d}+(M+2) \rho\right)} u_{t-1}-\frac{\phi \rho}{\lambda_{d}+(M+2) \rho} \mathrm{E}\left[\tilde{z}_{t-1} \mid H_{t-1}\right]
$$

Expected net demand is

$$
\begin{aligned}
\mathrm{E}\left[\tilde{D}_{t} \mid H_{t-1}\right] & =\mathrm{E}\left[\tilde{x}_{t}+M \tilde{y}_{t}+\tilde{z}_{t} \mid H_{t-1}\right] \\
& =\frac{\alpha}{\lambda_{d}+(M+2) \rho} u_{t-1}+\frac{\left(\lambda_{d}+\rho\right) \phi}{\lambda_{d}+(M+2) \rho} \mathrm{E}\left[\tilde{z}_{t-1} \mid H_{t-1}\right]
\end{aligned}
$$

As seen in Equation (3.31), price in period $t$ comprises the impact of unexpected demand on the expected value of asset, the expected value of the asset given all previously available information, and the transaction cost. As seen in Equation (3.32) and depicted in Figure 1, the model predicts that the sensitivity of the expected value of the risky asset to net demand (i.e., Kyle's lambda) steepens as information asymmetry increases and flattens as 
transaction costs increase. That is, $\frac{\partial \lambda_{d}}{\partial \bar{\sigma}}>0$ and $\frac{\partial \lambda_{d}}{\partial \rho}<0$. Kyle's lambda is decreasing in transaction costs because the market maker recognizes that informed investors choose to trade less when facing passed-through transaction costs. If transaction costs were zero, informed investors weighted redundant information fairly, and liquidity traders' demand was independent of past demand - i.e., if $\rho=0, \alpha=0$, and $\phi=0$ - this equilibrium would match the classic Kyle [1985] single-period model.

Trading on redundant information leads to predictable net demand, as seen in Equation (3.35). When $\alpha>0$, expected informed demand follows in the same direction as the prior net demand. When $\alpha<0$, expected informed demand partially reverses prior net demand. The market maker recognizes informed investors' misweighting of redundant information. Using the parameter $\lambda_{u}=-\frac{\alpha \lambda_{d}}{\lambda_{d}+(M+2) \rho}$, the market maker backs out the expected portion of demand due to trading on redundant information. Trading on redundant information does not affect the market maker's expectation of the value of the risky asset because the market maker knows the redundant information already. The misweighting of redundant information also does not affect information asymmetry, i.e., $\frac{\partial \lambda_{d}}{\partial \alpha}=0$.

Similarly, predictable liquidity trader demand also leads to predictable net order flow, as seen in Equation (3.35). When $\phi>0$, expected liquidity trade follows in the same direction as the prior liquidity trader demand; when $\phi<0$, expected liquidity trade partially reverses prior liquidity trader demand. The market maker backs out the expected portion of net order flow due to expected liquidity trade using the parameter $\lambda_{\phi}=-\frac{\phi \lambda_{d}\left(\lambda_{d}+\rho\right)}{\lambda_{d}+(M+2) \rho}$. Expected liquidity trade does not affect the market maker's expectation of the value of the risky asset and does not affect information asymmetry. Nevertheless, expected liquidity trade affects prices because the market maker passes through the trading costs of this order flow. Specifically, the market maker adjusts the market-clearing price by $\rho \frac{\left(\lambda_{d}+\rho\right) \phi}{\lambda_{d}+(M+2) \rho} \mathrm{E}\left[\tilde{z}_{t-1} \mid H_{t-1}\right]$. The price impact of expected liquidity trade increases in magnitude as transaction costs or information asymmetry increases.

The rational arbitrageurs reduce, but do not eliminate, the price impact of trading on redundant information and expected liquidity demand. If $M$ is finite, the rational arbitrageurs act like Cournot oligopolists, and would not completely overwhelm expected demand from informed investors and liquidity traders. As $M \rightarrow \infty$, the rational arbitrageurs' demand negates expected net demand from informed investors and liquidity traders. The time series of price changes would approach the pattern with $\rho>0, \alpha=0$, and $\phi=0$. 


\subsection{Time series properties of price changes}

To estimate informed investors' misweighting of redundant information, the $\alpha$ parameter, I study the time series of price changes. Let $\eta_{t}$ denote the price impact of unexpected demand, where

$$
\eta_{t} \equiv\left(\lambda_{d}+\rho\right)\left(D_{t}-\mathrm{E}\left[\tilde{D}_{t} \mid H_{t-1}\right]\right)=\frac{1}{2} v_{t}+\left(\lambda_{d}+\rho\right) \zeta_{t}
$$

By assumption, $\eta_{t}$ are independent and normally distributed random variables with means equal to zero and variances equal to $\frac{1}{4} \sigma_{v, t}^{2}+\left(\lambda_{d}+\rho\right)^{2} \sigma_{\zeta, t}^{2}$.

The change in the expected value of the risky asset equals what market makers learn from unexpected demand, as follows:

$$
u_{t}=\mathrm{E}\left[\tilde{V} \mid H_{t}\right]-\mathrm{E}\left[\tilde{V} \mid H_{t-1}\right]=\frac{\lambda_{d}}{\lambda_{d}+\rho} \eta_{t}
$$

The price change in period $t$ reflects the information content of the net demand in $t$ and the transaction costs of net demand in $t$ and $t-1$, as follows:

$$
\begin{aligned}
P_{t}-P_{t-1}= & \left(\lambda_{d}\left(D_{t}-\mathrm{E}\left[\tilde{D}_{t} \mid H_{t-1}\right]\right)+\mathrm{E}\left[\tilde{V} \mid H_{t-1}\right]+\rho D_{t}\right)-\left(\mathrm{E}\left[\tilde{V} \mid H_{t-1}\right]+\rho D_{t-1}\right) \\
= & \eta_{t}+\rho \mathrm{E}\left[\tilde{D}_{t} \mid H_{t-1}\right]-\rho D_{t-1} \\
= & \eta_{t}+\rho\left(\frac{\alpha}{\lambda_{d}+(M+2) \rho} u_{t-1}+\frac{\left(\lambda_{d}+\rho\right) \phi}{\lambda_{d}+(M+2) \rho} \mathrm{E}\left[\tilde{z}_{t-1} \mid H_{t-1}\right]\right) \\
& -\rho\left(\frac{1}{\lambda_{d}+\rho} \eta_{t-1}+\frac{\alpha}{\lambda_{d}+(M+2) \rho} u_{t-2}+\frac{\left(\lambda_{d}+\rho\right) \phi}{\lambda_{d}+(M+2) \rho} \mathrm{E}\left[\tilde{z}_{t-2} \mid H_{t-2}\right]\right) \\
= & \eta_{t}+\frac{\rho \phi}{\lambda_{d}+(M+2) \rho}\left(\lambda_{d}+\rho\right)\left(\mathrm{E}\left[\tilde{z}_{t-1} \mid H_{t-1}\right]-\mathrm{E}\left[\tilde{z}_{t-2} \mid H_{t-2}\right]\right) \\
& +\frac{\rho}{\lambda_{d}+\rho}\left(\frac{\alpha \lambda_{d}}{\lambda_{d}+(M+2) \rho}-1\right) \eta_{t-1}-\frac{\rho}{\lambda_{d}+\rho}\left(\frac{\alpha \lambda_{d}}{\lambda_{d}+(M+2) \rho}\right) \eta_{t-2}
\end{aligned}
$$

Having observed the history of order flow, $H_{t-1}$, market participants believe that liquidity demand in the prior period was

$$
\mathrm{E}\left[\tilde{z}_{t-1} \mid H_{t-1}\right]=\phi \mathrm{E}\left[\tilde{z}_{t-2} \mid H_{t-2}\right]+\frac{1}{\lambda_{d}+\rho}\left(\frac{\lambda_{d}+2 \rho}{2\left(\lambda_{d}+\rho\right)}\right) \eta_{t-1}
$$

Let

$$
\nu_{t} \equiv\left(\lambda_{d}+\rho\right) \mathrm{E}\left[\tilde{z}_{t} \mid H_{t}\right]
$$


and

$$
\psi \equiv \rho / \lambda_{d}
$$

Multiplying Equation (3.39) by $\lambda_{d}+\rho$, market participants' belief about the price impact of liquidity demand in the prior period can be written as

$$
\nu_{t-1}=\phi \nu_{t-2}+\frac{1+2 \psi}{2(1+\psi)} \eta_{t-1}
$$

Combining Equations (3.38), (3.41), and (3.42), price change in period $t$ can be written as

$$
\begin{aligned}
\Delta P_{t} & =\eta_{t}+\frac{\phi \psi}{1+(M+2) \psi}\left(\Delta \nu_{t-1}\right) \\
& +\frac{\psi}{1+\psi}\left(\frac{\alpha}{1+(M+2) \psi}-1\right) \eta_{t-1}-\frac{\psi}{1+\psi}\left(\frac{\alpha}{1+(M+2) \psi}\right) \eta_{t-2}
\end{aligned}
$$

where $\Delta \nu_{t-1}=\nu_{t-1}-\nu_{t-2}$.

Equation (3.43) shows that price changes exhibit an moving average process. If the market maker has zero transaction costs, price would equal the expected value of the risky asset in every round of trade, and price changes would follow a random walk; that is, if $\rho=0, P_{t}=\mathrm{E}\left[\tilde{V} \mid H_{t}\right] \forall t$, and $\Delta P_{t}=\eta_{t}$. If the market maker has positive transaction costs but all informed investors weight redundant information perfectly and liquidity trader demand were serially independent, prices would be mean reverting, as in Roll [1984]. That is, if $\rho>0, \phi=0$, and $\alpha=0$, the transaction cost portion of price changes, $\frac{\psi}{1+\psi} \eta_{t}$, would unwind exactly in the subsequent period.

If transaction costs are positive, $\rho>0$, price changes could exhibit momentum or mean reversion, depending on informed investors' misweighting of redundant information and the serial correlation of liquidity trader demand. Substituting for the first and second lagged $\nu_{t-1}$ terms, the time series of price changes can be written as

$$
\begin{aligned}
\Delta P_{t} & =\eta_{t}+\frac{\left(\alpha+\phi\left(\frac{1}{2}+\psi\right)-(1+(M+2) \psi)\right) \psi}{(1+\psi)(1+(M+2) \psi)} \eta_{t-1} \\
& +\frac{\left(-\alpha+\phi(\phi-1)\left(\frac{1}{2}+\psi\right)\right) \psi}{(1+\psi)(1+(M+2) \psi)} \eta_{t-2}+\frac{\phi^{2}(\phi-1) \psi}{1+(M+2) \psi} \nu_{t-3}
\end{aligned}
$$

Equation (3.44) shows that the current period price change can exhibit a positive association with the prior period unexpected price change if transaction costs are positive and informed investors' misweighting of redundant information is sufficiently positive. That is, $\operatorname{Cov}\left(\Delta P_{t}, \eta_{t-1} \mid H_{t-2}\right)>0$ if $\psi>0$ and $\alpha+\phi\left(\frac{1}{2}+\psi\right)>1+(M+2) \psi$.

In this model, serial correlation in liquidity trader demand alone would not predict momentum in returns. If $\alpha=0$, 
current period price change would exhibit a positive association with the prior period unexpected price change - i.e., $\operatorname{Cov}\left(\Delta P_{t}, \eta_{t-1} \mid H_{t-2}\right)>0-$ if $\phi>\frac{1+(M+2) \psi}{\frac{1}{2}+\psi}$. The inequality $\phi>\frac{1+(M+2) \psi}{\frac{1}{2}+\psi}$ cannot hold, however, because $\psi \geq 0$, $M \geq 0$, and $|\phi| \leq 1$ so that liquidity trader demand cannot grow unboundedly. Thus, only the overweighting of redundant information by informed investors can give rise to momentum in returns in this analytical model. ${ }^{6}$

Equation (3.44) further shows that the current period price change would exhibit a positive association with the unexpected price change two periods prior if transaction costs are positive and $\phi(\phi-1)\left(\frac{1}{2}+\psi\right)>\alpha$. For example, $\operatorname{Cov}\left(\Delta P_{t}, \eta_{t-2} \mid H_{t-3}\right)>0$ if $\alpha<0$ and $\phi<0$. The current period price change would exhibit a negative association with the unexpected price change two periods prior if transaction costs are positive and $\phi(\phi-1)\left(\frac{1}{2}+\psi\right)<\alpha$. For example, $\operatorname{Cov}\left(\Delta P_{t}, \eta_{t-2} \mid H_{t-3}\right)<0$ if $\alpha>0$ and $\phi>0$. This result comports with empirical evidence in Tetlock [2011] that firms with more stale news stories in one week exhibit reversion in returns in the subsequent week.

For a given level of $\alpha$ and $\phi$, the magnitudes of momentum and mean reversion in price changes are increasing in the ratio of transaction costs to information asymmetry, $\psi$. This result comports with extensive evidence that momentum in stock price changes appears greater when transaction costs are higher (e.g., Korajczyk and Sadka, 2004).

Finally, the influence of earlier price changes declines over time, given $|\phi| \leq 1$, because $\frac{\psi}{1+(M+2) \psi}<1$.

\section{Structural estimation and results}

\subsection{Estimation procedure}

The analytical model predicts that price changes exhibit the following state space process:

$$
\begin{aligned}
\Delta P_{t} & =\eta_{t}+\frac{\phi \psi}{1+(M+2) \psi}\left(\Delta \nu_{t-1}\right) \\
& +\frac{\psi}{1+\psi}\left(\frac{\alpha}{1+(M+2) \psi}-1\right) \eta_{t-1}-\frac{\psi}{1+\psi}\left(\frac{\alpha}{1+(M+2) \psi}\right) \eta_{t-2}
\end{aligned}
$$

where $\Delta P_{t}$ is the price change from period $t-1$ to period $t, \eta_{t}$ is the stock price impact of unexpected order flow in period $t, \psi \equiv \rho / \lambda_{d}$ is the ratio of transaction costs to information asymmetry, $\phi$ is the autoregressive parameter of liquidity trader demand, $\Delta \nu_{t-1}$ is the change in the market participants' belief about the price impact of expected liquidity demand from time $t-2$ to $t-1$, and $\alpha$ is the parameter for the extent to which informed investors

\footnotetext{
${ }^{6}$ In Appendix B, I show that a Kyle [1985] model with transaction costs and long-lived information also predicts mean reversion in returns, but cannot predict momentum in returns.
} 
misweight information that is already priced ("redundant information"). I substitute $\psi=\rho / \lambda_{d}$ because $\rho$ and $\lambda_{d}$ are not identifiable separately. Market participants' belief about the price impact of expected liquidity demand can be written as

$$
\nu_{t-1}=\phi \nu_{t-2}+\frac{1+2 \psi}{2(1+\psi)} \eta_{t-1}
$$

The parameter $M$ is not identifiable distinctly. For the purposes of the empirical estimation, I assume $M=1$. Assuming $M=1$ implies that the rational arbitrageur is a monopolist in exploiting predictable order flow. Since $M$ appears in the denominator of the coefficients, if I assumed $M>1$, estimates of $\alpha, \phi$, or $\psi$ would likely be higher. Even though rational arbitrageurs earn positive expected profits when $\rho>0$, I cannot observe arbitrageurs' cost of capital, risk aversion, or other fixed costs, and thus I cannot comment on the likely degree of competition among the arbitrageurs.

The parameter of interest is $\alpha$. If $\alpha$ is estimated to be greater than zero, that would suggest on average informed investors act like redundant information is novel private information. If $\alpha$ is estimated to be less than zero, that would suggest some informed investors back out redundant information from their private signals excessively.

The analytical model assumes that informed investors' private signals and unexpected net demand are independent and normally distributed. For consistency, I assume that the price impact of unexpected order flows, $\eta_{t}$, are independent and normally distributed with means equal to zero.

The analytical model above allows the variance of $\eta_{t}$ to exhibit heteroscedasticity over time, without specifying a particular form for this heteroscedasticity. The market participants in the analytical model know the variance of $\eta_{t}$ at all points in time. As an empirical researcher, however, I must estimate the variance of $\eta_{t}$. For simplicity, I assume that the variance of $\eta_{t}$ follows a generalized auto-regressive conditional heteroscedasticity (GARCH) process (See Engle, 2001 for a review). In particular, I assume that the variance of $\eta_{t}$, denoted $\sigma_{\eta, t}^{2}$, evolves according to a GARCH(1,1) process with normal shocks:

$$
\sigma_{\eta, t}^{2}=\beta_{0}+\beta_{1} \eta_{t-1}^{2}+\beta_{2} \sigma_{\eta, t-1}^{2}
$$

I estimate Equation (4.1) by maximum likelihood estimation. The estimation procedure attempts to identify the parameters $\alpha$ and $\psi$ that maximize the likelihood that observed price changes came from the estimated distribution of $\eta_{t}$, where price changes are normally distributed with conditional expectation equal to $\mathrm{E}\left[\Delta P_{t} \mid \eta_{0}, \ldots, \eta_{t-1}\right]$ (Wooldridge, 2010). ${ }^{7}$ Following Bollerslev [1986] and Durbin and Koopman [2012], the log-likelihood function for

\footnotetext{
${ }^{7}$ One could estimate Equation (4.1) by method of moments. The main advantage of maximum likelihood estimation as compared to
} 
this state space model is:

$$
L=\sum_{t=3}^{N} \ln \left(\frac{1}{\sqrt{2 \pi \sigma_{\eta, t}^{2}}} \exp \left(-\frac{\eta_{t}^{2}}{2 \sigma_{\eta, t}^{2}}\right)\right)=-\frac{N}{2} \ln (2 \pi)-\frac{1}{2} \sum_{t=3}^{N}\left[\ln \left(\sigma_{\eta, t}^{2}\right)+\frac{\eta_{t}^{2}}{\sigma_{\eta, t}^{2}}\right]
$$

where $N$ is the number of observations. To initialize the estimation, I set $\eta_{1}=\eta_{2}=0$ and $\sigma_{\eta, 3}^{2}$ equal to the variance of price changes over the sample period. I constraint the estimated parameters as follows: $\phi \in[-1,1], \psi \geq 0, \beta_{0} \geq 0$, $\beta_{1} \in[0,1]$, and $\beta_{2} \in\left[0,1-\beta_{1}\right]$.

Maximization of this log-likelihood function involves a non-linear optimization that is vulnerable to identifying local maxima as optimal parameters. To address this weakness, I use nine sets of random starting values for each parameter. From these starting values, I also use two optimization methods from a non-linear optimization package in R: the spectral projected gradient method and bound optimization by quadratic approximation (Nash and Varadhan, 2011). From the 18 sets of optimized parameters, I select the set of parameters with the highest log-likelihood value.

\subsection{Sample selection and variable measurement}

To hold information asymmetry and transaction costs constant within an estimation, I estimate Equation (4.1) by firm-quarter. Within a firm-quarter, firm characteristics and secular factors that would affect information asymmetry and transaction costs, such as firm size or market volatility, are likely to vary little.

My sample comprises stock price changes during stock exchange hours only. In the analytical model, public information arrives only through the price impact of trades, rather than through public announcements. Public announcements generally occur while U.S. stock exchanges are closed because U.S. stock exchange rules discourage companies from releasing material information during stock exchange hours. Further, little trading takes place while U.S. stock exchanges are closed; Barclay and Hendershott [2003] find that 4 percent of the average daily trading volume occurs after-hours for the 250 highest volume firms on the Nasdaq Stock Exchange. The lack of liquidity while stock exchanges are closed suggests that overnight price changes primarily reflect shocks to public information. The analytical model abstracts from shocks to public information because all investors can observe this information and should incorporate it into their beliefs unbiasedly. Price changes that occur while stock exchanges are open represent the net information content of order flow (French and Roll, 1986). ${ }^{8}$

method of moments is that maximum likelihood estimation is the most efficient estimation procedure asymptotically. The main drawback is that maximum likelihood estimation relies on assumptions about the conditional distribution of the dependent variable. In effect, if the theoretical model is misspecified or relies on incorrect distributional assumptions, the estimated parameters would be inconsistent.

${ }^{8}$ The analytical model could be extended to allow for overnight price changes by modifying the market maker's pricing strategy. 
I draw price data for every firm-trading day from 2003 through 2014 from the WRDS TAQ dataset, which contains intraday trade and quote data for all securities listed on the New York Stock Exchange, American Stock Exchange, Nasdaq National Market System, and Nasdaq Small Cap issues. For a trading day to be included in the sample, I require that the firm appears in the CRSP daily stock price table on that date.

Since the Kyle model posits that order flow from informed and uninformed investors arrives as an aggregated batch, I group stock prices into five-minute, 12-minute, and 30-minute intervals. Grouping prices into time intervals also reduces the market microstructure effects of high frequency trading. ${ }^{9}$ For each time interval, I measure the trade price as the volume-weighted average price. For example, if the only two trades within an interval were $\$ 10.00$ for 9900 shares and $\$ 10.10$ for 100 shares, I use $\$ 10.001$ as the volume-weighted average price for that interval. I calculate price changes as the change in the natural logarithm of the volume-weighted average prices, consistent with Hasbrouck [2009].

The analytical model assumes that private information signals and unexpected liquidity trader demand arrive in fixed time intervals. To be consistent with this assumption, I restrict the sample to actively traded firms. For a trading day to be included in the sample, I require that it not have a gap between trades of longer than one time interval. For example, when estimating the model using five-minute intervals, I remove any trading day that has two consecutive five-minute intervals without a trade. For a firm-quarter to be included in the sample, I require that it have at least 20 trading days that satisfy this criterion. A more generalized analytical model might allow for an endogenous schedule of sequential, market-clearing auctions. Classic analytical models of how private information affects prices typically assume a fixed schedule of sequential auctions (e.g., Kyle, 1985, Glosten and Milgrom, 1985). I follow this convention. Empirically, these sample selection criteria imply that firms with sporadic liquidity trader demand have been excluded.

Using five-minute returns, the estimates were conducted for approximately 107,850 firm-quarters (on average, 2,247 firms per quarter). These firm-quarter estimations used a mean and median of 4,242 and 4,710 price changes over consecutive five-minute intervals. U.S. stock exchanges have on average 63 trading days per quarter. Each trading day lasts six-and-a-half hours, or 78 five-minute intervals. At the mean (median) number of observations per firmquarter, the estimations used approximately 54 (60) days per firm-quarter or 67 (75) observations per trading day. Figure 5 plots the time-series of the number of unique firms and median and mean number of observations per firm

\footnotetext{
${ }^{9}$ In high frequency markets, informed investors often split large orders into small ones and mimic the quoting behavior of market makers in attempt to disguise the information content of their trades (Easley, Lopez de Prado, and O'Hara, 2012, Cready, Kumas, and Subasi, 2014). Easley, Lopez de Prado, and O'Hara [2016] find that aggregating trades into intervals of between one minute and 60 minutes reduces the vast majority of the noise due to microstructure effects, saves on computing time, and captures the information content of trades at least as well as traditional tick tests do (e.g., Lee and Ready, 1991). In their study of Chicago Mercantile Exchange S\&P 500 futures contracts, the authors show that using five-minute bars eliminates 88 percent of the market microstructure noise and reduces computational demands by 95 percent.
} 
by calendar quarter.

Using 12-minute returns, the estimates were conducted for approximately 136,500 firm-quarters (on average, 2,844 firms per quarter). These firm-quarter estimations used a mean and median of 1,862 and 1,997 price changes over consecutive 12-minute intervals. On U.S. stock exchanges, each trading day lasts thirty-two 12-minute intervals. At the mean (median) number of observations per firm-quarter, the estimations used approximately 57 (61) days per firm-quarter or 30 (31) observations per trading day. Figure 7 plots the time-series of the number of unique firms and median and mean number of observations per firm by calendar quarter.

Using 30-minute returns, the estimates were conducted for approximately 160,700 firm-quarters (on average, 3,348 firms per quarter). These firm-quarter estimations used a mean and median of 729 and 767 price changes over consecutive 30-minute intervals. On U.S. stock exchanges, each trading day lasts thirteen 30-minute intervals. At the mean (median) number of observations per firm-quarter, the estimations used approximately 56 (59) days per firm-quarter or 11.6 (12) observations per trading day. Figure 7 plots the time-series of the number of unique firms and median and mean number of observations per firm by calendar quarter.

\subsection{Results}

Tables 1 to 3 show the distributions of parameter estimates - investors' misweighting of redundant information, $\alpha$, the autoregressive parameter of liquidity trader demand, $\phi$, the ratio of transaction costs to the information asymmetry of order flow, $\psi$, and the coefficients of the variance of the time series - using five-minute returns, 12-minute returns, and 30-minute returns, respectively. Figures 8 to 16 show histograms of the estimated $\alpha$, $\phi$, and $\psi$ parameters, estimated using five-minute returns, 12-minute returns, and 30-minute returns. Figures 17 to 25 plot time series of the estimated $\alpha, \phi$, and $\psi$ parameters.

Estimated $\alpha$ parameters greater than zero suggest that investors behave as if their private signals have less redundant information and more private information than the signals truly have. Estimated $\alpha$ parameters less than zero suggest that investors behave as if their private signals have more redundant information and less private information than the signals truly have. Using five-minute returns, I find that the mean (median) estimated $\alpha$ parameter is approximately 0.48 (0.49). Using 12-minute returns, I find that the mean (median) estimated $\alpha$ parameter is approximately 0.63 (0.63). Using 30-minute returns, I find that the mean (median) estimated $\alpha$ parameter is approximately $0.74(0.76)$. At these levels of $\alpha$, informed investors treat a substantial fraction of the redundant information that was revealed

in the prior time interval as if it was private information. Using five-minute returns, approximately 72 percent of the estimated $\alpha$ parameters are greater than zero; 66 percent of the estimated $\alpha$ parameters are greater than 
zero at the 10 percent statistical significance level; 65 percent of the estimated $\alpha$ parameters are greater than zero at the 5 percent statistical significance level; and 64 percent of the estimated $\alpha$ are greater than zero at the 1 percent statistical significance level. Approximately 24 percent of the estimated $\alpha$ parameters are less than zero at the 10 percent statistical significance level and 23 percent of the estimated $\alpha$ parameters are less than zero at the 1 percent statistical significance level. Using 12-minute returns, approximately 79 percent of the estimated $\alpha$ parameters are greater than zero; 73 percent of the estimated $\alpha$ parameters are greater than zero at the 10 percent statistical significance level; 73 percent of the estimated $\alpha$ parameters are greater than zero at the 5 percent statistical significance level; and 71 percent of the estimated $\alpha$ are greater than zero at the 1 percent statistical significance level. Approximately 15 percent of the estimated $\alpha$ parameters are less than zero at the 10 percent statistical significance level and 14 percent of the estimated $\alpha$ parameters are less than zero at the 1 percent statistical significance level. Using 30-minute returns, approximately 82 percent of the estimated $\alpha$ parameters are greater than zero; 67 percent of the estimated $\alpha$ parameters are greater than zero at the 10 percent statistical significance level; 65 percent of the estimated $\alpha$ parameters are greater than zero at the 5 percent statistical significance level; and 62 percent of the estimated $\alpha$ are greater than zero at the 1 percent statistical significance level. Approximately 11 percent of the estimated $\alpha$ parameters are less than zero at the 10 percent statistical significance level and 8 percent of the estimated $\alpha$ parameters are less than zero at the 1 percent statistical significance level. These results suggest that, for the vast majority of firm-quarters, investors overweight redundant information.

The estimates of the parameter representing the autocorrelation of liquidity trader demand, $\phi$, suggest that liquidity trader demand exhibits positive autocorrelation. Using five-minute returns, the estimated $\phi$ parameters have a mean and median of 0.38 and 0.56 . Approximately 71 percent of the estimated $\phi$ parameters are greater than zero; 64 percent of the estimated $\phi$ parameters are greater than zero at the 10 percent statistical significance level; 63 percent of the estimated $\phi$ parameters are greater than zero at the 5 percent statistical significance level; and 62 percent of the estimated $\phi$ are greater than zero at the 1 percent statistical significance level. Approximately 25 percent of the estimated $\phi$ parameters are less than zero at the 10 percent statistical significance level and 24 percent of the estimated $\phi$ parameters are less than zero at the 1 percent statistical significance level. Using 12-minute returns, the estimated $\phi$ parameters have a mean and median of 0.45 and 0.67 . Approximately 74 percent of the estimated $\phi$ parameters are greater than zero; 67 percent of the estimated $\phi$ parameters are greater than zero at the 10 percent statistical significance level; 66 percent of the estimated $\phi$ parameters are greater than zero at the 5 percent statistical significance level; and 64 percent of the estimated $\phi$ are greater than zero at the 1 percent statistical significance level. Approximately 21 percent of the estimated $\phi$ parameters are less than zero at the 10 percent statistical significance level and 20 percent of the estimated $\phi$ parameters are less than zero at the 1 percent statistical significance level. Using 30-minute returns, the estimated $\phi$ parameters have a mean and median of 0.44 and 0.66 . Approximately 74 
percent of the estimated $\phi$ parameters are greater than zero; 59 percent of the estimated $\phi$ parameters are greater than zero at the 10 percent statistical significance level; 57 percent of the estimated $\phi$ parameters are greater than zero at the 5 percent statistical significance level; and 54 percent of the estimated $\phi$ are greater than zero at the 1 percent statistical significance level. Approximately 16 percent of the estimated $\phi$ parameters are less than zero at the 10 percent statistical significance level and 15 percent of the estimated $\phi$ parameters are less than zero at the 1 percent statistical significance level. The tendency for liquidity trader demand to exhibit positive autocorrelation is consistent with the theoretical model in Dontoh, Ronen, and Sarath [2003].

The estimates of the parameter representing the ratio of transaction costs to Kyle's lambda, $\psi$, have a mean and median of 0.54 and 0.39 using five-minute returns, 0.44 and 0.34 using 12-minute returns, and 0.43 and 0.33 using 30-minute returns. At these levels, approximately 25 to 35 percent of the price impact of trades is temporary and lacks information content. As benchmarks, since the price impact of a trade is the sum of transaction costs and Kyle's lambda, $\psi=0.33(\psi=0.67)$ implies that approximately 25 percent (40 percent) of the price impact of trades is due to transaction costs and 75 percent (60 percent) of the price impact of trades is due to information asymmetry. Using five-minute returns, approximately 40 percent of the estimated $\psi$ parameters are less than 0.33 and 76 percent of the estimated $\psi$ parameters are less than 0.67 . Using 12-minute returns, approximately 49 percent of the estimated $\psi$ parameters are less than 0.33 and 84 percent of the estimated $\psi$ parameters are less than 0.67. Using 30-minute returns, approximately 50 percent of the estimated $\psi$ parameters are less than 0.33 and 85 percent of the estimated $\psi$ parameters are less than 0.67 . These results suggest that, in general, the price impact of trades largely is permanent and reflects information asymmetry.

These estimates of the ratio of the temporary portion to the permanent portion of the price impact of trades are consistent with prior research. Using proprietary data from Alliance-Bernstein from January 2009 to June 2011, Bershova and Rakhlin [2013] find that the price impact of trades reverts by 5 to 10 percent in the first five minutes, approximately 10 to 20 percent in the first 10 minutes, and approximately one-third in the first hour following the completion of a large order. Using proprietary data from a large investment manager from 1998 to 2011, Frazzini, Israel, and Moskowitz [2012] find that approximately 30 percent of the price impact of trades reverts within 24 hours. The vast majority of the reversion in price impact appears to occur through overnight price changes. Out of the average price impact per trade of approximately 9 basis points, approximately one-half basis point of the reversion appears to occur during trading hours.

At these levels of $\alpha, \phi$, and $\psi$, stock price changes tend to exhibit mean reversion. Using five-minute returns, the estimated first-lag moving average coefficient exhibits a mean and median of -0.20 and -0.17 (not tabulated). That is, if unexpected order flow affected price by 1 percent, one would expected a mean 20 basis point (median 17 basis 
point) reversion in returns in the subsequent five-minute interval. If $\alpha$ and $\phi$ were zero and $\psi$ equaled its mean (median), these coefficients would be $-0.35(-0.28)$. The estimated second-lag moving average coefficient exhibits a mean and median of -0.043 and -0.044 . That is, if unexpected order flow affected price by 1 percent, one would expected a mean 4.3 (median 4.4) basis point reversion in stock price two five-minute intervals later. If $\alpha$ and $\phi$ were zero, these coefficients would equal zero. Using 12-minute returns, the estimated first-lag moving average coefficient exhibits a mean and median of -0.14 and -0.13 . That is, if unexpected order flow affected price by 1 percent, one would expected a mean 14 basis point (median 13 basis point) reversion in returns in the subsequent 12-minute interval. If $\alpha$ and $\phi$ were zero and $\psi$ equaled its mean (median), these coefficients would be $-0.31(-0.25)$. The estimated second-lag moving average coefficient exhibits a mean and median of -0.064 and -0.063 . Using 30 -minute returns, the estimated first-lag moving average coefficient exhibits a mean and median of -0.13 and -0.12 . That is, if unexpected order flow affected price by 1 percent, one would expected a mean 13 basis point (median 12 basis point) reversion in returns in the subsequent 30-minute interval. If $\alpha$ and $\phi$ were zero and $\psi$ equaled its mean (median), these coefficients would be $-0.30(-0.25)$. The estimated second-lag moving average coefficient exhibits a mean and median of -0.081 and -0.078 . Histograms of these estimated coefficients appears in Figures 26 to 28.

The estimated coefficients of the variance updating process show that the variance of price change fluctuates over time, as well as mean-reverts quickly. Using five-minute returns, the auto-regressive term in the GARCH structure, $\beta_{1}$, exhibits a mean of 0.59 and median of 0.52 , which suggests that a one-standard deviation stock price change is associated with a 72 to 77 percent increase in the variance of returns in the subsequent period. The moving average term in the GARCH structure, $\beta_{2}$, exhibits a mean of 0.18 and median of 0.09 , which suggests that changes in variance have a half-life of approximately 1.4 to 2.7 periods. ${ }^{10}$ At the mean and median levels of the intercept term, $\beta_{0}$, annualized stock price volatility is approximately 61 percent and 21 percent per year. In comparison, for the same sample of firms over 2003 to 2014, the volatility of returns from the opening price to closing price exhibited a mean and median of 51 percent and 42 percent per year. Using 12-minute returns, the auto-regressive term in the GARCH structure, $\beta_{1}$, exhibits a mean of 0.48 and median of 0.49 , which suggests that a one-standard deviation stock price change is associated with a 69 to 70 percent increase in the variance of returns in the subsequent period. The moving average term in the GARCH structure, $\beta_{2}$, exhibits a mean of 0.21 and median of 0.19 , which suggests that changes in variance have a half-life of approximately 1.8 to 1.9 periods. At the mean and median levels of the intercept term, $\beta_{0}$, annualized stock price volatility is approximately 52 percent and 34 percent per year. Using 30 -minute returns, the auto-regressive term in the GARCH structure, $\beta_{1}$, exhibits a mean of 0.52 and median of 0.73, which suggests that a one-standard deviation stock price change is associated with a 72 to 85 percent increase in the variance of returns in the subsequent period. The moving average term in the GARCH structure, $\beta_{2}$, exhibits

\footnotetext{
${ }^{10}$ The half life of changes in variance is $\ln (0.5) / \ln \left(\beta_{1}+\beta_{2}\right)$ in this GARCH specification.
} 
a mean of 0.48 and median of 0.47 , which suggests that changes in variance have a half-life of approximately 2.3 periods. At the mean and median levels of the intercept term, $\beta_{0}$, annualized stock price volatility is approximately 53 percent and 33 percent per year.

To assess goodness of fit, I consider the likelihood ratio statistic of these estimations. The likelihood ratio statistic jointly tests the statistical significance of the estimated parameters against a null hypothesis. Using five-minute returns, as compared to the null hypothesis that $\alpha=0, \phi=0, \psi=0$, and the variance of unexpected returns is time-varying, I find that approximately 97 percent of the estimations have likelihood ratio statistics that are statistically significant at the 1 percent level. Using 12-minute returns, as compared to the null hypothesis that $\alpha=0, \phi=0, \psi=0$, and the variance of unexpected returns is time-varying, approximately 98 percent of the estimations have likelihood ratio statistics that are statistically significant at the 1 percent level. Using 30 -minute returns, as compared to the null hypothesis that $\alpha=0, \phi=0, \psi=0$, and the variance of unexpected returns is time-varying, approximately 99 percent of the estimations have likelihood ratio statistics that are statistically significant at the 1 percent level. These result suggests that the structural model captures the time-series properties of returns better than a random walk model with heteroscedastic returns does.

\section{Construct validity tests}

I offer three tests to support my claim that the estimated $\alpha$ parameters measure investors' misweighting of redundant information and the estimated $\phi$ parameters measure serial correlation in liquidity trader demand.

\subsection{The viability of trading on redundant information}

In the analytical model, informed investors' expected profits decrease as $\alpha$ diverges from zero (See Section A.2). Trading on redundant information does not, however, completely wipe out informed investors' expected profits as long as $|\alpha|$ is not too large. I solve the analytical model numerically for the $\alpha$ parameter at which informed investors would break even, inclusive of trading costs, information asymmetry, serially correlated liquidity trader demand, and rational arbitrageur demand. In Figure 2, I plot the (positive root of) $\alpha$ at which informed investors would break even with $M=0$ and $\phi=0$. For any $\bar{\sigma} \in(0,2]$ and $\rho \in(0,2]$, informed investors' expected profits are still positive as long as $|\alpha|<2.0$. As depicted, this break-even level of $\alpha$ is increasing in $\rho$, increasing in $\bar{\sigma}$ if $\rho$ is sufficiently low, and decreasing in $\bar{\sigma}$ if $\rho$ is sufficiently high. In Figure 3, I plot the minimum break-even level of the redundant information parameter, $\alpha$, for any $\bar{\sigma} \in(0,2]$ and $\rho \in(0,2]$ as a function of expected liquidity trader demand and the number of arbitrageurs (i.e., the minimum point one would observe on Figure 2 for various levels of $\phi$ and $M$ ). The lowest break-even level of $\alpha$ is 1.7 , when $M=0$ and $\phi=1$. The minimum break-even level of $\alpha$ is increasing 
in $M$ because rational arbitrageurs mitigate the price impact of trading on redundant information. The minimum break-even level of $\alpha$ is decreasing in $\phi$ because serially correlated liquidity trader demand exacerbates the price impact of trading on redundant information.

I use the results of the empirical estimations to study whether informed investors still earn positive expected profits, despite their misweighting of redundant information. Table 4 shows the fraction of estimations in which the absolute value of the estimated $\alpha$ parameter is below the minimum break-even level of $\alpha$ for any $\bar{\sigma} \in(0,2]$ and $\rho \in(0,2]$. Specifically, the table shows the quintiles of the estimated $\phi$ parameters, the theoretical minimum break-even level of $|\alpha|$ at upper bound of the $\phi$ quintile, and the percent of estimations with $|\alpha|$ below the minimum break-even level of $|\alpha|$ at upper bound of the $\phi$ quintile. Based on the parameters estimated using five-minute returns, I find that 96 percent of the absolute value of the estimated $\alpha$ parameters are below the minimum break-even level of $|\alpha|$ at upper bound of the $\phi$ quintile. Based on the parameters estimated using 12-minute returns, I find that 95 percent of the absolute value of the estimated $\alpha$ parameters are below the minimum break-even level of $|\alpha|$ at upper bound of the $\phi$ quintile. Based on the parameters estimated using 30-minute returns (not tabulated), I find that 94 percent of the absolute value of the estimated $\alpha$ parameters are below the minimum break-even level of $|\alpha|$ at upper bound of the $\phi$ quintile. The percentages of the estimated $\alpha$ parameters that are below the minimum break-even level of $|\alpha|$ appear consistent across the quintiles of the estimated $\phi$ parameters for all three horizons of returns. These results suggest that informed investors earn positive expected profits despite misweighting redundant information in the vast majority of cases.

\subsection{Mean reversion in the estimated parameters}

The analytical model shows that rational arbitrageurs who trade against predictable order flow earn positive expected profits that are increasing in $\alpha^{2}$ and $\phi^{2}$. These rational arbitrageurs might delay taking advantage, however, until the misweighting reaches extreme levels and enough time passes for rational arbitrageurs to recognize the opportunity (Abreu and Brunnermeier, 2002). This argument suggests that extreme levels of information misweighting and serial correlation in liquidity trader demand are likely to be fleeting. Empirically, $\alpha$ and $\phi$ are likely to exhibit mean reversion over time.

To test these predictions, I study the time series of changes in the estimated $\alpha$ and $\phi$ parameters using an autoregressive model with two lags. Table 5 shows the results. Based on the parameters estimated using five-minute returns, changes in $\alpha$ appear to revert by 66 percent in the subsequent quarter and by an additional 33 percent two quarters later. Changes in $\phi$ appear to revert by 66 percent in the subsequent quarter and by an additional 33 percent two quarters later. Based on the parameters estimated using 12-minute returns, changes in $\alpha$ appear to revert by 66 
percent in the subsequent quarter and by an additional 32 percent two quarters later. Changes in $\phi$ appear to revert by 66 percent in the subsequent quarter and by an additional 33 percent two quarters later. Based on the parameters estimated using 30-minute returns (not tabulated), changes in $\alpha$ appear to revert by 66 percent in the subsequent quarter and by an additional 33 percent two quarters later. Changes in $\phi$ appear to revert by 66 percent in the subsequent quarter and by an additional 33 percent two quarters later. These results are materially unchanged after allowing for calendar quarter fixed effects. Overall, investors' misweighting of redundant information and the autocorrelation in liquidity trader demand appear to mean revert substantially over time. These results are consistent with rational arbitrageurs exploiting investors' predictable order flow with some delay.

\subsection{Trading volume}

In Section A.4, I derive expressions for expected trading volume from informed investors who misweight redundant information, liquidity traders whose demand is serially correlated, and rational arbitrageurs who trade to take advantage of other investors' mistakes. Expected trading volume from informed investors who misweight redundant information, $\mathrm{E}\left[\left|x_{t}\right|\right]$, can be written as

$$
\mathrm{E}\left[\left|x_{t}\right|\right] \propto b_{0, t}^{x}+\left(b_{1}^{x} \alpha^{2}-b_{2}^{x} \alpha \phi+b_{3}^{x} \phi^{2}\right) \sigma_{\eta, t}^{2}+b_{4}^{x} \phi^{4} \sigma_{\nu, t}^{2}
$$

where $\sigma_{\eta, t}^{2}$ is the variance of unexpected price changes, $\sigma_{\nu, t}^{2}$ is the variance of the price impact of expected liquidity trader demand, $b_{0, t}^{x}$ is proportional to the variance of private information flows, and $b_{1}^{x}, b_{2}^{x}$, $b_{3}^{x}$, and $b_{4}^{x}$ are timeinvariant constants. The coefficient on $\alpha \phi \sigma_{\eta, t}^{2}$ is negative because an informed investor who misweights redundant information trades as if serially correlated liquidity trader demand is a competitor in demand.

Expected trading volume from liquidity traders whose demand is serially correlated, $\mathrm{E}\left[\left|z_{t}\right|\right]$, can be written as

$$
\mathrm{E}\left[\left|z_{t}\right|\right] \propto b_{0, t}^{z}+b_{3}^{z} \phi^{2} \sigma_{\eta, t}^{2}-b_{5, t}^{z} \phi^{2}
$$

where $b_{3}^{z}$ is a time-invariant constant and $b_{5, t}^{z}$ is proportional to the variance of private information flows. The coefficient $b_{0, t}$ is greater than zero because the variance of unexpected liquidity trader demand is assumed to be correlated with the variance of private information flows.

Expected trading volume from rational arbitrageurs who take advantage of other investors' mistakes, $\mathrm{E}\left[\left|y_{t}\right|\right]$, can be written as

$$
\mathrm{E}\left[\left|y_{t}\right|\right] \propto\left(b_{1}^{y} \alpha^{2}+b_{2}^{y} \alpha \phi+b_{3}^{y} \phi^{2}\right) \sigma_{\eta, t}^{2}+b_{4}^{y} \phi^{4} \sigma_{\nu, t}^{2}
$$


These three expressions can be consolidated as

$$
\begin{gathered}
\mathrm{E}\left[\left|x_{t}\right|+M\left|y_{t}\right|+\left|z_{t}\right|\right] \propto b_{0, t}+b_{1}\left[\alpha^{2} \sigma_{\eta, t}^{2}\right]+b_{2}\left[\alpha \phi \sigma_{\eta, t}^{2}\right]+b_{3}\left[\phi^{2} \sigma_{\eta, t}^{2}\right] \\
+b_{4}\left[\phi^{4} \sigma_{\nu, t}^{2}\right]+b_{5, t}\left[\phi^{2}\right]
\end{gathered}
$$

where $\mathrm{E}\left[\left|x_{t}\right|+M\left|y_{t}\right|+\left|z_{t}\right|\right]$ denotes expected trading volume.

To test this predicted relationship between trading volume and the estimated parameters, I estimate the following regression:

$$
\begin{aligned}
\ln \left(\operatorname{Turn}_{j, q}\right)= & b_{1}\left[\alpha^{2} \sigma_{\eta, t}^{2}\right]_{j, q}+b_{2}\left[\alpha \phi \sigma_{\eta, t}^{2}\right]_{j, q}+b_{3}\left[\phi^{2} \sigma_{\eta, t}^{2}\right]_{j, q} \\
& +b_{4}\left[\phi^{4} \sigma_{\nu, t}^{2}\right]_{j, q}+b_{5}\left[\phi^{2}\right]_{j, q}+\sum_{j} b_{j}+\sum_{q} b_{q}+\epsilon_{j, q}
\end{aligned}
$$

where the dependent variable is the natural log of quarterly share turnover - total volume divided by average shares outstanding - and $\epsilon_{j, q}$ is an error term. The regressions include firm and calendar quarter fixed effects, denoted $\sum_{j} b_{j}$ and $\sum_{q} b_{q}$, because the variance of the fundamental value of a firm and the variance of unexpected liquidity trader demand are assumed to vary across firms and over time. If the estimated $\alpha$ parameters measure investors' misweighting of redundant information and the estimated $\phi$ parameters measure autocorrelation in liquidity trader demand, the analytical model predicts that $b_{1}>0, b_{3}>0, b_{4}>0$, and $b_{5}<0$.

Table 6 shows the results. In the estimation of Equation (5.5) using the parameters estimated on five-minute returns and the estimation of Equation (5.5) using the parameters estimated on 12-minute returns, I find $b_{1}>0, b_{4}>0$, and $b_{5}<0$ at the 0.1 percent statistical significance level. The estimated $b_{3}$ coefficients are positive but not statistically significant. Using the parameters estimated using 30-minute returns (not tabulated), I find $b_{1}>0$ and $b_{4}>0$ at the 0.1 percent statistical significance level. The estimated $b_{3}$ and $b_{5}$ coefficients are not statistically significant. These coefficients align with those predicted from the analytical model, and support my claim that the estimated $\alpha$ parameters measure investors' misweighting of redundant information and the estimated $\phi$ parameters measure autocorrelation in liquidity trader demand.

\section{Conclusion}

Overall, these results suggest an information processing bias that contributes to momentum and mean reversion in stock price returns. In prior literature, identification of information processing biases proved challenging because observable proxies for the presence and magnitude of these biases, such as returns volatility and trading volume, also 
could be influenced by trading costs and information asymmetry. This study addresses the identification challenge by offering an analytical model and structural estimation framework that separate investors' misweighting of information that is already priced from trading frictions and information asymmetry. I estimate this structural model and find that, on average, investors behave as if redundant information is private information. This result extends Tetlock [2011], who finds that firms with more stale news stories in one week exhibit returns reversals in the subsequent week.

Future work could extend this paper in analytical or empirical domains. Future analytical work could introduce additional investor types, such as investment style chasers (e.g., Barberis and Shleifer, 2003); long-lived information, noisy private signals, and heterogeneous investors (e.g., Foster and Viswanathan, 1996); or, more detailed market microstructure characteristics (e.g., Adrian et al., 2016). The challenge for analytical work on information processing biases is to provide an empirical framework in which information processing biases are estimable distinctly from genuine information advantages and frictions to arbitrage.

Future empirical work could examine how investors' misperception of the information already in prices varies with communication among capital markets participants. For example, corporate managers and information intermediaries might attempt to exploit this information processing bias. Clement, Frankel, and Miller [2003] argue that management earnings guidance that confirms guidance disclosed previously reduces investors' uncertainty about future earnings realizations. An alternative explanation could be that investors behave like confirming management guidance has more novel information than the announcement truly has. If so, the variance of their posterior beliefs could be excessively low. Similarly, corporate managers with equity-linked incentives might take advantage of investors' information processing bias by repeating good news disclosures in multiple venues or formats (e.g., in mandatory filings, conference calls, presentations to investors, and social media channels) while mentioning bad news disclosures only the requisite number of times. Bayesian investors would back out this repetitive disclosure, but investors who misunderstand what information already is reflected in prices might believe that the repeated disclosures contain new news. If sell-side analysts anticipate that investors will respond excessively to the information already in prices, their earnings forecasts are likely to reiterate corporate managers' guidance (e.g., Feng and McVay, 2010). In all, this non-Bayesian investor behavior could affect the quality of communication between corporate managers, information intermediaries, and investors. 


\section{Exhibits}

Table 1: Estimated parameters of the structural model

The following tables show descriptive statistics for the estimated parameters of the structural model. $\alpha$ measures the extent to which informed investors misweight information that is already priced ("redundant information"). The overarching null hypothesis is $\alpha=0$. $\phi$ is the estimated autoregressive parameter of liquidity trader demand. $\psi$ is the estimated ratio of trading costs to information asymmetry. The variance of unexpected price changes is assumed to follow a $\operatorname{GARCH}(1,1)$ process with parameters $\beta_{0}, \beta_{1}$, and $\beta_{2}$. I impose the following constraints on the parameter estimates: $\psi \geq 0, \phi \in[-1,1], \beta_{0} \geq 0, \beta_{1} \in[0,1]$, and $\beta_{2} \in\left[0,1-\beta_{1}\right]$. I estimate the parameter set $\left\{\alpha, \phi, \psi, \beta_{0}, \beta_{1}, \beta_{2}\right\}$ by maximizing the log-likelihood function in Equation (4.4).

Parameters are estimated by firm-quarter from 2003 through 2014. Thorough descriptions of the sample and variable construction appear in Section 4.2.

This table shows the parameters estimated using five-minute returns and assuming that there is one rational arbitrageur who trades against investors' predictable order flow.

\begin{tabular}{|c|c|c|c|c|c|c|c|c|}
\hline & \multirow[b]{2}{*}{ Mean } & \multirow[b]{2}{*}{ St.Dev. } & \multicolumn{5}{|c|}{ Percentiles } & \multirow[b]{2}{*}{ Num.Obs. } \\
\hline & & & $1 \mathrm{st}$ & 25 th & Median & 75 th & 99th & \\
\hline $\begin{array}{l}\text { Investors' misweighting of } \\
\text { redundant information, } \alpha\end{array}$ & 0.475 & 0.829 & -1.743 & -0.075 & 0.487 & 1.031 & 2.342 & 107,852 \\
\hline t-statistic $\left(H_{0}: \alpha=0\right)$ & 87.3 & 230.7 & -290.6 & -0.5 & 22.4 & 103.3 & $1,405.0$ & 107,852 \\
\hline $\begin{array}{l}\text { Autoregressive parameter of } \\
\text { liquidity trader demand, } \phi\end{array}$ & 0.375 & 0.622 & -0.986 & -0.123 & 0.556 & 0.981 & 1.000 & 107,852 \\
\hline t-statistic $\left(H_{0}: \phi=0\right)$ & $1,839.5$ & $6,314.4$ & $-2,614.3$ & -1.5 & 19.6 & 360.3 & $4,2450.2$ & 107,852 \\
\hline $\begin{array}{l}\text { Ratio of transaction costs to } \\
\text { Kyle's lambda, } \psi\end{array}$ & 0.535 & 0.448 & 0.062 & 0.252 & 0.392 & 0.642 & 2.401 & 107,852 \\
\hline t-statistic $\left(H_{0}: \psi=0\right)$ & 195.6 & 245.4 & 0.0 & 44.8 & 120.8 & 250.3 & 1496.0 & 107,852 \\
\hline $\begin{array}{l}\text { GARCH intercept } \\
\text { parameter, } \beta_{0} \text { (annualized) }\end{array}$ & 0.085 & 0.157 & 0.004 & 0.017 & 0.036 & 0.076 & 0.878 & 107,852 \\
\hline $\begin{array}{l}\text { GARCH autoregressive } \\
\text { parameter, } \beta_{1}\end{array}$ & 0.587 & 0.118 & 0.249 & 0.520 & 0.597 & 0.666 & 0.820 & 107,852 \\
\hline $\begin{array}{l}\text { GARCH moving average } \\
\text { parameter, } \beta_{2}\end{array}$ & 0.177 & 0.123 & 0.001 & 0.087 & 0.164 & 0.236 & 0.567 & 107,852 \\
\hline
\end{tabular}


Table 2: Estimated parameters of the structural model, continued

The following table shows descriptive statistics for the parameters of the structural model, $\left\{\alpha, \phi, \psi, \beta_{0}, \beta_{1}, \beta_{2}\right\}$, estimated using 12-minute returns and assuming that there is one rational arbitrageur who trades against investors' predictable order flow.

\begin{tabular}{lcccccccc}
\hline & & & \multicolumn{5}{c}{ Percentiles } \\
\cline { 5 - 7 } & Mean & St.Dev. & 1 st & 25 th & Median & 75 th & 99 th & Num.Obs. \\
\hline $\begin{array}{l}\text { Investors' misweighting of } \\
\text { redundant information, } \alpha\end{array}$ & 0.625 & 0.761 & -1.252 & 0.112 & 0.634 & 1.136 & 2.419 & 136,513 \\
$\quad$ t-statistic $\left(H_{0}: \alpha=0\right)$ & 59.0 & 128.6 & -70.6 & 0.8 & 17.6 & 60.4 & 809.7 & 136,513 \\
$\begin{array}{l}\text { Autoregressive parameter of } \\
\text { liquidity trader demand, } \phi\end{array}$ & 0.445 & 0.595 & -0.882 & -0.017 & 0.667 & 0.986 & 1.000 & 136,513 \\
$\quad$ t-statistic $\left(H_{0}: \phi=0\right)$ & 339.7 & $1,002.0$ & -715.2 & 0.0 & 14.2 & 176.3 & 6173.0 & 136,513 \\
$\begin{array}{l}\text { Ratio of transaction costs to } \\
\text { Kyle's lambda, } \psi\end{array}$ & 0.438 & 0.355 & 0.085 & 0.223 & 0.338 & 0.523 & 2.227 & 136,513 \\
$\quad$ t-statistic $\left(H_{0}: \psi=0\right)$ & 84.8 & 102.8 & 0.0 & 21.7 & 55.3 & 110.0 & 653.8 & 136,513 \\
$\begin{array}{l}\text { GARCH intercept } \\
\text { parameter, } \beta_{0} \text { (annualized) }\end{array}$ & 0.086 & 0.156 & 0.003 & 0.017 & 0.036 & 0.079 & 0.878 & 136,513 \\
$\begin{array}{l}\text { GARCH autoregressive } \\
\text { parameter, } \beta_{1}\end{array}$ & 0.477 & 0.142 & 0.135 & 0.383 & 0.488 & 0.575 & 0.797 & 136,513 \\
$\begin{array}{l}\text { GARCH moving average } \\
\text { parameter, } \beta_{2}\end{array}$ & 0.208 & 0.128 & 0.001 & 0.119 & 0.193 & 0.278 & 0.612 & 136,513 \\
\hline
\end{tabular}


Table 3: Estimated parameters of the structural model, continued

The following table shows descriptive statistics for the parameters of the structural model, $\left\{\alpha, \phi, \psi, \beta_{0}, \beta_{1}, \beta_{2}\right\}$, estimated using 30-minute returns and assuming that there is one rational arbitrageur who trades against investors' predictable order flow.

\begin{tabular}{|c|c|c|c|c|c|c|c|c|}
\hline & \multirow[b]{2}{*}{ Mean } & \multirow[b]{2}{*}{ St.Dev. } & \multicolumn{5}{|c|}{ Percentiles } & \multirow[b]{2}{*}{ Num.Obs. } \\
\hline & & & $1 \mathrm{st}$ & 25 th & Median & 75 th & 99th & \\
\hline $\begin{array}{l}\text { Investors' misweighting of } \\
\text { redundant information, } \alpha\end{array}$ & 0.742 & 0.785 & -1.195 & 0.198 & 0.757 & 1.294 & 2.397 & 160,715 \\
\hline t-statistic $\left(H_{0}: \alpha=0\right)$ & 18.7 & 36.8 & -18.2 & 0.2 & 6.0 & 20.7 & 218.6 & 160,715 \\
\hline $\begin{array}{l}\text { Autoregressive parameter of } \\
\text { liquidity trader demand, } \phi\end{array}$ & 0.454 & 0.584 & -0.983 & 0.023 & 0.663 & 0.981 & 1.000 & 160,715 \\
\hline t-statistic $\left(H_{0}: \phi=0\right)$ & 22.9 & 89.4 & -262.7 & 0.0 & 3.3 & 24.43 & 459.2 & 160,715 \\
\hline $\begin{array}{l}\text { Ratio of transaction costs to } \\
\text { Kyle's lambda, } \psi\end{array}$ & 0.427 & 0.329 & 0.083 & 0.213 & 0.328 & 0.516 & 1.940 & 160,715 \\
\hline t-statistic $\left(H_{0}: \psi=0\right)$ & 29.7 & 35.5 & 0.0 & 6.2 & 18.6 & 40.2 & 206.3 & 160,715 \\
\hline $\begin{array}{l}\text { GARCH intercept } \\
\text { parameter, } \beta_{0} \text { (annualized) }\end{array}$ & 0.071 & 0.133 & 0.002 & 0.013 & 0.029 & 0.066 & 0.878 & 160,715 \\
\hline $\begin{array}{l}\text { GARCH autoregressive } \\
\text { parameter, } \beta_{1}\end{array}$ & 0.521 & 0.224 & 0.103 & 0.305 & 0.548 & 0.730 & 0.841 & 160,715 \\
\hline $\begin{array}{l}\text { GARCH moving average } \\
\text { parameter, } \beta_{2}\end{array}$ & 0.222 & 0.127 & 0.019 & 0.145 & 0.188 & 0.253 & 0.639 & 160,715 \\
\hline
\end{tabular}




\section{Table 4: The viability of trading on redundant information}

This table describes the fraction of estimations in which the absolute value of the estimated $\alpha$ parameter is below the minimum break-even level of $\alpha$ for any $\bar{\sigma} \in(0,2]$ and $\rho \in(0,2]$. Panel A tabulates the $\alpha$ and $\phi$ parameters estimated using five-minute returns; Panel B tabulates the $\alpha$ and $\phi$ parameters estimated using 12-minute returns. Each panel tabulates quintiles of the estimated $\phi$ parameters, the theoretical minimum break-even level of $|\alpha|$ at upper bound of the $\phi$ quintile, and the percent of estimations with $|\alpha|$ below the theoretical minimum break-even level of $|\alpha|$. Similar results obtain using the parameters estimated on 30-minute returns, and are available on request.

Panel A: Parameters estimated using five-minute returns

\begin{tabular}{llll}
\hline $\begin{array}{l}\text { Quintile of } \\
\text { estimated } \phi\end{array}$ & Range of estimated $\phi$ & $\begin{array}{l}\text { Theoretical } \\
\text { minimum break-even } \\
\text { level of }|\alpha| \text { at upper } \\
\text { bound of } \phi \text { quintile }\end{array}$ & $\begin{array}{l}\text { Percent of estimations } \\
\text { with }|\alpha| \text { below minimum } \\
\text { break-even level of }|\alpha|\end{array}$ \\
\hline 1 & $(-1,-0.285]$ & 2.273 & $97 \%$ \\
2 & $(-0.285,0.314]$ & 2.056 & 97 \\
3 & $(-0.314,0.778]$ & 1.927 & 96 \\
4 & $(0.778,0.990]$ & 1.880 & 95 \\
5 & $(0.990,1.000]$ & 1.878 & 96 \\
\hline Total & & & $96 \%$ \\
\hline
\end{tabular}

Panel B: Parameters estimated using 12-minute returns

\begin{tabular}{llll}
\hline $\begin{array}{l}\text { Quintile of } \\
\text { estimated } \phi\end{array}$ & Range of estimated $\phi$ & $\begin{array}{l}\text { Theoretical } \\
\text { minimum break-even } \\
\text { level of }|\alpha| \text { at upper } \\
\text { bound of } \phi \text { quintile }\end{array}$ & $\begin{array}{l}\text { Percent of estimations } \\
\text { with }|\alpha| \text { below minimum } \\
\text { break-even level of }|\alpha|\end{array}$ \\
\hline 1 & $(-1,-0.186]$ & 2.234 & $95 \%$ \\
2 & $(-0.186,0.431]$ & 2.020 & 96 \\
3 & $(0.431,-0.870]$ & 1.906 & 95 \\
4 & $(0.870,0.994]$ & 1.880 & 95 \\
5 & $(0.994,1.000]$ & 1.878 & 95 \\
\hline Total & & & $95 \%$ \\
\hline
\end{tabular}


Table 5: Mean reversion in investors' misweighting of redundant information

This table describes the time series properties of the estimated parameters for investors' misweighting of redundant information, $\alpha$, and the autocorrelation of liquidity trader demand, $\phi$. In Panel $\mathrm{A}$, the dependent variables is the change in the estimated $\alpha$ parameter for a firm, $\Delta \alpha_{j, q}=\alpha_{j, q}-\alpha_{j, q-1}$. The explanatory variables are one-quarter and two-quarter lagged changes in estimated $\alpha$ parameters, $\Delta \alpha_{j, q-1}$ and $\Delta \alpha_{j, q-2}$. In Panel $\mathrm{B}$, the dependent variables is the change in the estimated $\phi$ parameter for a firm, $\Delta \phi_{j, q}$. The explanatory variables are one-quarter and two-quarter lagged changes in estimated $\phi$ parameters, $\Delta \phi_{j, q-1}$ and $\Delta \phi_{j, q-2}$. In each panel, the regressions in columns (II) and (IV) include calendar quarter fixed effects.

Standard errors are clustered by firm and calendar quarter, and appear in parentheses beneath the estimated coefficients. Similar results obtain using the parameters estimated on 30-minute returns, and are available on request.

Panel A: Time series properties of estimated $\alpha$ parameters

\begin{tabular}{|c|c|c|c|c|}
\hline \multirow[b]{2}{*}{ Dependent variable $=\Delta \alpha_{j, q}$} & \multicolumn{2}{|c|}{ Estimated on five-minute returns } & \multicolumn{2}{|c|}{ Estimated on 12-minute returns } \\
\hline & (I) & (II) & (III) & $(\mathrm{IV})$ \\
\hline \multirow[t]{2}{*}{$\Delta \alpha_{j, q-1}$} & $-0.657^{* * *}$ & $-0.657^{* * *}$ & $-0.661^{* * *}$ & $-0.661^{* * *}$ \\
\hline & $(0.004)$ & $(0.004)$ & $(0.003)$ & $(0.003)$ \\
\hline \multirow[t]{4}{*}{$\Delta \alpha_{j, q-2}$} & $-0.328^{* * *}$ & $-0.328^{* * *}$ & $-0.324^{* * *}$ & $-0.324^{* * *}$ \\
\hline & $(0.005)$ & $(0.005)$ & $(0.003)$ & $(0.003)$ \\
\hline & -0.003 & & -0.000 & \\
\hline & $(0.002)$ & & $(0.008)$ & \\
\hline Calendar quarter fixed effects & No & Yes & No & Yes \\
\hline $\mathrm{R}^{2}$ (full) & 0.326 & 0.327 & 0.327 & 0.330 \\
\hline $\mathrm{R}^{2}$ (within) & & 0.326 & & 0.328 \\
\hline Num. obs. & 939,48 & 93,948 & 119,797 & 119,797 \\
\hline
\end{tabular}

${ }^{* * *} p<0.001,{ }^{* *} p<0.01,{ }^{*} p<0.05$

Panel B: Time series properties of estimated $\phi$ parameters

\begin{tabular}{|c|c|c|c|c|}
\hline \multirow[b]{2}{*}{ Dependent variable $=\Delta \phi_{j, q}$} & \multicolumn{2}{|c|}{ Estimated on five-minute returns } & \multicolumn{2}{|c|}{ Estimated on 12-minute returns } \\
\hline & (I) & (II) & (III) & (IV) \\
\hline \multirow[t]{2}{*}{$\Delta \phi_{j, q-1}$} & $-0.664^{* * *}$ & $-0.664^{* * *}$ & $-0.664^{* * *}$ & $-0.664^{* * *}$ \\
\hline & $(0.004)$ & $(0.004)$ & $(0.003)$ & $(0.003)$ \\
\hline \multirow{2}{*}{$\Delta \phi_{j, q-2}$} & $-0.334^{* * *}$ & $-0.334^{* * *}$ & $-0.332^{* * *}$ & $-0.332^{* * *}$ \\
\hline & $(0.003)$ & $(0.003)$ & $(0.002)$ & $(0.002)$ \\
\hline \multirow[t]{2}{*}{ Intercept } & -0.001 & & -0.002 & \\
\hline & $(0.003)$ & & $(0.003)$ & \\
\hline Calendar quarter fixed effects & No & Yes & No & Yes \\
\hline $\mathrm{R}^{2}$ (full) & 0.331 & 0.332 & 0.331 & 0.332 \\
\hline $\mathrm{R}^{2}$ (within) & & 0.331 & & 0.331 \\
\hline Num. obs. & 93,948 & 93,948 & 119,797 & 119,797 \\
\hline
\end{tabular}

${ }^{* * *} p<0.001,{ }^{* *} p<0.01,{ }^{*} p<0.05$ 


\section{Table 6: Investors' misweighting of redundant information and trading volume}

This table describes the association between investors' misweighting of redundant information and trading volume. Based on the expression for expected trading volume derived in Section A.4, I estimate the following regression:

$$
\begin{aligned}
\ln \left(\operatorname{Turn}_{j, q}\right)= & b_{1}\left[\alpha^{2} \sigma_{\eta, t}^{2}\right]_{j, q}+b_{2}\left[\alpha \phi \sigma_{\eta, t}^{2}\right]_{j, q}+b_{3}\left[\phi^{2} \sigma_{\eta, t}^{2}\right]_{j, q} \\
& +b_{4}\left[\phi^{4} \sigma_{\nu, t}^{2}\right]_{j, q}+b_{5}\left[\phi^{2}\right]_{j, q}+\sum_{j} b_{j}+\sum_{q} b_{q}+\epsilon_{j, q}
\end{aligned}
$$

where the dependent variable is the natural log of quarterly share turnover - total volume divided by average shares outstanding - and $\epsilon_{j, q}$ is the error term. The explanatory variables were estimated by firm-quarter and are normalized to have means equal to zero and variances equal to one. The regressions include firm and calendar quarter fixed effects because the variance of the fundamental value of a firm and the variance of unexpected liquidity trader demand which drive trading volume in the absence of predictable demand - are assumed to vary across firms and over time. The analytical model predicts that $b_{1}>0, b_{3}>0, b_{4}>0$, and $b_{5}<0$.

Standard errors are clustered by firm and calendar quarter, and appear in parentheses beneath the estimated coeffi-

\begin{tabular}{|c|c|c|}
\hline Dependent variable $=\ln \left(\right.$ Turn $\left._{j, q}\right)$ & Estimated on five-minute returns & Estimated on 12 -minute returns \\
\hline \multirow[t]{2}{*}{$\alpha^{2} \sigma_{\eta, t}^{2}$} & $0.062^{* * *}$ & $0.041^{* * *}$ \\
\hline & $(0.016)$ & $(0.008)$ \\
\hline \multirow[t]{2}{*}{$\alpha \phi \sigma_{\eta, t}^{2}$} & -0.006 & -0.002 \\
\hline & $(0.004)$ & $(0.002)$ \\
\hline \multirow[t]{2}{*}{$\phi^{2} \sigma_{\eta, t}^{2}$} & 0.069 & 0.016 \\
\hline & $(0.036)$ & $(0.017)$ \\
\hline \multirow[t]{2}{*}{$\phi^{4} \sigma_{\nu, t}^{2}$} & $0.030^{* * *}$ & $0.034^{* * *}$ \\
\hline & $(0.004)$ & $(0.005)$ \\
\hline \multirow[t]{2}{*}{$\phi^{2}$} & $-0.026^{* * *}$ & $-0.015^{* * *}$ \\
\hline & $(0.003)$ & $(0.003)$ \\
\hline Firm fixed effects & Yes & Yes \\
\hline Calendar quarter fixed effects & Yes & Yes \\
\hline $\mathrm{R}^{2}$ (full) & 0.644 & 0.615 \\
\hline $\mathrm{R}^{2}$ (within) & 0.014 & 0.009 \\
\hline Num. obs. & 107,716 & 136,285 \\
\hline
\end{tabular}
cients. Similar results obtain using the parameters estimated on 30-minute returns, and are available on request.

\footnotetext{
${ }^{* * *} p<0.001,{ }^{* *} p<0.01,{ }^{*} p<0.05$
} 
Figure 1: Kyle's lambda as a function of information asymmetry and transaction costs Kyle's lambda measures the sensitivity of the expected value of the risky asset to unexpected order flow.

\section{Kyle's lambda}

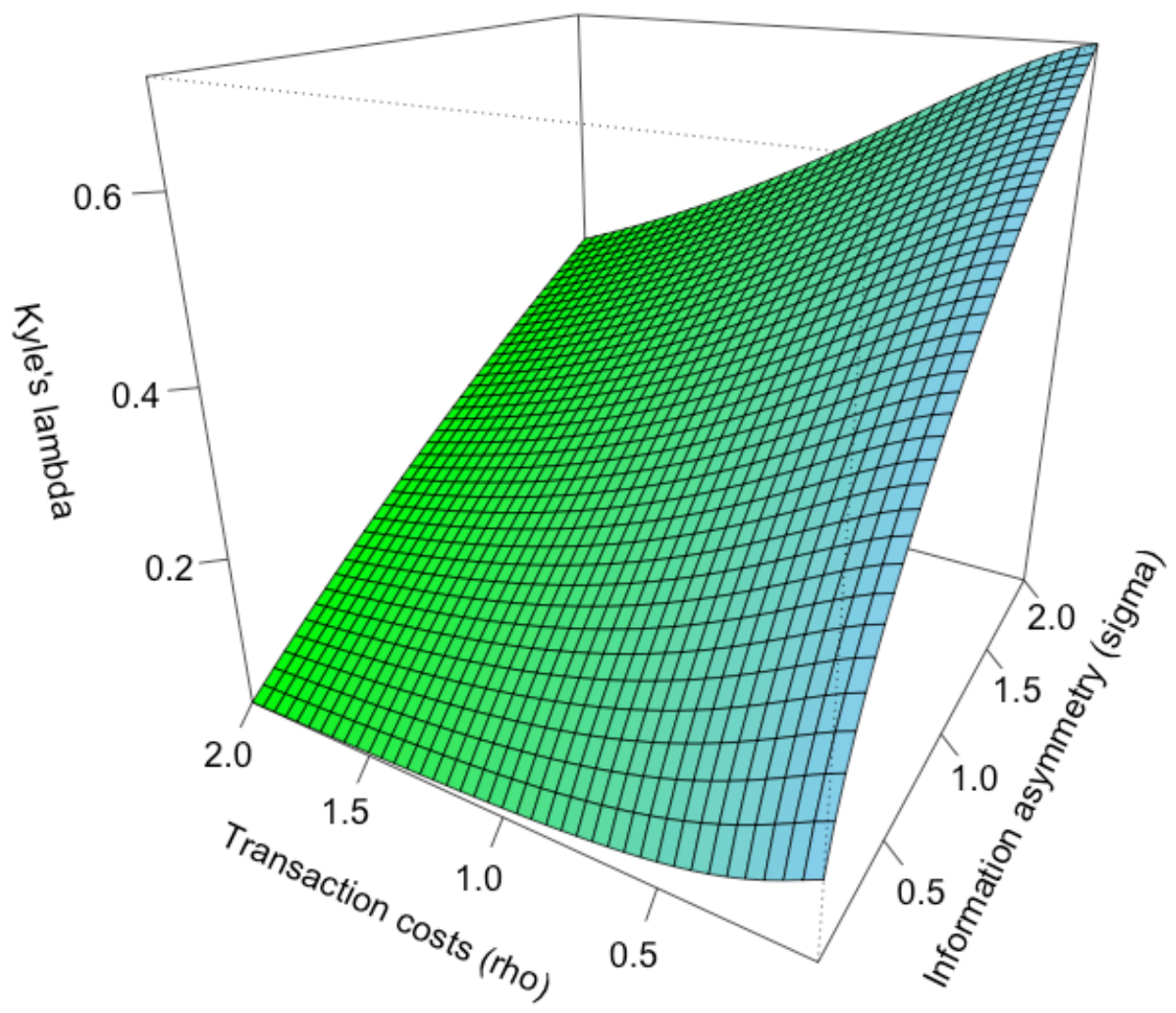


Figure 2: The break-even level of the redundant information parameter, $\alpha$, as a function of information asymmetry and transaction costs with $\phi=0$ and $M=0$

\section{Break-even misweighting of redundant information}

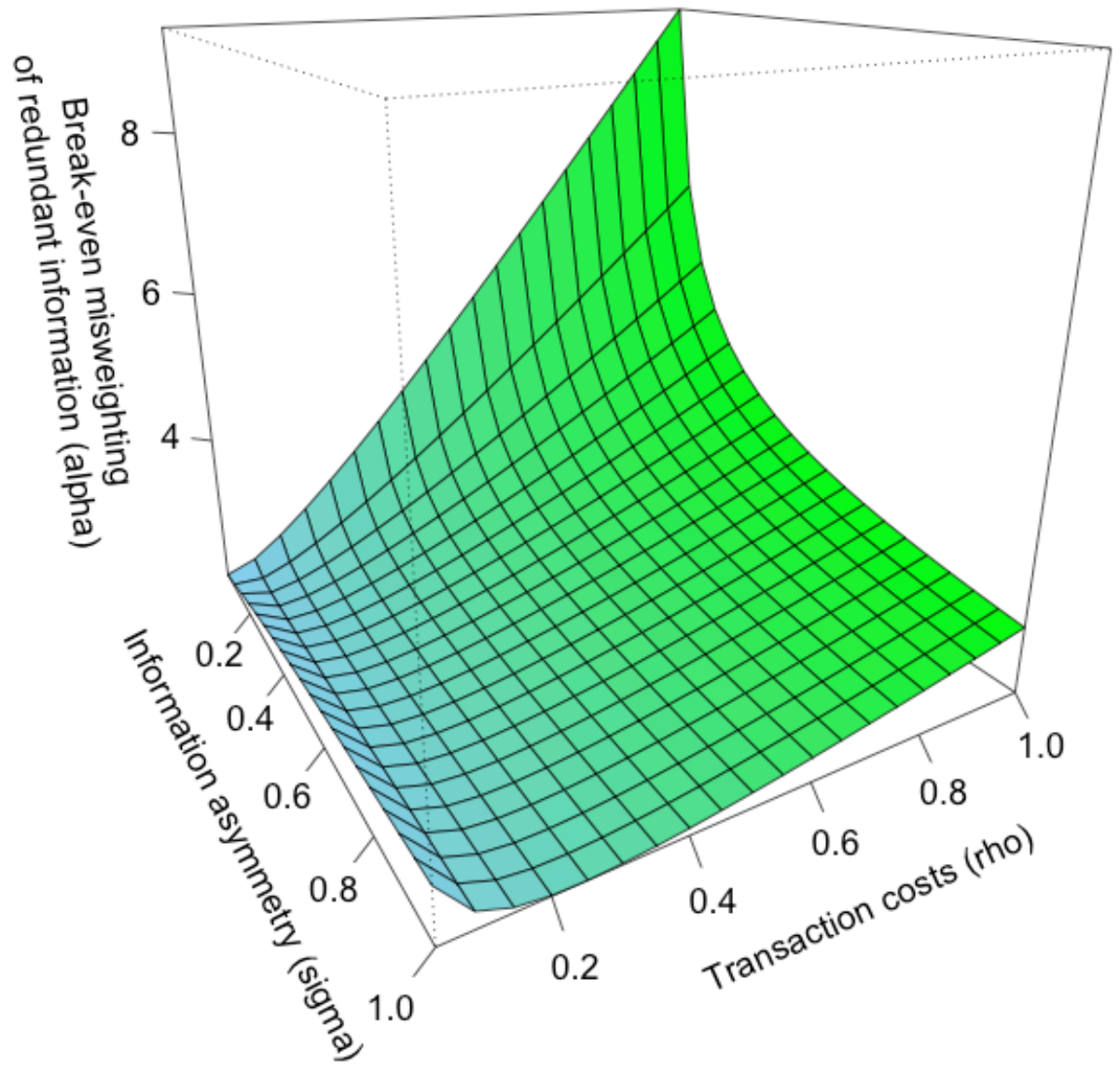


Figure 3: The break-even level of the redundant information parameter, $\alpha$, as a function of expected liquidity trader demand and the number of arbitrageurs

\section{Break-even misweighting of redundant information}

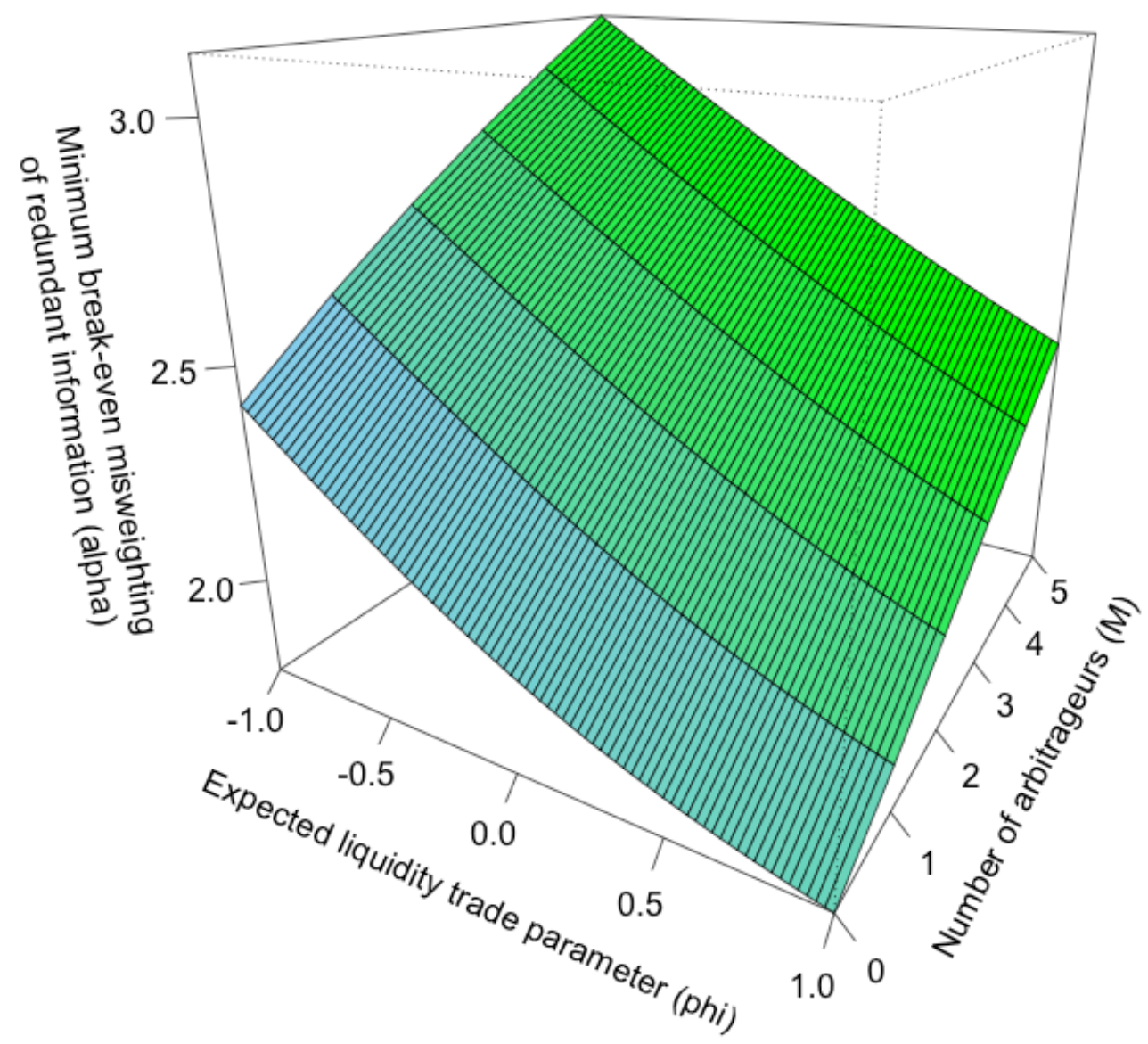


Figure 4: Rational arbitrageurs' expected profit

The following charts show a rational arbitrageur's expected profits as a function of information asymmetry (sigma) and transaction costs (rho).
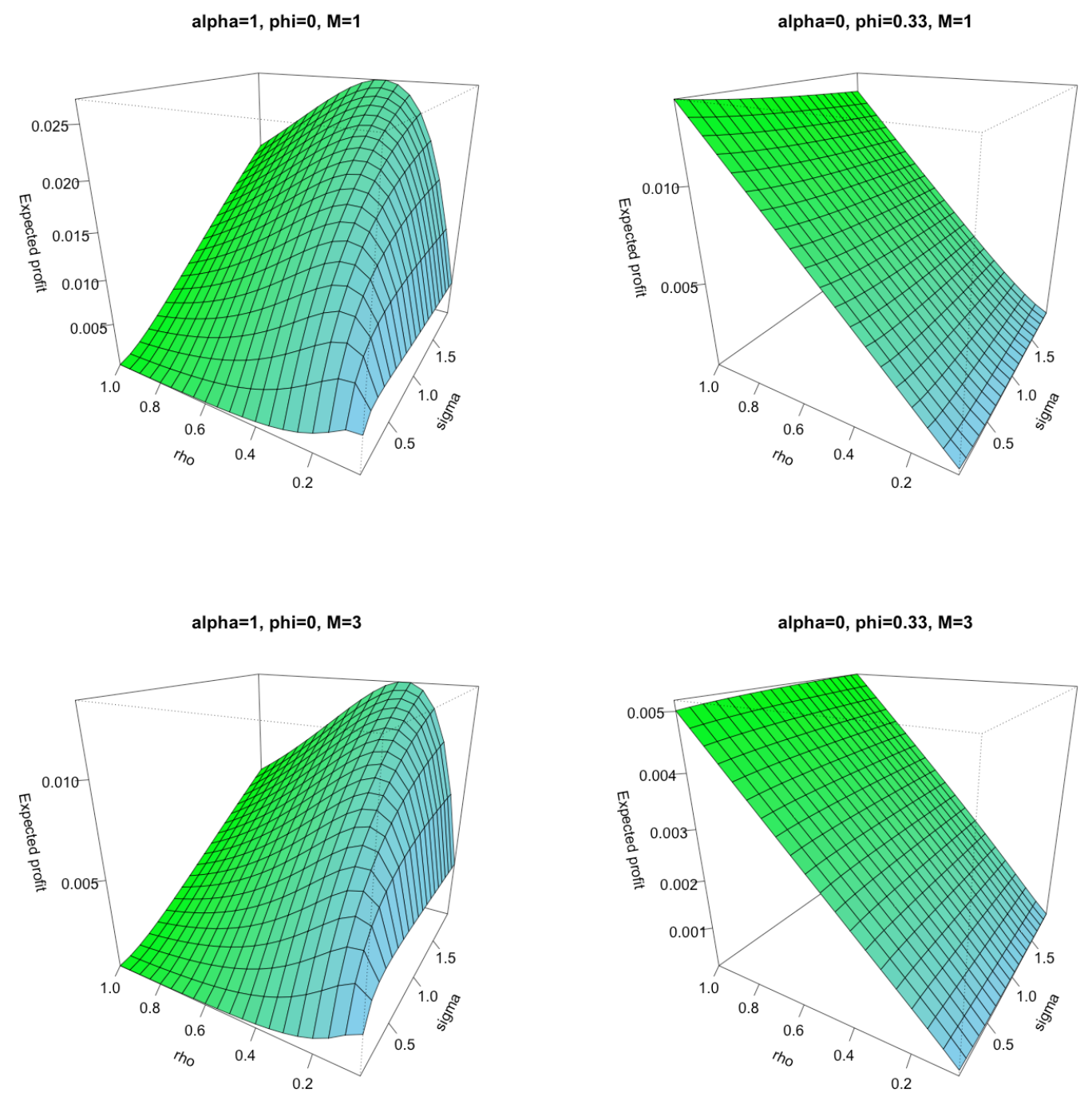
Figure 5: Sample size by calendar quarter, estimations using five-minute returns

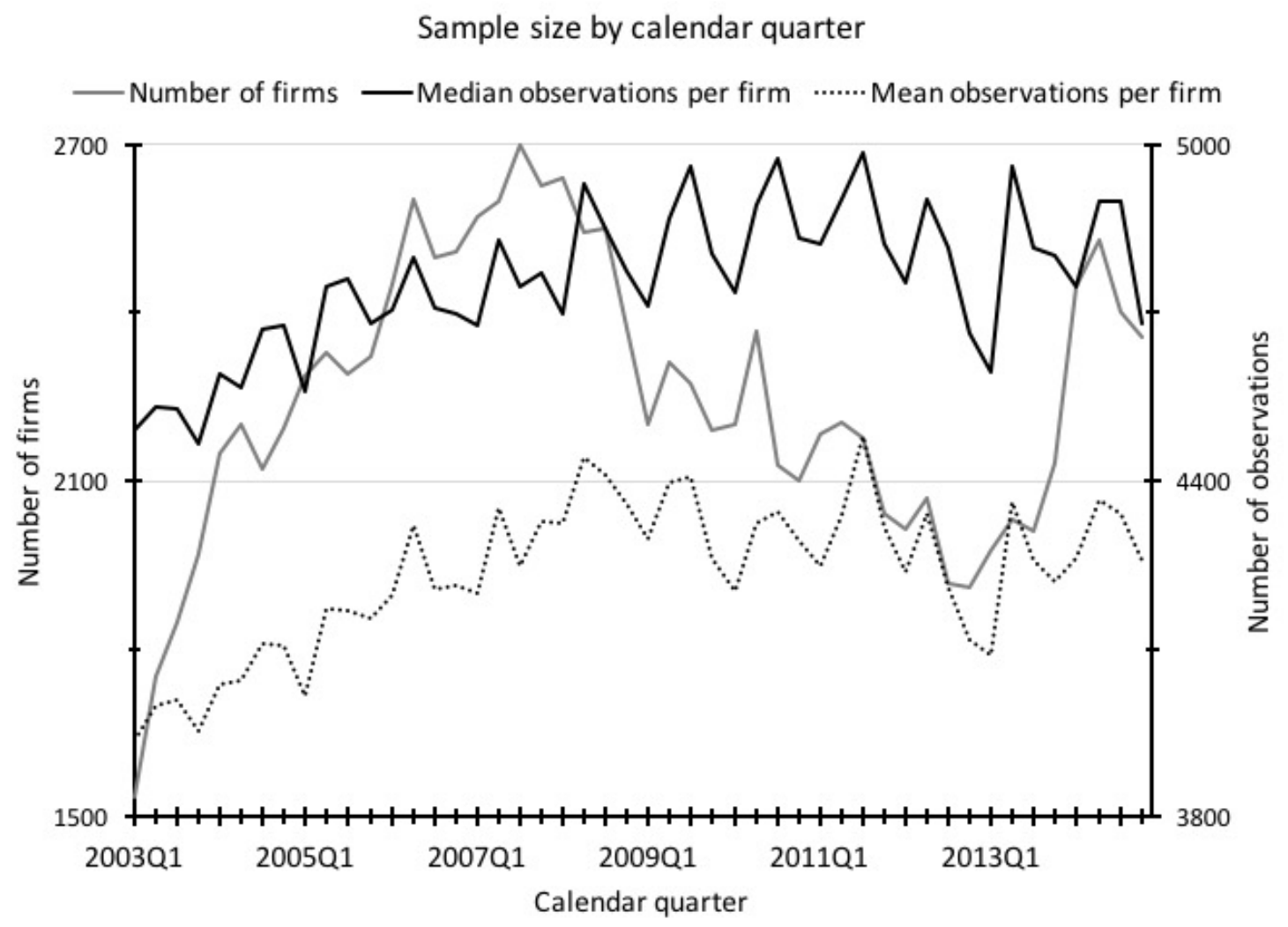


Figure 6: Sample size by calendar quarter, estimations using 12-minute returns

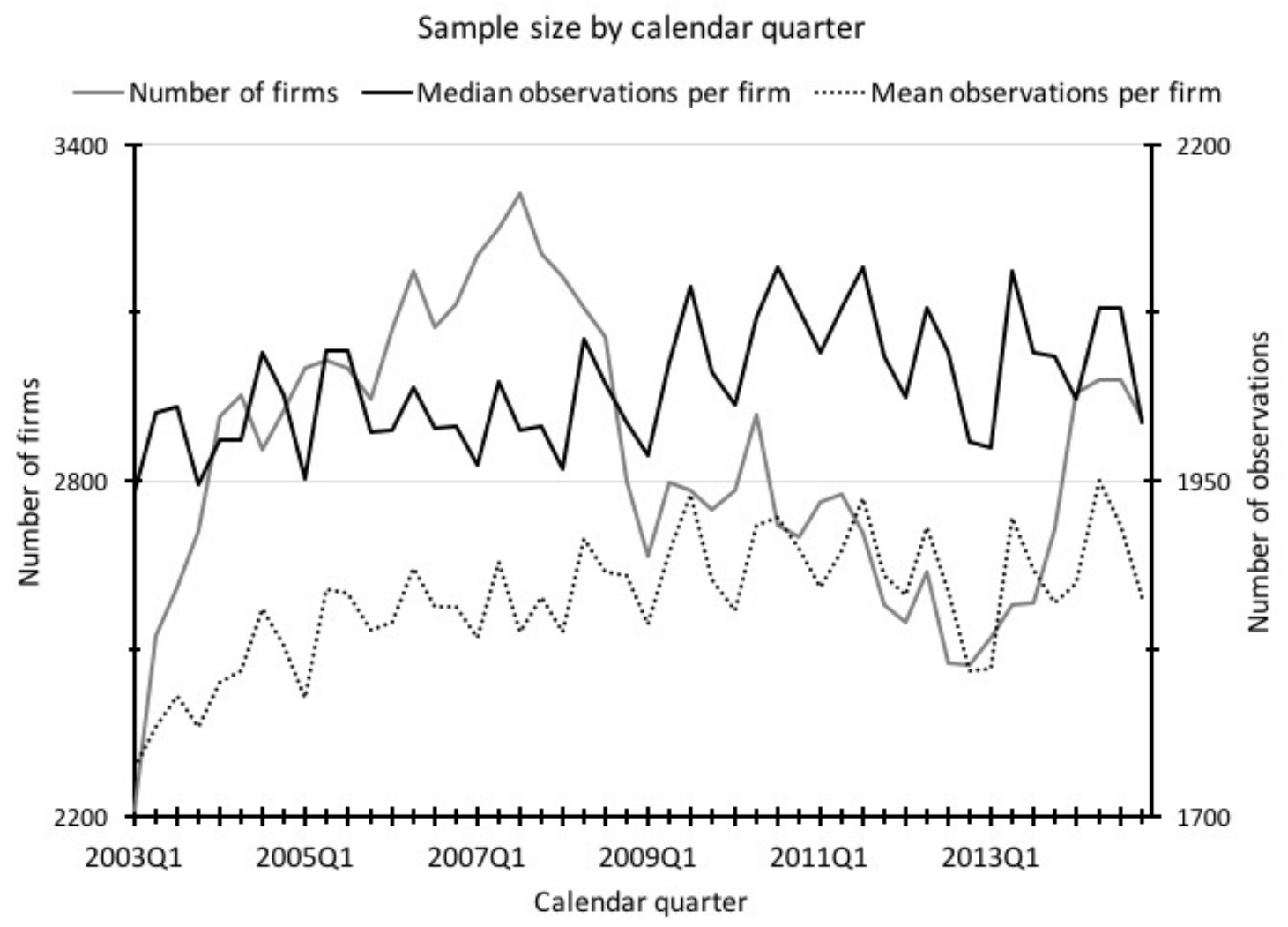


Figure 7: Sample size by calendar quarter, estimations using 30-minute returns

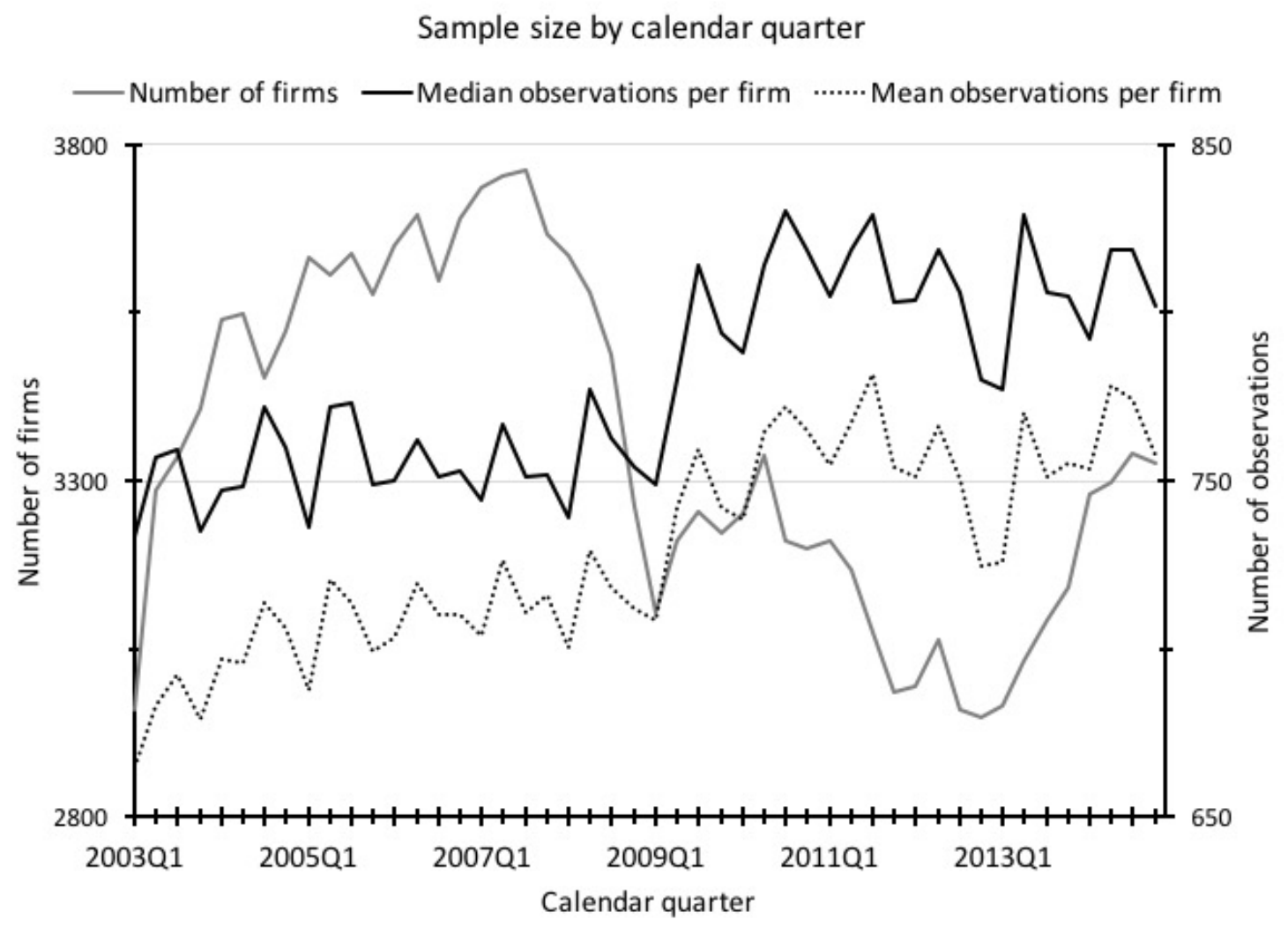


Figure 8: Histogram of estimated $\alpha$ parameters, investors' misweighting of redundant information, estimations using five-minute returns

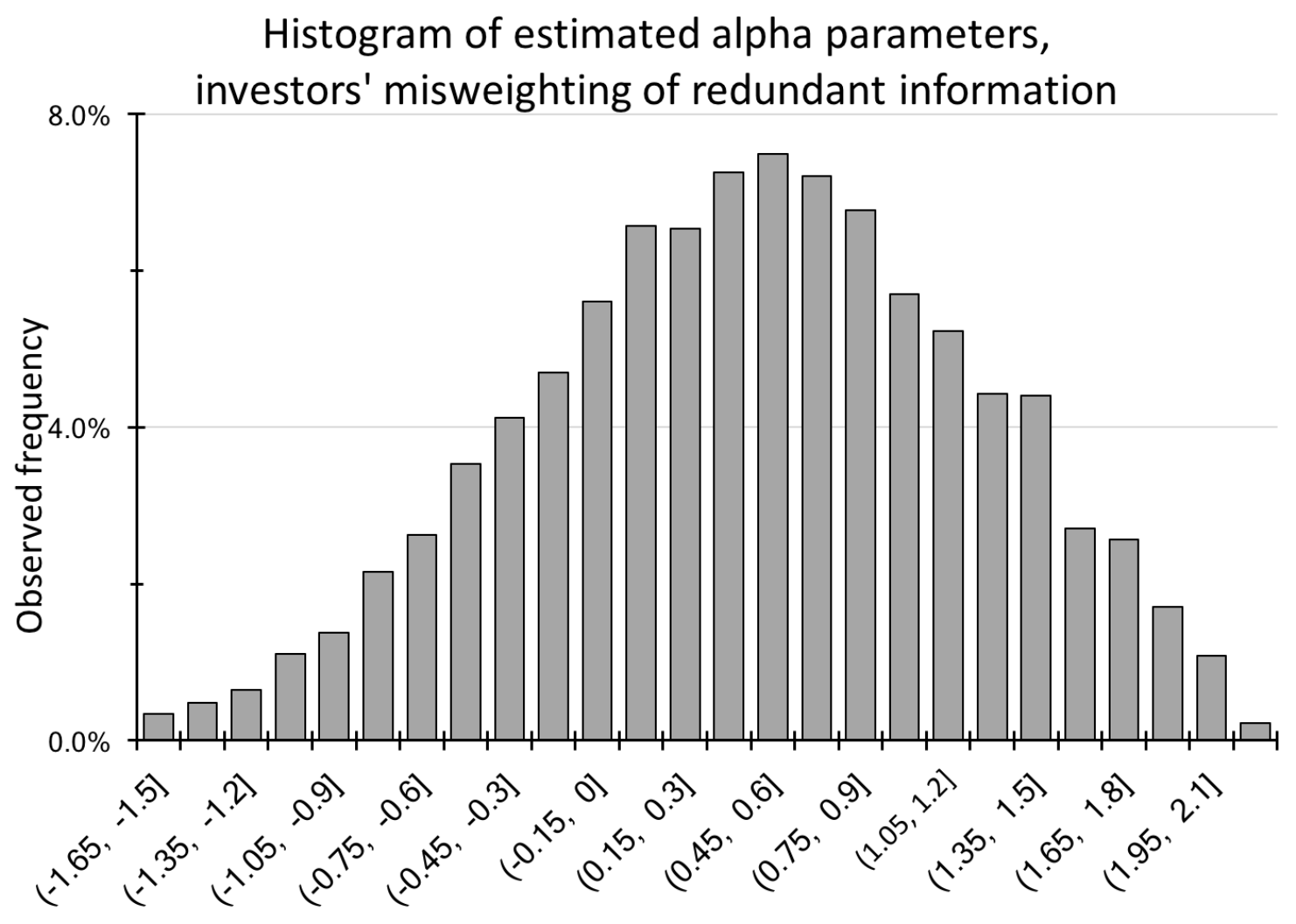


Figure 9: Histogram of estimated $\phi$ parameters, the autoregressive parameter of liquidity trader demand, estimations using five-minute returns

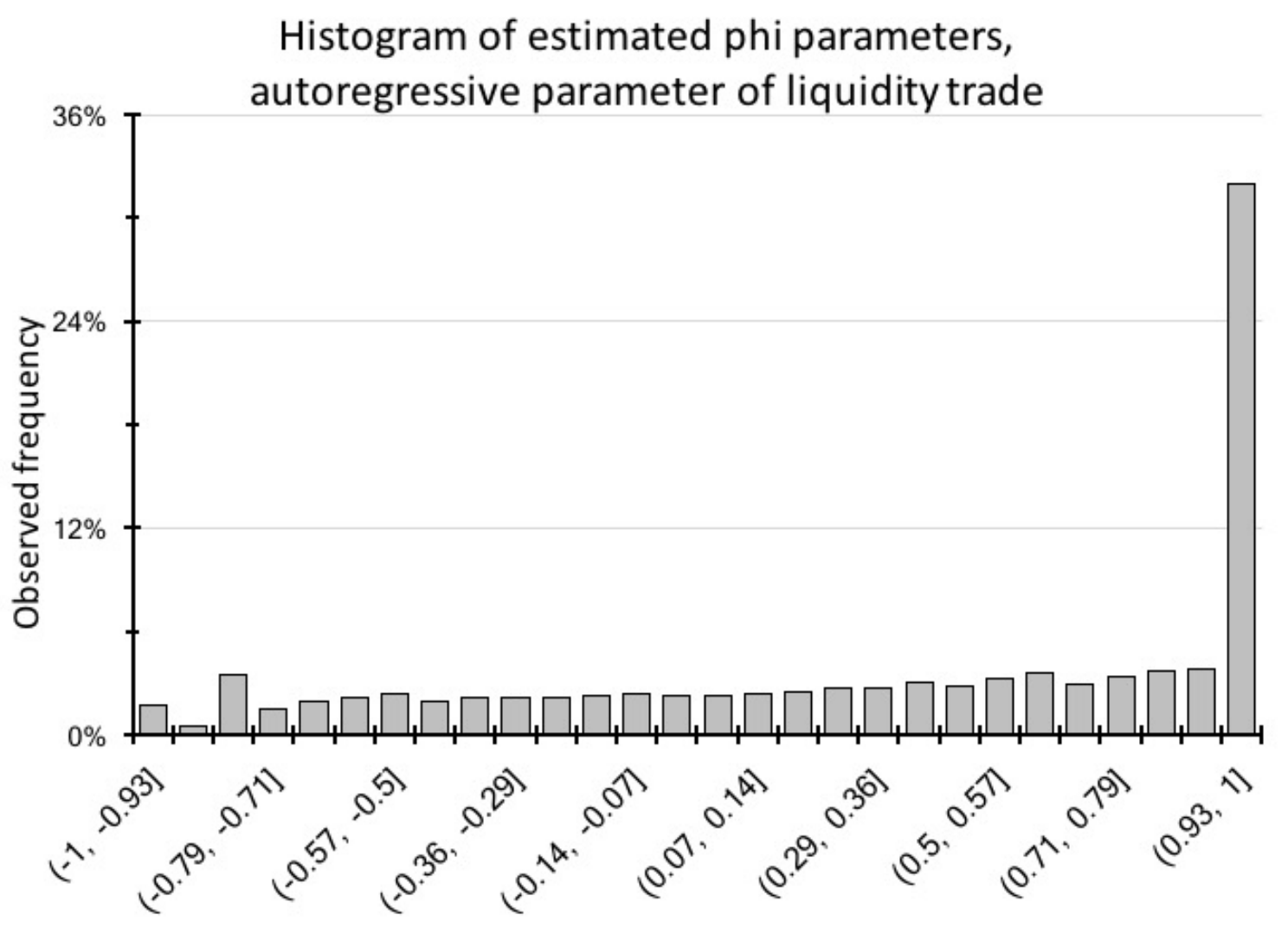


Figure 10: Histogram of estimated $\psi$ parameters, the ratio of transaction costs to the Kyle's lambda, estimations using five-minute returns

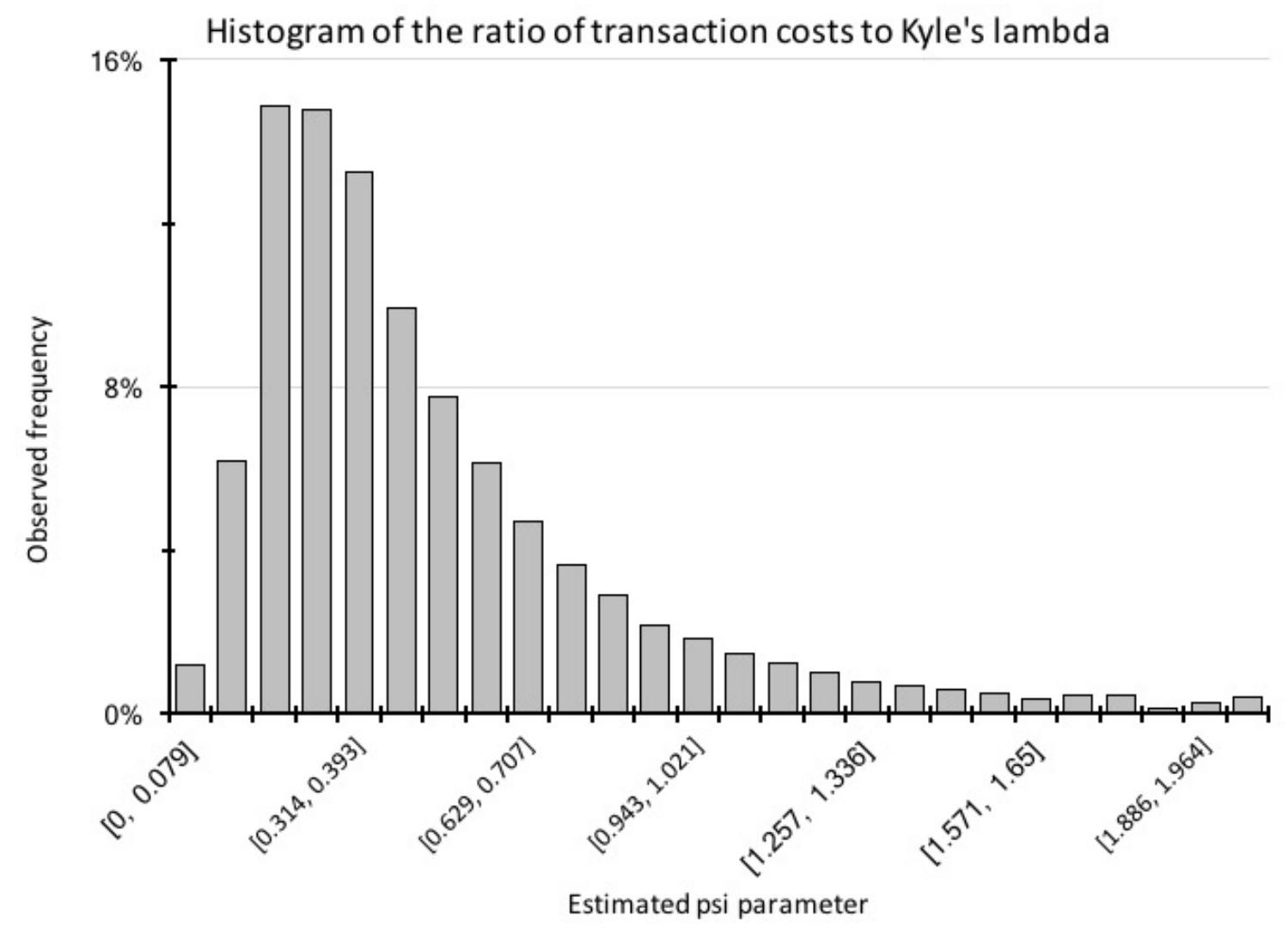


Figure 11: Histogram of estimated $\alpha$ parameters, investors' misweighting of redundant information, estimations using 12-minute returns

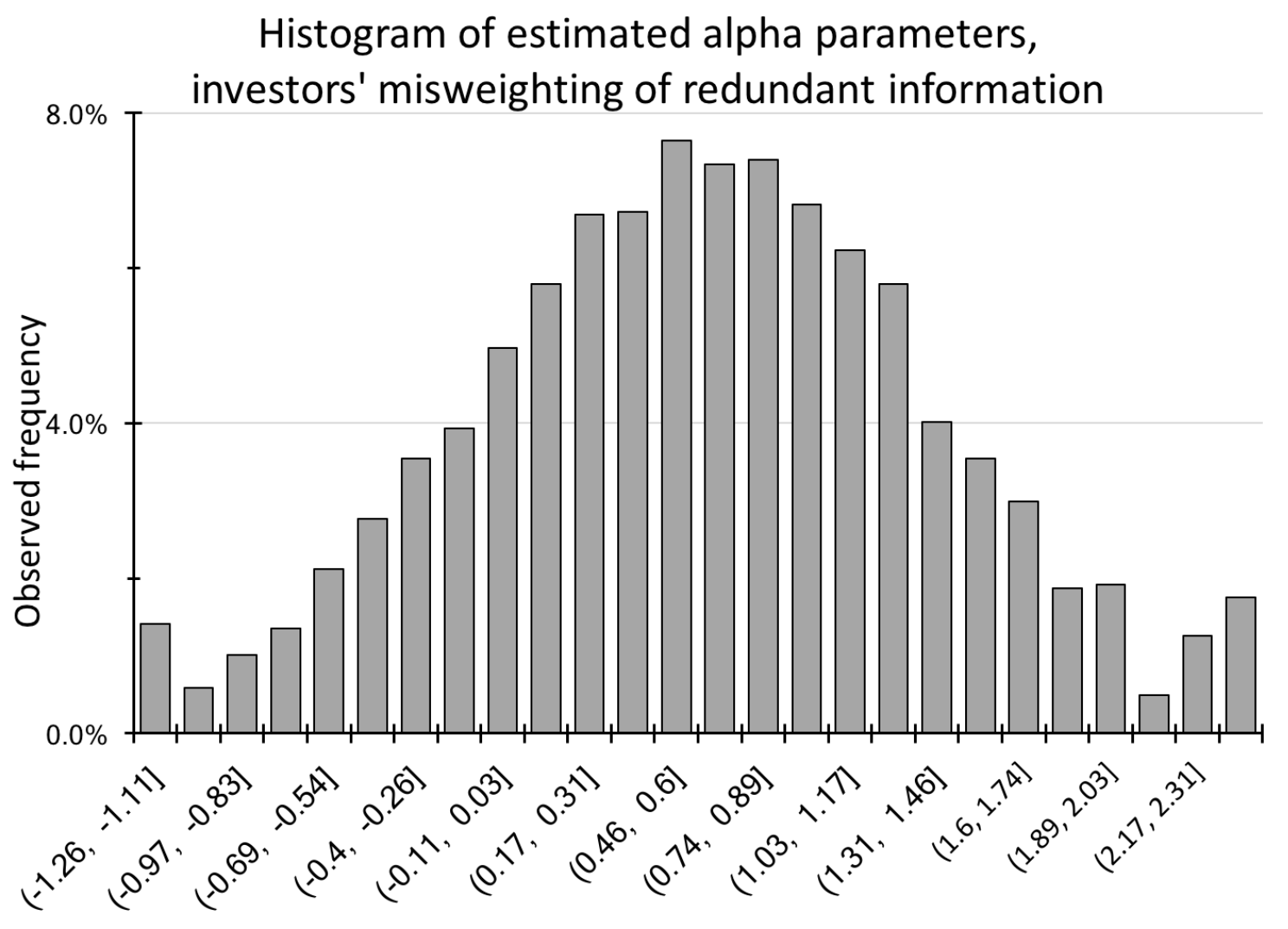


Figure 12: Histogram of estimated $\phi$ parameters, the autoregressive parameter of liquidity trader demand, estimations using 12-minute returns

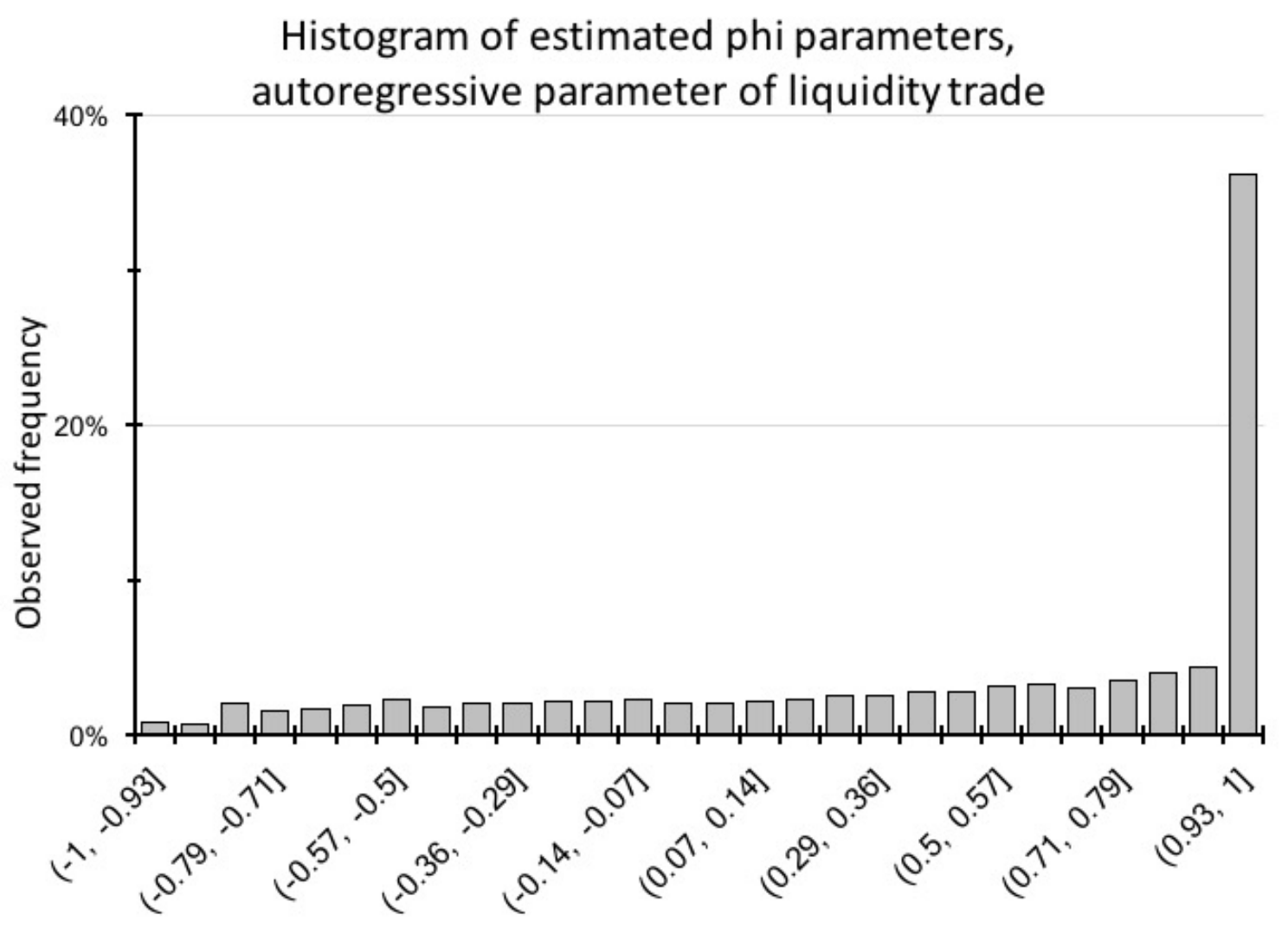


Figure 13: Histogram of estimated $\psi$ parameters, the ratio of transaction costs to the Kyle's lambda, estimations using 12-minute returns

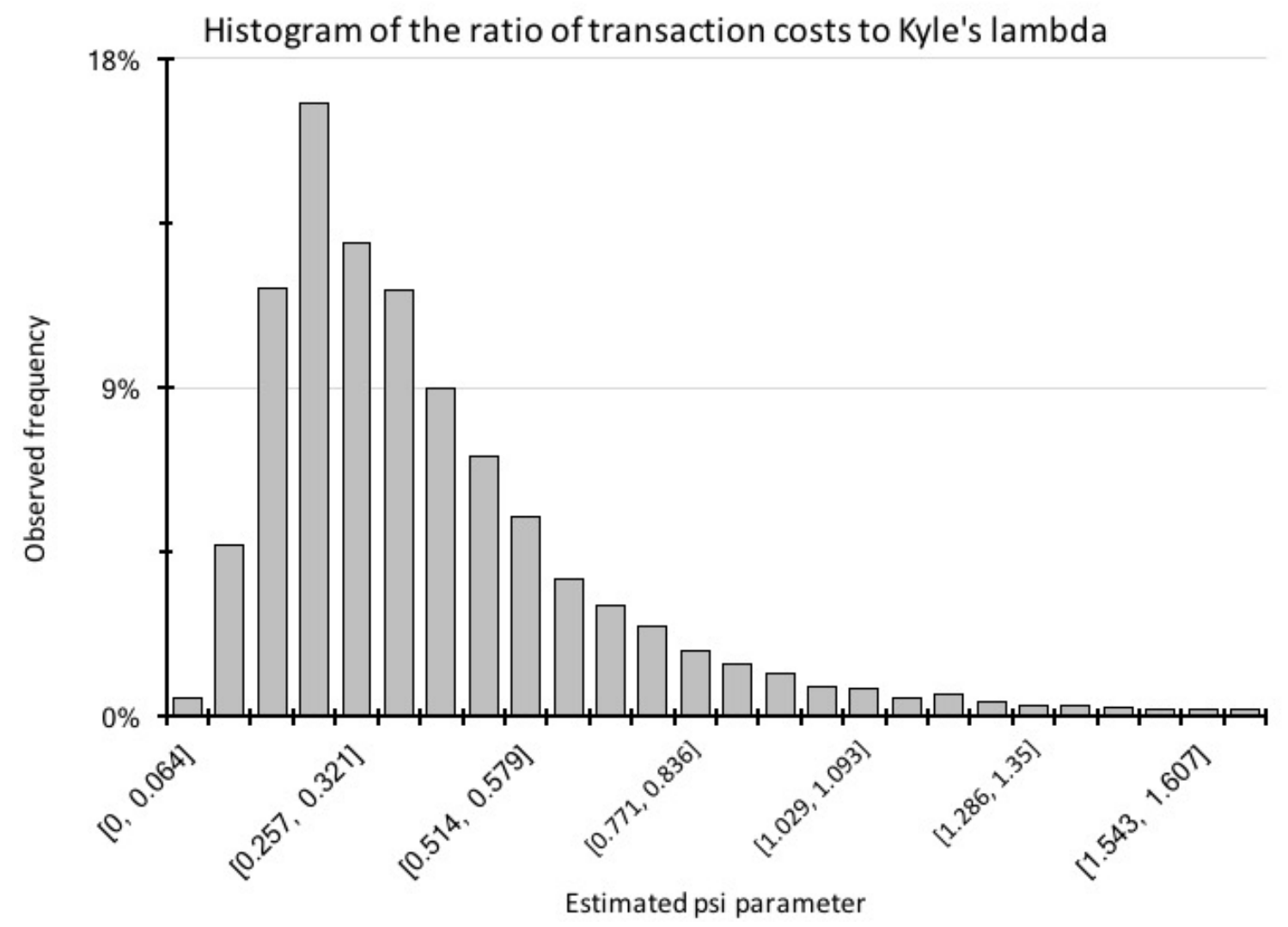


Figure 14: Histogram of estimated $\alpha$ parameters, investors' misweighting of redundant information, estimations using 30-minute returns

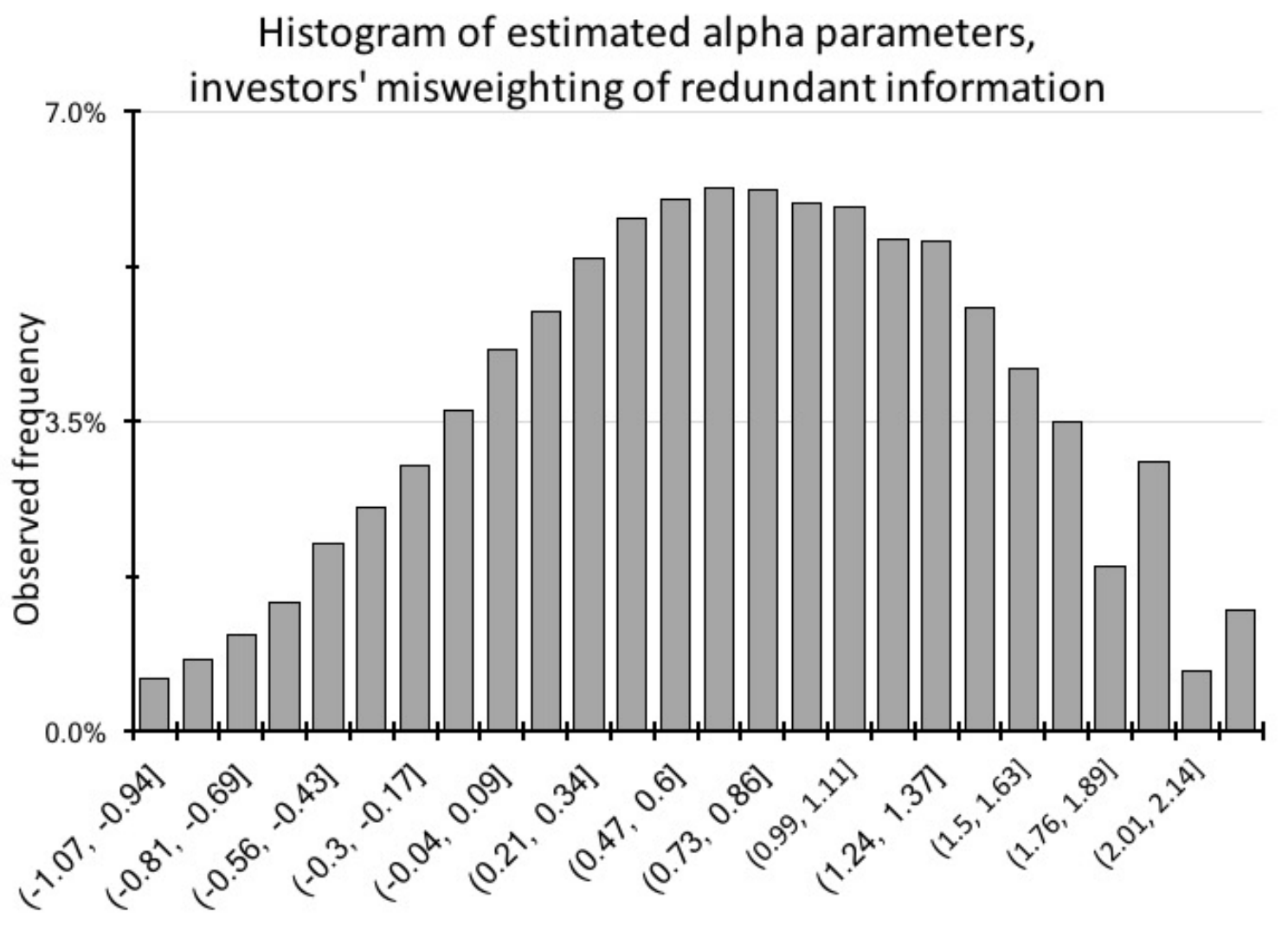


Figure 15: Histogram of estimated $\phi$ parameters, the autoregressive parameter of liquidity trader demand, estimations using 30-minute returns

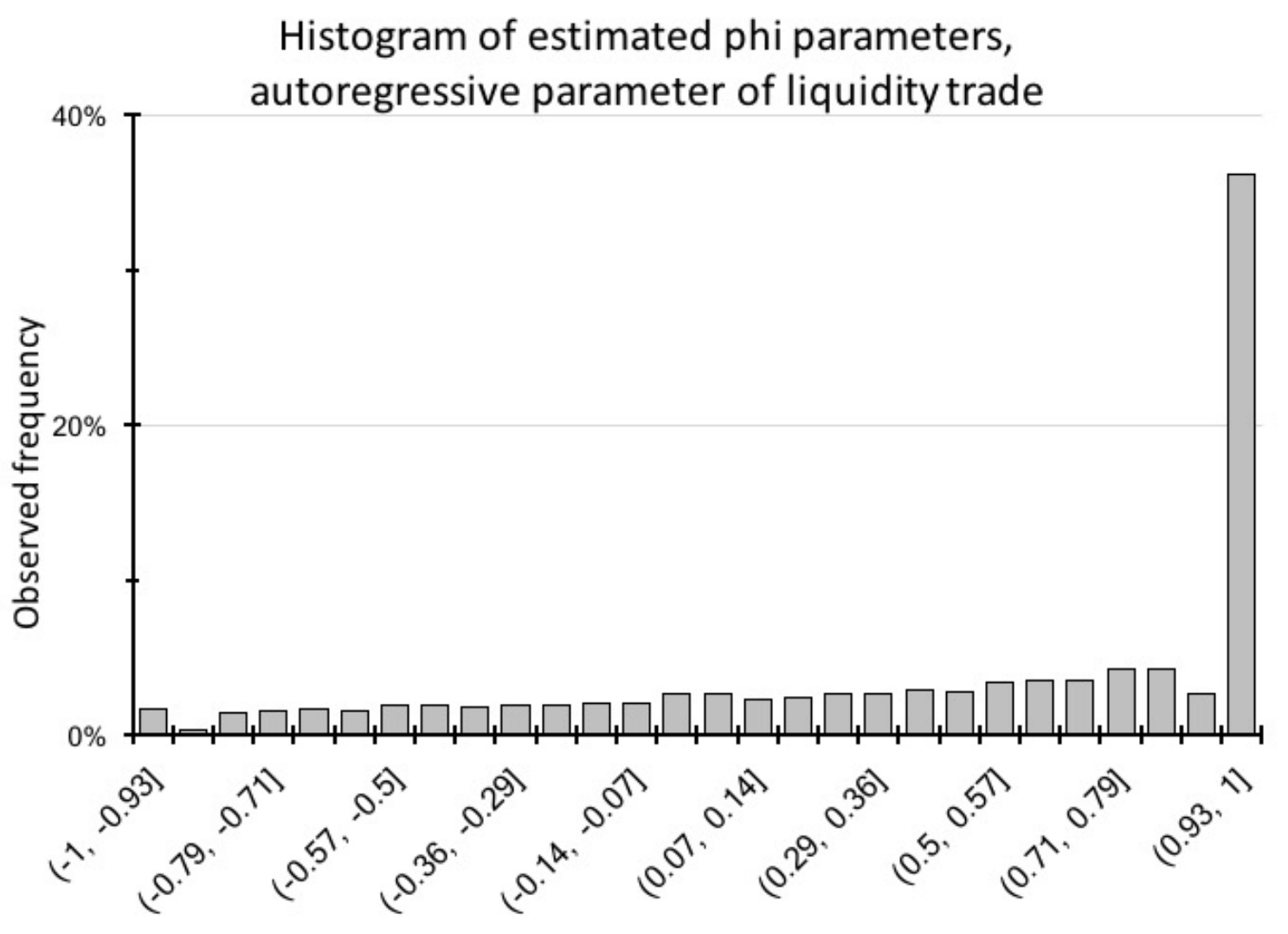


Figure 16: Histogram of estimated $\psi$ parameters, the ratio of transaction costs to the Kyle's lambda, estimations using 30-minute returns

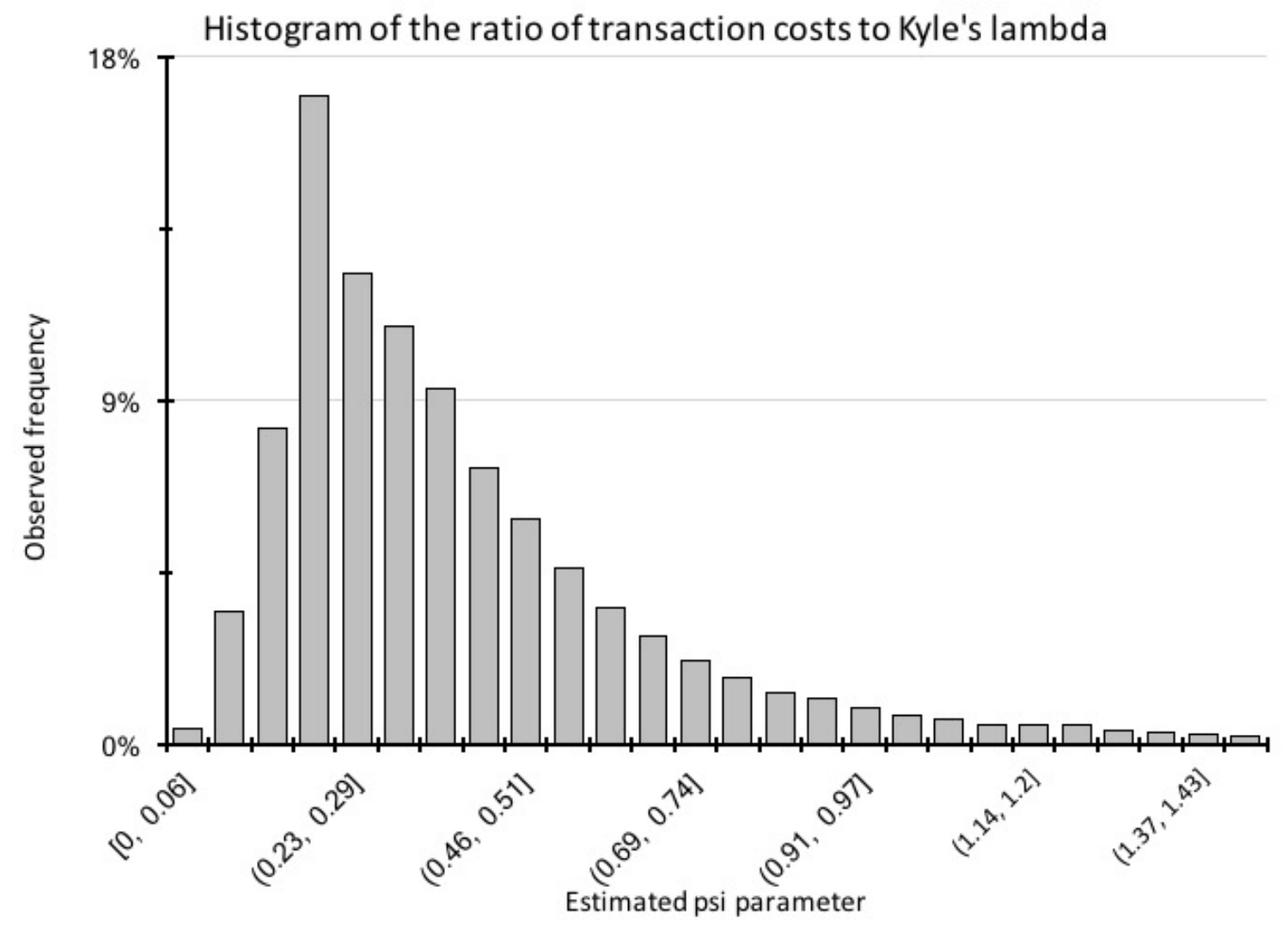


Figure 17: Time series of estimated $\alpha$ parameters, investors' misweighting of redundant information, estimations using five-minute returns

Time series of estimated alpha parameters

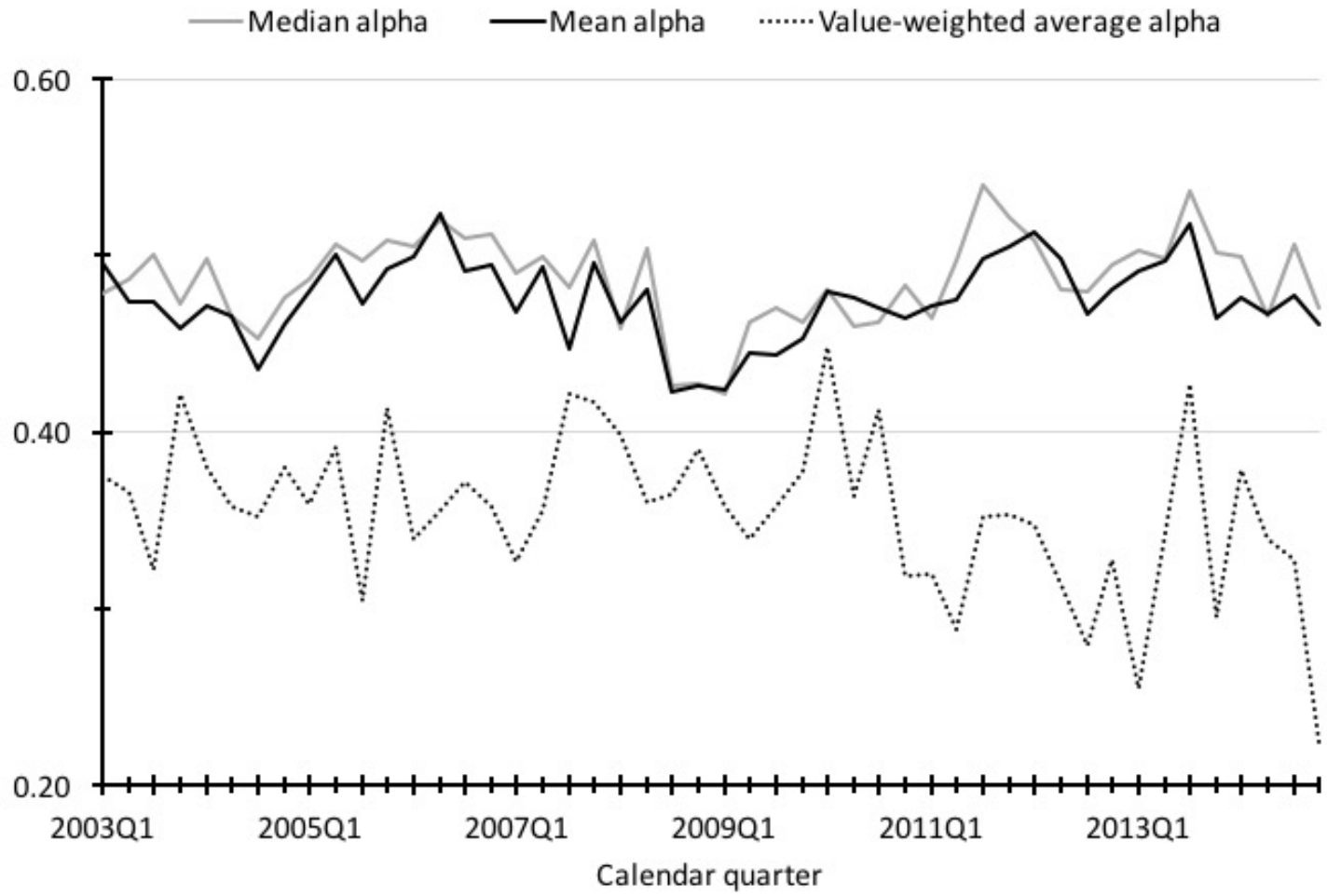


Figure 18: Time series of estimated estimated $\phi$ parameters, the autoregressive parameter of liquidity trader demand, estimations using five-minute returns

Time series of estimated phi parameters

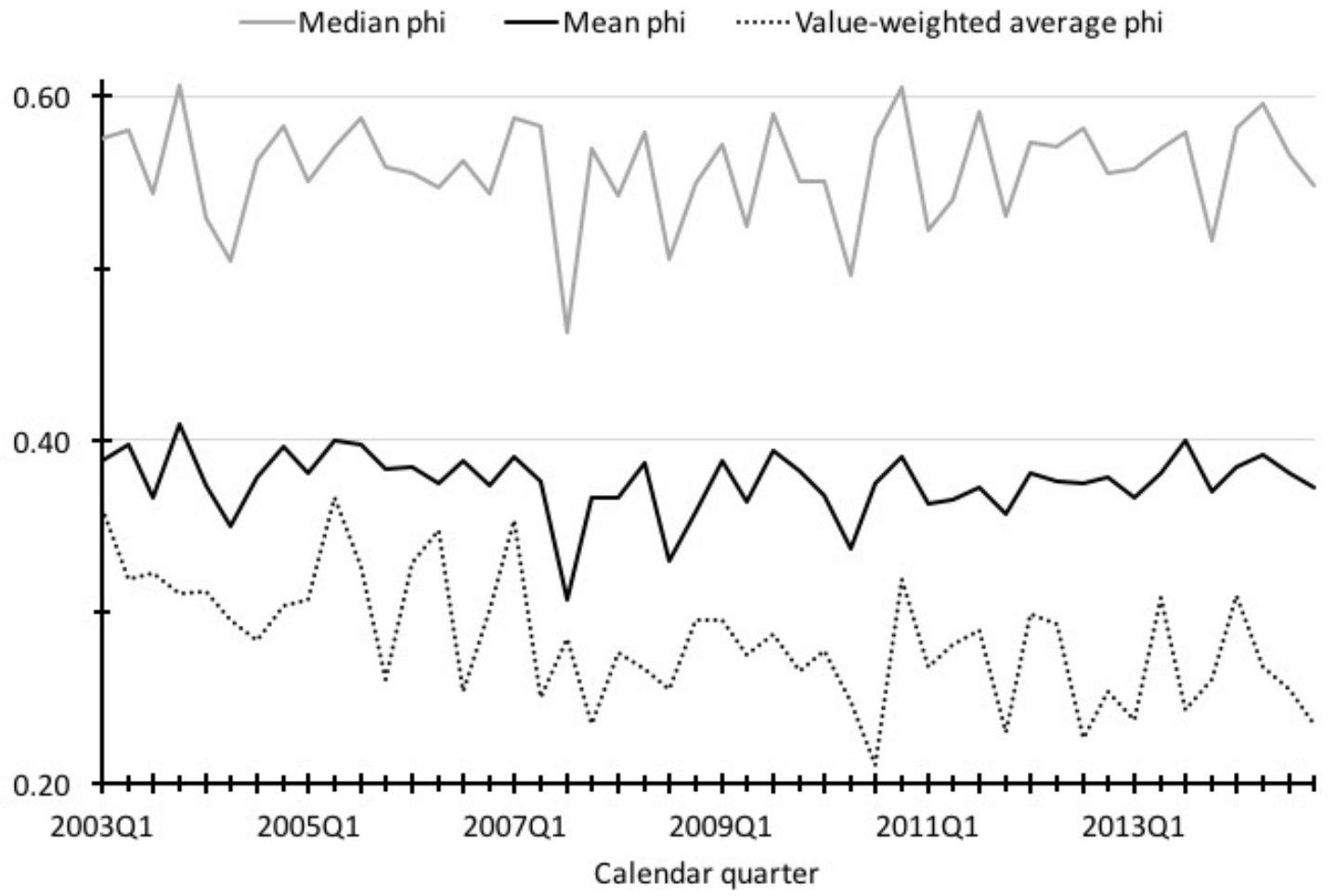


Figure 19: Time series of estimated $\psi$ parameters, the ratio of transaction costs to the Kyle's lambda, estimations using five-minute returns

Time series of estimated psi parameters

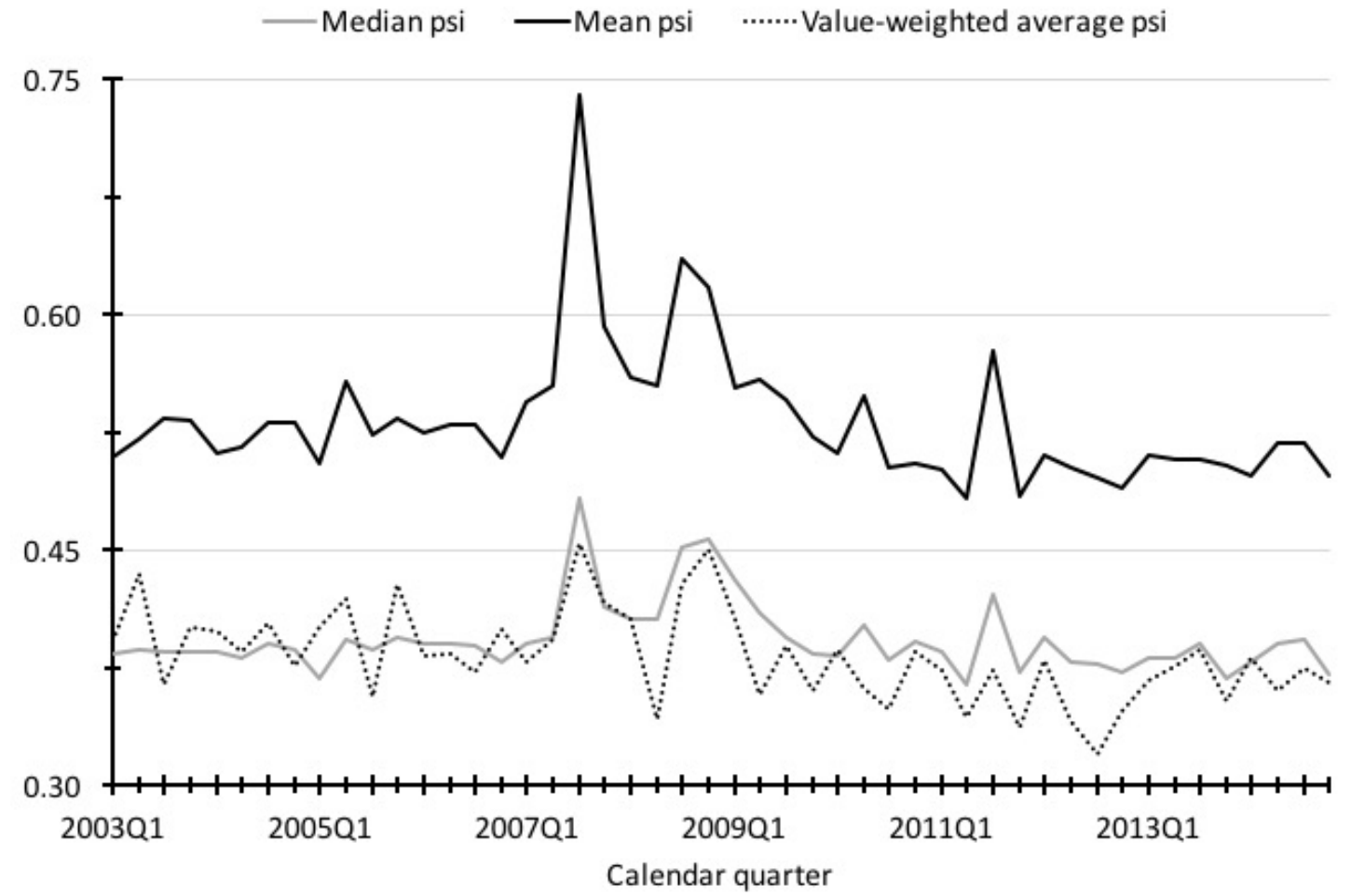


Figure 20: Time series of estimated $\alpha$ parameters, investors' misweighting of redundant information, estimations using 12-minute returns

Time series of estimated alpha parameters

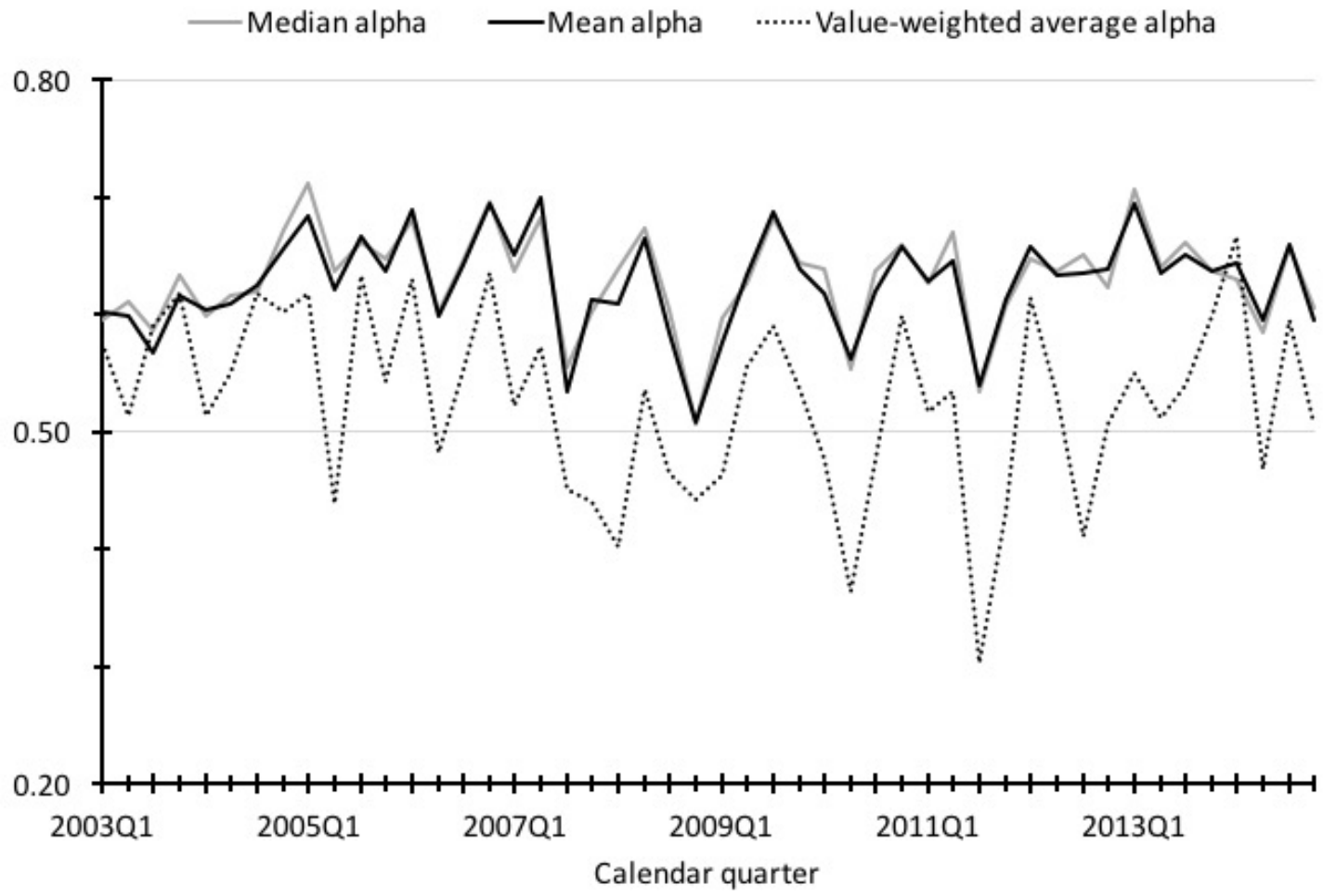


Figure 21: Time series of estimated estimated $\phi$ parameters, the autoregressive parameter of liquidity trader demand, estimations using 12-minute returns

Time series of estimated phi parameters

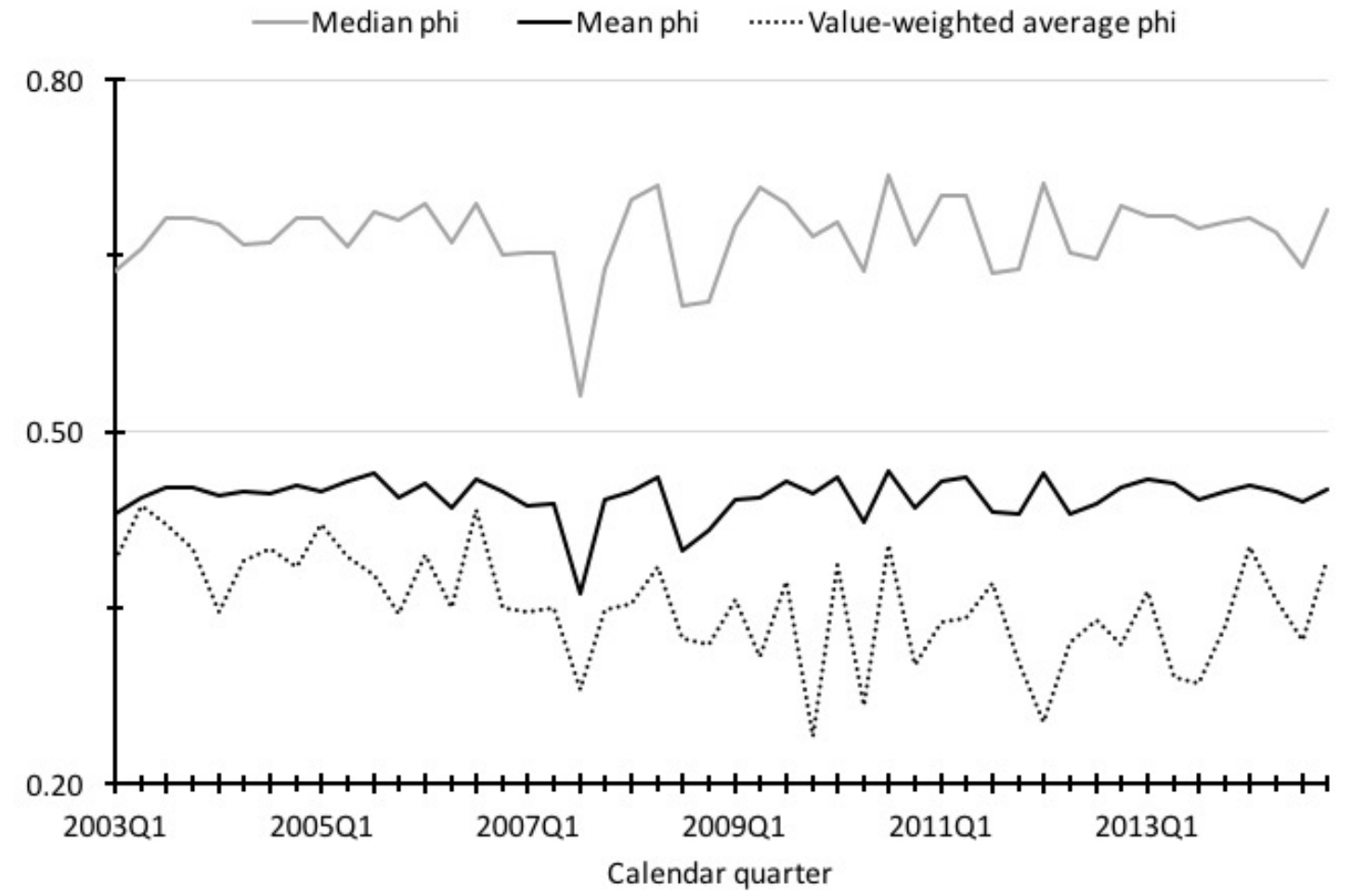


Figure 22: Time series of estimated $\psi$ parameters, the ratio of transaction costs to the Kyle's lambda, estimations using 12-minute returns

Time series of estimated psi parameters

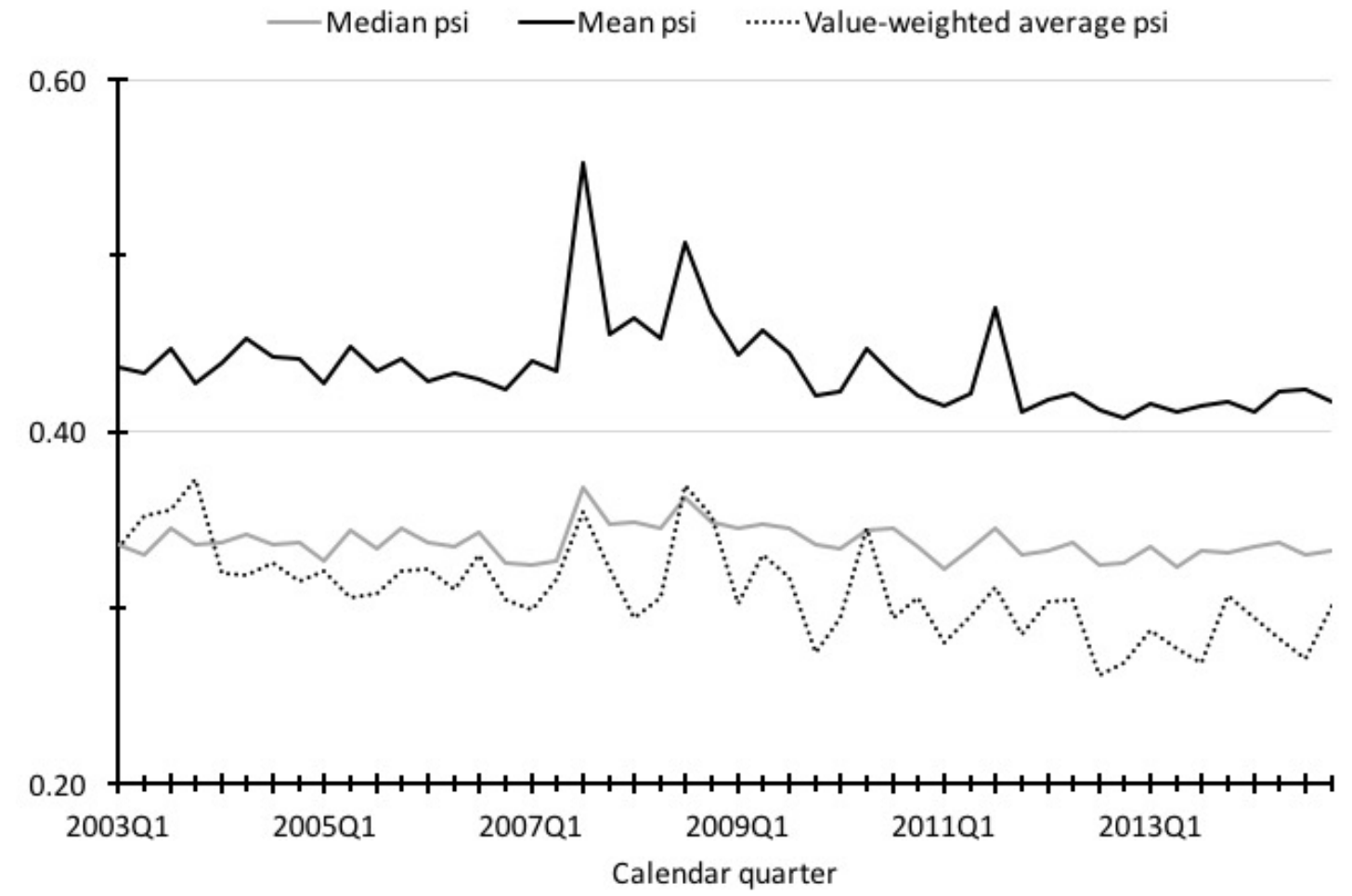


Figure 23: Time series of estimated $\alpha$ parameters, investors' misweighting of redundant information, estimations using 30-minute returns

Time series of estimated alpha parameters

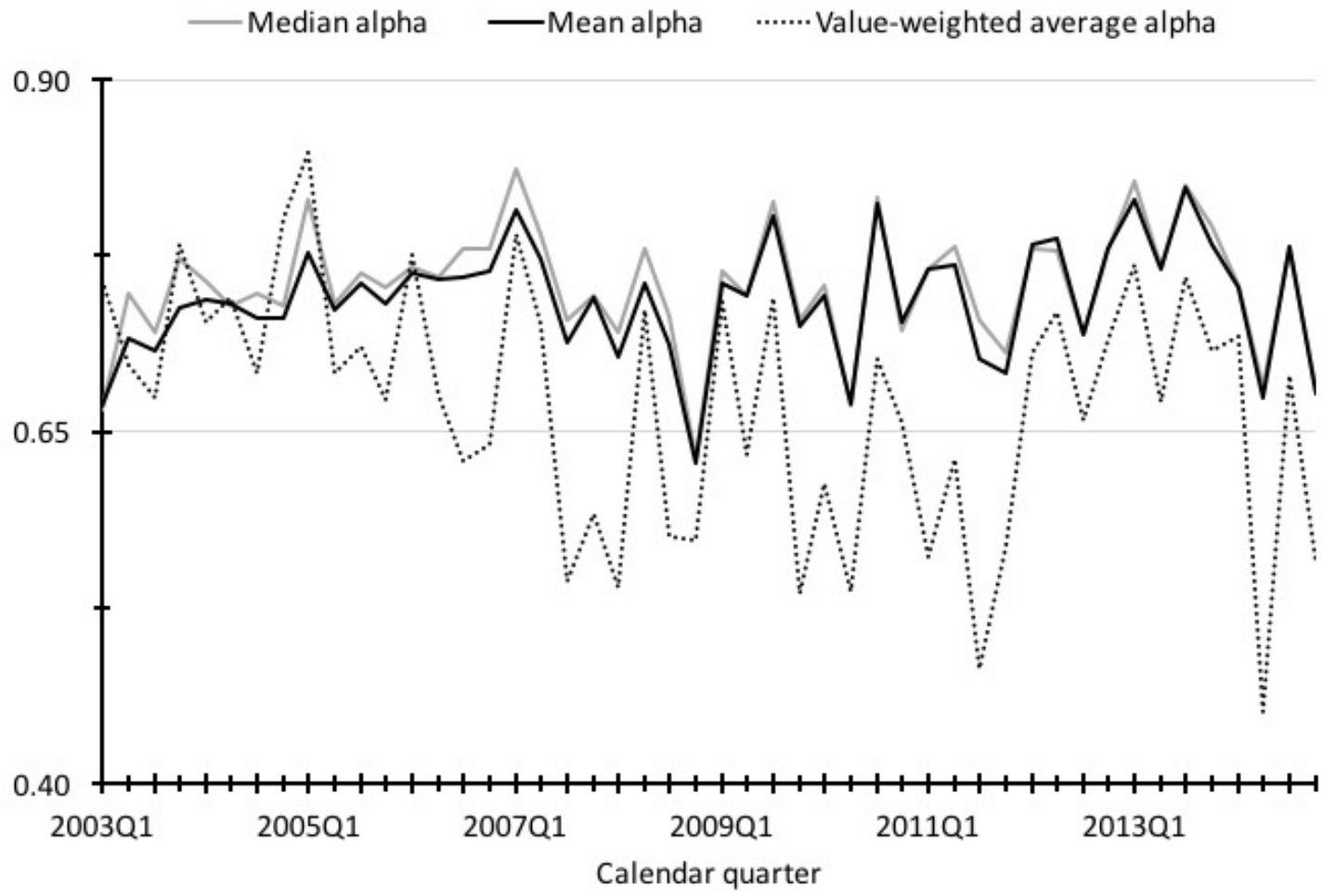


Figure 24: Time series of estimated estimated $\phi$ parameters, the autoregressive parameter of liquidity trader demand, estimations using 30-minute returns

Time series of estimated phi parameters

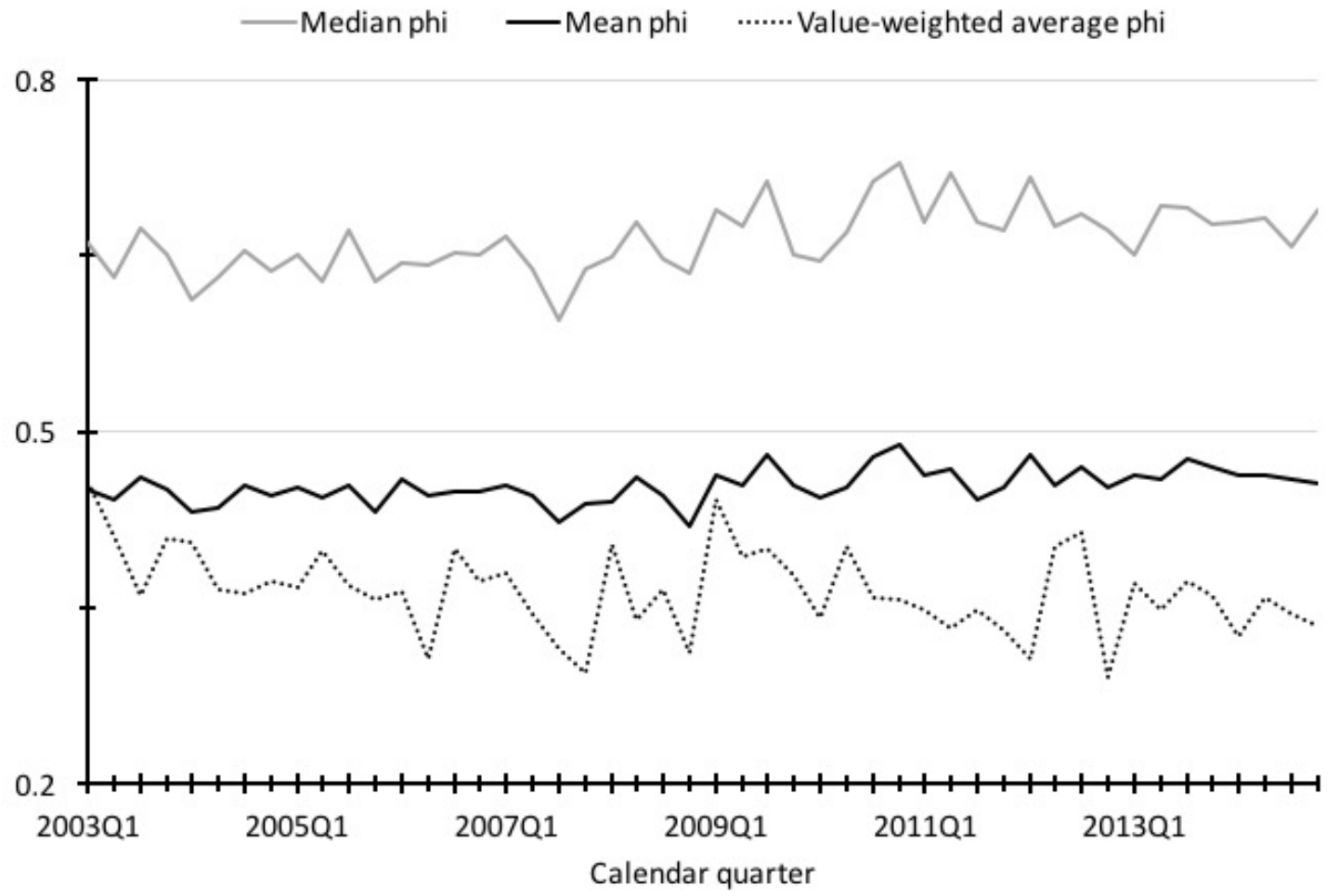


Figure 25: Time series of estimated $\psi$ parameters, the ratio of transaction costs to the Kyle's lambda, estimations using 30-minute returns

Time series of estimated psi parameters

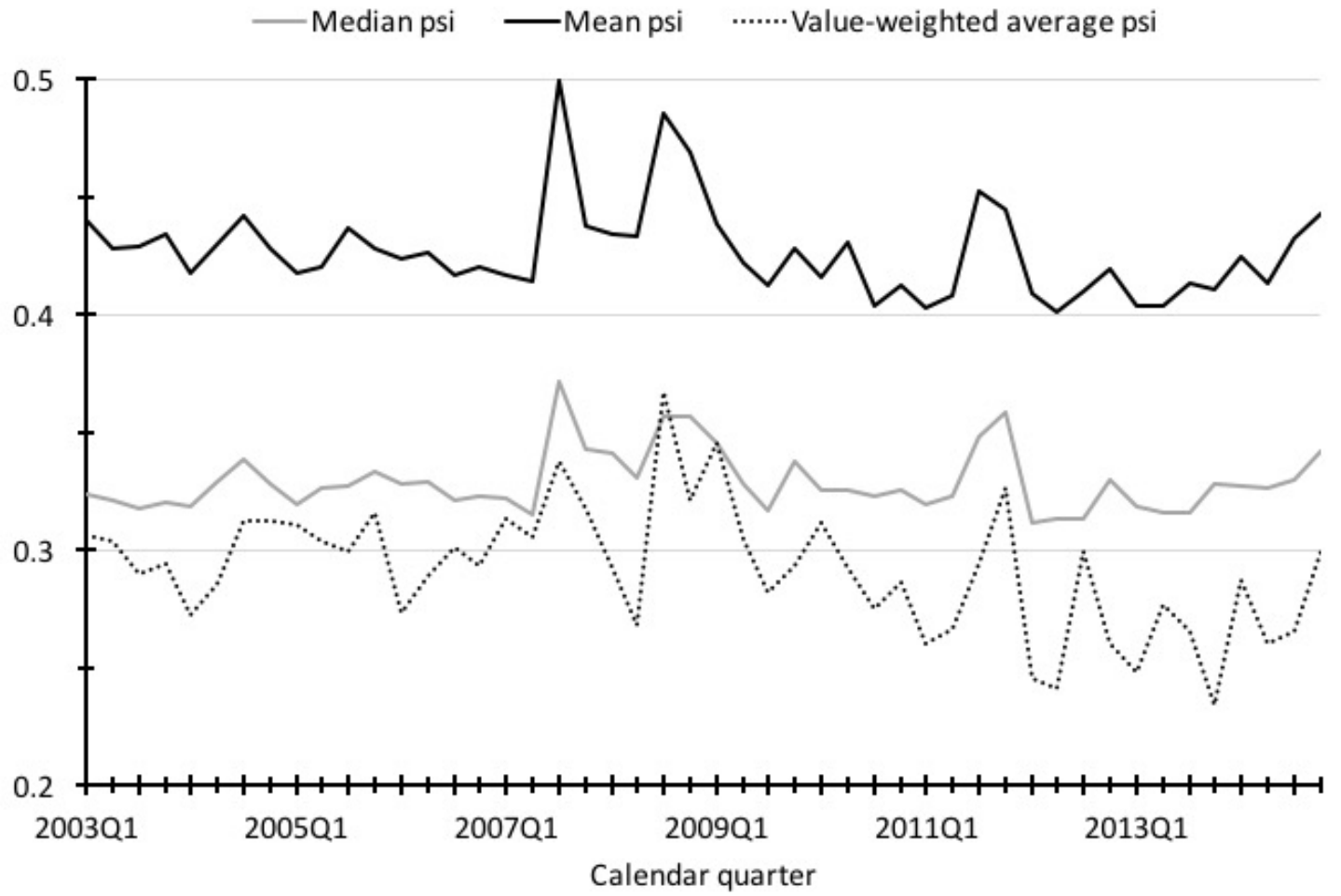


Figure 26: Histogram of estimated moving average coefficients, estimations using five-minute returns

Histogram of estimated moving average coefficients

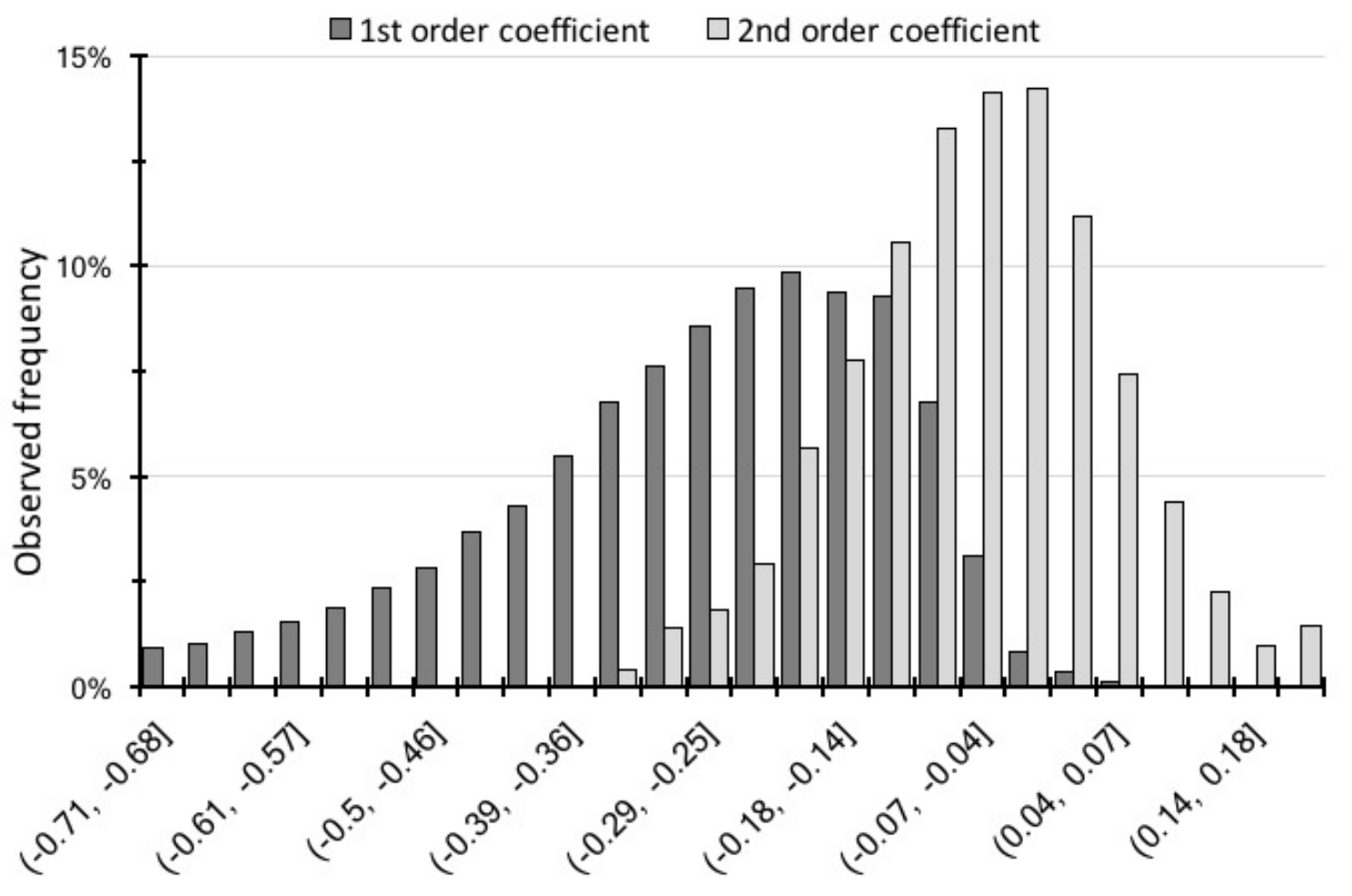


Figure 27: Histogram of estimated moving average coefficients, estimations using 12-minute returns

Histogram of estimated moving average coefficients

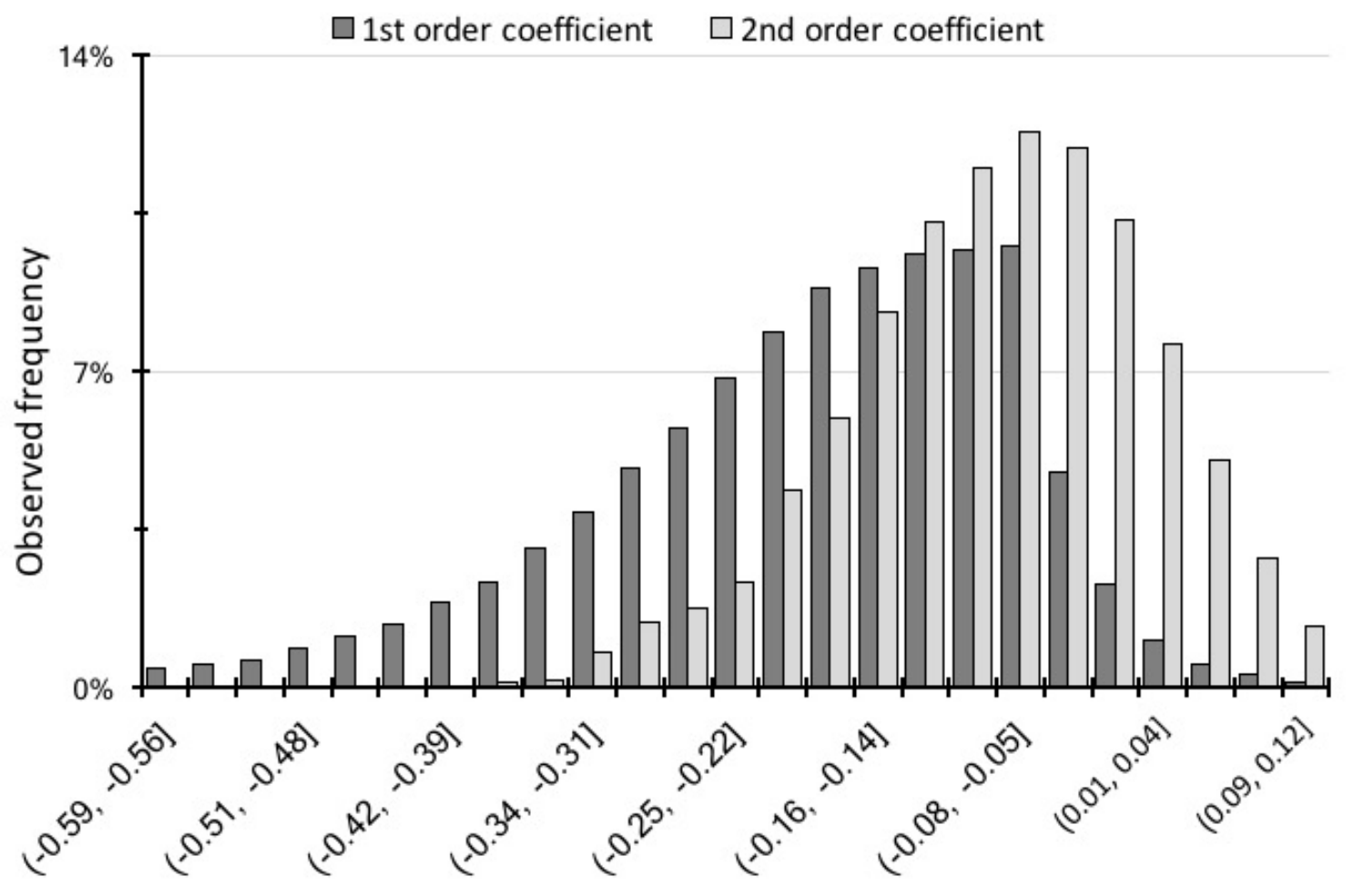


Figure 28: Histogram of estimated moving average coefficients, estimations using 30-minute returns

Histogram of estimated moving average coefficients

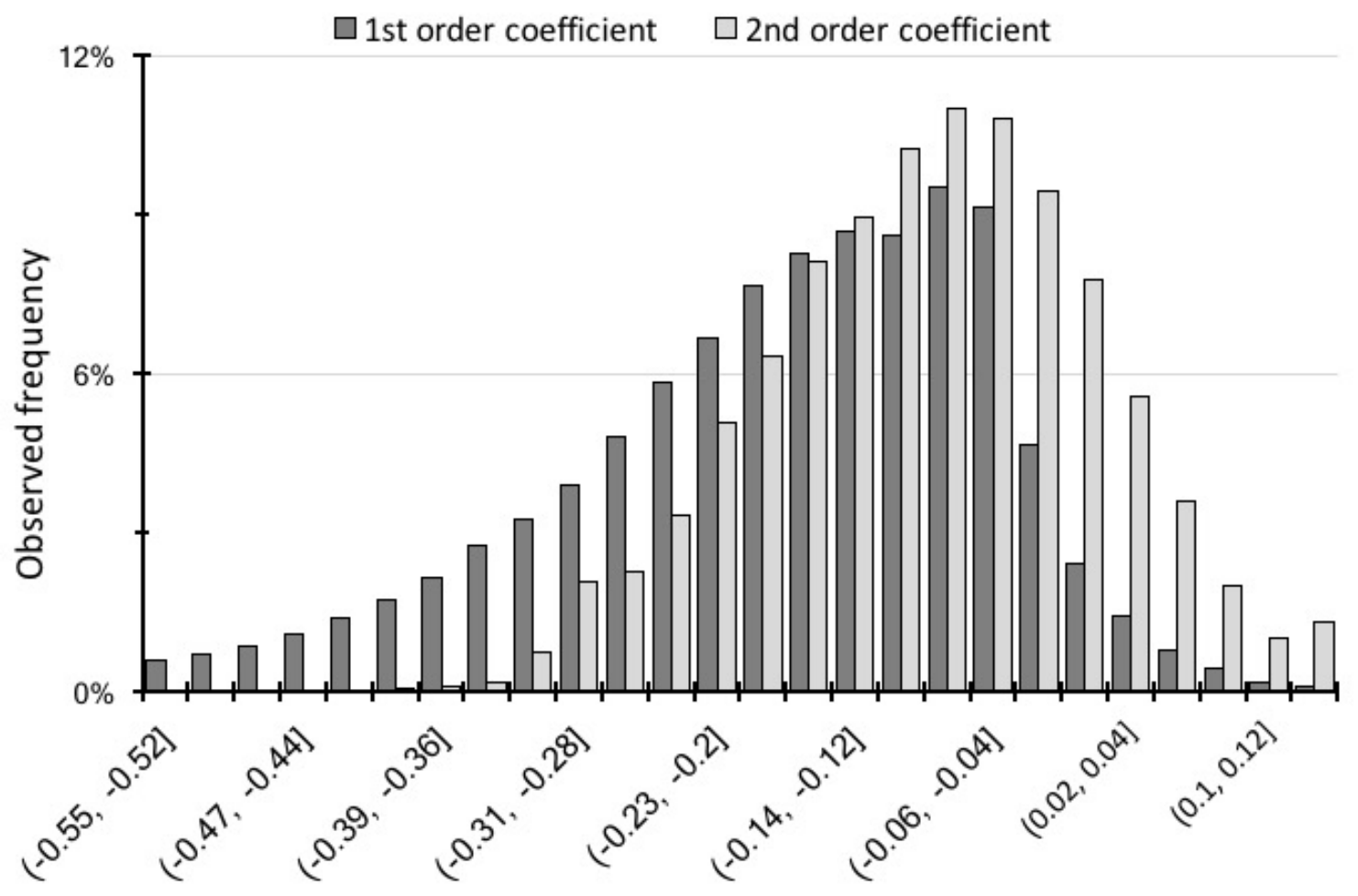




\section{References}

Dilip Abreu and Markus K Brunnermeier. Synchronization risk and delayed arbitrage. Journal of Financial Economics, 66(2-3):341-360, November 2002.

Dilip Abreu and Markus K Brunnermeier. Bubbles and Crashes. Econometrica, 71(1):173-204, January 2003.

Anat Admati and Paul C Pfleiderer. A Theory of Intraday Patterns: Volume and Price Variability. The Review of Financial Studies, 1(1):3-40, January 1988.

Tobias Adrian, Agostino Capponi, Erik Vogt, and Hongzhong Zhang. Intraday Market Making with Overnight Inventory Costs. Available at SSRN, September 2016.

Yakov Amihud and Haim Mendelson. Dealership market: Market-making with inventory. Journal of Financial Economics, 8(1):31-53, March 1980.

Gene Amromin and Steven A Sharpe. From the Horse's Mouth: Economic Conditions and Investor Expectations of Risk and Return. Management Science, 60(4):845-866, April 2014.

Clifford S Asness, Tobias Moskowitz, and Lasse Heje Pedersen. Value and Momentum Everywhere. The Journal of Finance, 68(3):929-985, June 2013.

Bok Baik, Jun-Koo Kang, and Jin-Mo Kim. Local institutional investors, information asymmetries, and equity returns. Journal of Financial Economics, 97(1):81-106, July 2010.

Snehal Banerjee. Learning from Prices and the Dispersion in Beliefs. The Review of Financial Studies, 24(9): 3025-3068, September 2011.

Snehal Banerjee and Brett Green. Signal or noise? Uncertainty and learning about whether other traders are informed. Journal of Financial Economics, 117(2):398-423, August 2015.

Snehal Banerjee, Ron Kaniel, and Ilan Kremer. Price Drift as an Outcome of Differences in Higher-Order Beliefs. The Review of Financial Studies, 22(9):3707-3734, September 2009.

Brad M Barber and Terrance Odean. Boys Will be Boys: Gender, Overconfidence, and Common Stock Investment. The Quarterly Journal of Economics, 116(1):261-292, 2001.

Nicholas Barberis and Andrei Shleifer. Style investing. Journal of Financial Economics, 68(2):161-199, May 2003.

Nicholas Barberis, Robin Greenwood, Lawrence Jin, and Andrei Shleifer. X-CAPM: An extrapolative capital asset pricing model. Journal of Financial Economics, 115(1):1-24, January 2015. 
Michael J Barclay and Terrence Hendershott. Price Discovery and Trading After Hours. The Review of Financial Studies, 16(4):1041-1073, October 2003.

Itzhak Ben-David, John R Graham, and Campbell R Harvey. Managerial Miscalibration. The Quarterly Journal of Economics, 128(4):1547-1584, November 2013.

Nataliya Bershova and Dmitry Rakhlin. The non-linear market impact of large trades: evidence from buy-side order flow. Quantitative Finance, 13(11):1759-1778, December 2013.

Fischer Black. Noise. The Journal of Finance, 41(3):529-543, July 1986.

Tim Bollerslev. Generalized autoregressive conditional heteroskedasticity. Journal of Econometrics, 31(3):307-327, April 1986.

Mark M Carhart. On Persistence in Mutual Fund Performance. The Journal of Finance, 52(1):57, March 1997.

Hyuk Choe, Bong-Chan Kho, and René M Stulz. Do Domestic Investors Have More Valuable Information About Individual Stocks than Foreign Investors? National Bureau of Economic Research Working Paper, January 2001.

Nicole Choi, Mark Fedenia, Hilla Skiba, and Tatyana Sokolyk. Portfolio concentration and performance of institutional investors worldwide. Journal of Financial Economics, 123(1):189-208, January 2017.

Michael B Clement, Richard M Frankel, and Jeffrey Miller. Confirming Management Earnings Forecasts, Earnings Uncertainty, and Stock Returns. Journal of Accounting Research, 41(4):653-679, September 2003.

Joshua D Coval and Tobias Moskowitz. Home Bias at Home: Local Equity Preference in Domestic Portfolios. The Journal of Finance, 54(6):2045-2073, December 1999.

Joshua D Coval and Tobias Moskowitz. The Geography of Investment: Informed Trading and Asset Prices. Journal of Political Economy, 109(4):811-841, 2001.

William M Cready, Abdullah Kumas, and Musa Subasi. Are Trade Size-Based Inferences About Traders Reliable? Evidence from Institutional Earnings-Related Trading. Journal of Accounting Research, 52(4):877-909, September 2014.

Kent Daniel and David A Hirshleifer. Overconfident Investors, Predictable Returns, and Excessive Trading $\dagger$. The Journal of Economic Perspectives, 29(4):61-88, November 2015.

Kent Daniel, David A Hirshleifer, and Avanidhar Subrahmanyam. Investor Psychology and Security Market Underand Overreactions. The Journal of Finance, 53(6):1839-1885, December 1998. 
Werner F M De Bondt and Richard H Thaler. Does the Stock Market Overreact? The Journal of Finance, 40(3): 793, July 1985.

J Bradford DeLong, Andrei Shleifer, Lawrence H Summers, and Robert J Waldmann. Positive Feedback Investment Strategies and Destabilizing Rational Speculation. The Journal of Finance, 45(2):379, June 1990.

A Dontoh, Joshua Ronen, and B Sarath. On the Rationality of the Post-Announcement Drift. Review of Accounting Studies, 8(1):69-104, 2003.

Trond M Døskeland and Hans K Hvide. Do Individual Investors Have Asymmetric Information Based on Work Experience? The Journal of Finance, 66(3):1011-1041, May 2011.

James Durbin and Siem Jan Koopman. Time series analysis by state space methods. Oxford University Press, Oxford, 2nd edition, 2012.

Tomáš Dvořák. Do Domestic Investors Have an Information Advantage? Evidence from Indonesia. The Journal of Finance, 60(2):817-839, April 2005.

David Easley, Marcos Lopez de Prado, and Maureen O'Hara. Flow Toxicity and Liquidity in a High-frequency World. The Review of Financial Studies, 25(5):1457-1493, May 2012.

David Easley, Marcos Lopez de Prado, and Maureen O'Hara. Discerning information from trade data. Journal of Financial Economics, 120(2):269-285, May 2016.

Robert F Engle. GARCH 101: The Use of ARCH/GARCH Models in Applied Econometrics. The Journal of Economic Perspectives, 15(4):157-168, October 2001.

Mei Feng and Sarah E McVay. Analysts' Incentives to Overweight Management Guidance When Revising Their Short-Term Earnings Forecasts. The Accounting Review, 85(5):1617-1646, September 2010.

Paul E Fischer and Robert E Verrecchia. Public information and heuristic trade. Journal of Accounting and Economics, 27(1):89-124, February 1999.

F Douglas Foster and S Viswanathan. Strategic Trading When Agents Forecast the Forecasts of Others. The Journal of Finance, 51(4):1437, September 1996.

Andrea Frazzini, Ronen Israel, and Tobias Moskowitz. Trading Costs of Asset Pricing Anomalies. Available at SSRN, December 2012.

Kenneth R French and James M Poterba. Investor Diversification and International Equity Markets. American Economic Review, 81(2):222-226, 1991. 
Kenneth R French and Richard Roll. Stock return variances. Journal of Financial Economics, 17(1):5-26, September 1986.

Kenneth A Froot and Tarun Ramadorai. Institutional Portfolio Flows and International Investments. The Review of Financial Studies, 21(2):937-971, April 2008.

Christopher C Géczy and Mikhail Samonov. 215 Years of Global Multi-Asset Momentum: 1800-2014 (Equities, Sectors, Currencies, Bonds, Commodities and Stocks). Available at SSRN, 2015.

Christopher C Géczy and Mikhail Samonov. Two Centuries of Price-Return Momentum. Financial Analysts Journal, 72(5):32-56, September 2016.

Simon Gervais and Terrance Odean. Learning to Be Overconfident. The Review of Financial Studies, 14(1):1-27, January 2001.

Mariassunta Giannetti and Luc A Laeven. The flight home effect: Evidence from the syndicated loan market during financial crises. Journal of Financial Economics, 104(1):23-43, April 2012.

Markus Glaser, Thomas Langer, and Martin Weber. True Overconfidence in Interval Estimates: Evidence Based on a New Measure of Miscalibration. Journal of Behavioral Decision Making, 26(5):405-417, December 2013.

Lawrence R Glosten and Paul R Milgrom. Bid, ask and transaction prices in a specialist market with heterogeneously informed traders. Journal of Financial Economics, 14(1):71-100, March 1985.

John R Graham, Campbell R Harvey, and Hai Huang. Investor Competence, Trading Frequency, and Home Bias. Management Science, 55(7):1094-1106, July 2009.

Robin Greenwood and Andrei Shleifer. Expectations of Returns and Expected Returns. The Review of Financial Studies, 27(3):714-746, March 2014.

John M Griffin, Federico Nardari, and René M Stulz. Do Investors Trade More When Stocks Have Performed Well? Evidence from 46 Countries. The Review of Financial Studies, 20(3):905-951, May 2007.

Mark Grinblatt and Matti Keloharju. The investment behavior and performance of various investor types: a study of Finland's unique data set. Journal of Financial Economics, 55(1):43-67, January 2000.

Mark Grinblatt and Matti Keloharju. Sensation Seeking, Overconfidence, and Trading Activity. The Journal of Finance, 64(2):549-578, April 2009.

Sanford J Grossman. Dynamic Asset Allocation and the Informational Efficiency of Markets. The Journal of Finance, 50(3):773-787, July 1995. 
John R M Hand. A Test of the Extended Functional Fixation Hypothesis. The Accounting Review, 65(4):740-763, October 1990 .

J Michael Harrison and David M Kreps. Speculative Investor Behavior in a Stock Market with Heterogeneous Expectations. The Quarterly Journal of Economics, 92(2):323, May 1978.

Campbell R Harvey, Yan Liu, and Heqing Zhu. ... and the Cross-Section of Expected Returns. The Review of Financial Studies, 29(1):5-68, January 2016.

Joel Hasbrouck. Trading Costs and Returns for U.S. Equities: Estimating Effective Costs from Daily Data. The Journal of Finance, 64(3):1445-1477, June 2009.

Harald Hau. Location Matters: An Examination of Trading Profits. The Journal of Finance, 56(5):1959-1983, October 2001.

Jia He, Lilian Ng, and Qinghai Wang. Quarterly Trading Patterns of Financial Institutions. The Journal of Business, 77(3):493-509, July 2004.

Steven L Heston, Robert A Korajczyk, and Ronnie Sadka. Intraday Patterns in the Cross-section of Stock Returns. The Journal of Finance, 65(4):1369-1407, August 2010.

David A Hirshleifer and Siew Hong Teoh. Limited attention, information disclosure, and financial reporting. 36(1-3): 337-386, December 2003.

David A Hirshleifer, Sonya S Lim, and Siew Hong Teoh. Limited Investor Attention and Stock Market Misreactions to Accounting Information. Review of Asset Pricing Studies, 1(1):35-73, December 2011.

Thomas Ho and Hans R Stoll. Optimal dealer pricing under transactions and return uncertainty. Journal of Financial Economics, 9(1):47-73, March 1981.

Arvid O I Hoffmann and Thomas Post. How return and risk experiences shape investor beliefs and preferences. Accounting 85 Finance, pages n/a-n/a, 2015.

Steven Huddart, Mark H Lang, and Michelle H Yetman. Volume and Price Patterns Around a Stock's 52-Week Highs and Lows: Theory and Evidence. Management Science, 55(1):16-31, 2009.

Narasimhan Jegadeesh and Sheridan D Titman. Returns to Buying Winners and Selling Losers: Implications for Stock Market Efficiency. The Journal of Finance, 48(1):65, March 1993.

Narasimhan Jegadeesh and Sheridan D Titman. Profitability of Momentum Strategies: An Evaluation of Alternative Explanations. The Journal of Finance, 56(2):699-720, April 2001. 
Jun-Koo Kang and René M Stulz. Why is there a home bias? An analysis of foreign portfolio equity ownership in Japan. Journal of Financial Economics, 46(1):3-28, October 1997.

Oliver Kim and Robert E Verrecchia. Pre-announcement and event-period private information. Journal of Accounting and Economics, 24(3):395-419, December 1997.

Leonid Kogan, Stephen A Ross, Jiang Wang, and Mark M Westerfield. The Price Impact and Survival of Irrational Traders. The Journal of Finance, 61(1):195-229, 2006.

Robert A Korajczyk and Ronnie Sadka. Are Momentum Profits Robust to Trading Costs? The Journal of Finance, 59(3):1039-1082, June 2004.

Albert S Kyle. Continuous Auctions and Insider Trading. Econometrica, 53(6):1315, November 1985.

Albert S Kyle and F Albert Wang. Speculation Duopoly with Agreement to Disagree: Can Overconfidence Survive the Market Test? The Journal of Finance, 52(5):2073-2090, December 1997.

Charles M C Lee and Mark J Ready. Inferring Trade Direction from Intraday Data. The Journal of Finance, 46(2): 733-746, June 1991.

Ulrike Malmendier and Stefan Nagel. Depression Babies: Do Macroeconomic Experiences Affect Risk Taking?*. The Quarterly Journal of Economics, 126(1):373-416, February 2011.

Tobias Moskowitz, Yao Hua Ooi, and Lasse Heje Pedersen. Time series momentum. Journal of Financial Economics, 104(2):228-250, May 2012.

John C Nash and Ravi Varadhan. Unifying Optimization Algorithms to Aid Software System Users: optimx for R. Journal of Statistical Software, 43(1):1-14, August 2011.

Lilian Ng and Qinghai Wang. Institutional trading and the turn-of-the-year effect. Journal of Financial Economics, 74(2):343-366, November 2004.

Robert Novy-Marx and Mihail Velikov. A Taxonomy of Anomalies and Their Trading Costs. The Review of Financial Studies, 29(1):104-147, January 2016.

Terrance Odean. Volume, Volatility, Price, and Profit When All Traders Are Above Average. The Journal of Finance, 53(6):1887-1934, December 1998.

Richard Roll. A Simple Implicit Measure of the Effective Bid-Ask Spread in an Efficient Market. The Journal of Finance, 39(4):1127, September 1984. 
Ronnie Sadka. Liquidity risk and the cross-section of hedge-fund returns. Journal of Financial Economics, 98(1): 54-71, October 2010.

Andrei Shleifer and Robert W Vishny. The Limits of Arbitrage. The Journal of Finance, 52(1):35-55, March 1997.

Richard G Sloan. Do Stock Prices Fully Reflect Information in Accruals and Cash Flows about Future Earnings? The Accounting Review, 71(3):289-315, July 1996.

Meir Statman, Steven Thorley, and Keith Vorkink. Investor Overconfidence and Trading Volume. The Review of Financial Studies, 19(4):1531-1565, December 2006.

Hans R Stoll. Inferring the Components of the Bid-Ask Spread: Theory and Empirical Tests. The Journal of Finance, 44(1):115-134, 1989.

Paul C Tetlock. All the News That's Fit to Reprint: Do Investors React to Stale Information? The Review of Financial Studies, 24(5):1481-1512, May 2011.

Richard H Thaler. Behavioral Economics: Past, Present, and Future. American Economic Review, 106(7):1577-1600, July 2016 .

Hal R Varian. Differences of Opinion in Financial Markets. In Courtenay C Stone, editor, Financial Risk Theory, Evidence and Implications: Proceedings of the Eleventh Annual Economic Policy Conference of the Federal Reserve Bank of St. Louis., pages 3-37. Springer Netherlands, Dordrecht, 1989.

Robert E Verrecchia. Information Acquisition in a Noisy Rational Expectations Economy. Econometrica, 50(6):1415, November 1982.

Ross L Watts and Jerrold L Zimmerman. Positive Accounting Theory. Contemporary topics in accounting series. Prentice-Hall, 1986.

Jeffrey M Wooldridge. Econometric Analysis of Cross Section and Panel Data. MIT Press, 2nd edition, 2010.

Wei Xiong. Bubbles, Crises, and Heterogeneous Beliefs. National Bureau of Economic Research Working Paper, March 2013.

Hongjun Yan. Natural Selection in Financial Markets: Does It Work? Management Science, 54(11):1935-1950, November 2008 . 


\section{A Additional properties of the analytical model}

\section{A.1 Equilibrium characterization}

The unique equilibrium satisfies:

$$
\begin{gathered}
\lambda_{d}=\frac{\left(\frac{1}{2\left(\lambda_{d}+\rho\right)}\right) \sigma_{v, t}^{2}}{\left(\frac{1}{2\left(\lambda_{d}+\rho\right)}\right)^{2} \sigma_{v, t}^{2}+\sigma_{\zeta, t}^{2}} \\
\Rightarrow 4 \lambda_{d}\left(\lambda_{d}+\rho\right)^{2}+\bar{\sigma} \lambda_{d}-2\left(\lambda_{d}+\rho\right) \bar{\sigma}=0 \\
\Rightarrow \lambda_{d}^{3}+2 \rho \lambda_{d}^{2}+\left(\rho^{2}-\frac{1}{4} \bar{\sigma}\right) \lambda_{d}-\frac{1}{2} \bar{\sigma} \rho=0
\end{gathered}
$$

Since $\lambda_{d}+\rho$ must be positive to satisfy the informed investor's profit maximization problem, $\lambda_{d}$ must be positive to satisfy Equation (A.2). Also, the left hand side expression of Equation (A.3) is increasing in $\lambda_{d}$. Thus, this polynomial has one real root for $\lambda_{d}$ in which $\lambda_{d} \geq-\rho$ and $\lambda_{d}>0$. By assumption, $\frac{\sigma_{v, t}^{2}}{\sigma_{\zeta, t}^{2}}=\bar{\sigma}$ and $\rho$ are constant over time, so $\lambda_{d}$ is constant over time.

To satisfy the parameters in the market maker's pricing function,

$$
\begin{gathered}
\kappa_{u}=\frac{\alpha-\left(\lambda_{d}+\rho\right) M \gamma_{u}-\lambda_{u}}{2\left(\lambda_{d}+\rho\right)}=\frac{\alpha-\left(\lambda_{d}+\rho\right) M\left(-\frac{\left(\lambda_{d}+\rho\right) \kappa_{u}+\lambda_{u}}{(M+1)\left(\lambda_{d}+\rho\right)}\right)-\lambda_{u}}{2\left(\lambda_{d}+\rho\right)} \\
\Rightarrow \kappa_{u}=\frac{(M+1) \alpha-\lambda_{u}}{(M+2)\left(\lambda_{d}+\rho\right)} \\
\gamma_{u}=-\frac{\left(\lambda_{d}+\rho\right) \kappa_{u}+\lambda_{u}}{(M+1)\left(\lambda_{d}+\rho\right)}=-\frac{\left(\lambda_{d}+\rho\right) \frac{\alpha-\left(\lambda_{d}+\rho\right) M \gamma_{u}-\lambda_{u}}{2\left(\lambda_{d}+\rho\right)}+\lambda_{u}}{(M+1)\left(\lambda_{d}+\rho\right)} \\
\Rightarrow \gamma_{u}=\frac{-\alpha-\lambda_{u}}{(M+2)\left(\lambda_{d}+\rho\right)} \\
\lambda_{u}=-\lambda_{d}\left(\kappa_{u}+M \gamma_{u}\right)=-\lambda_{d}\left(\frac{(M+1) \alpha-\lambda_{u}}{(M+2)\left(\lambda_{d}+\rho\right)}+M\left(\frac{-\alpha-\lambda_{u}}{(M+2)\left(\lambda_{d}+\rho\right)}\right)\right) \\
\Rightarrow \lambda_{u}=\frac{-\lambda_{d} \alpha}{\lambda_{d}+(M+2) \rho}
\end{gathered}
$$




$$
\begin{aligned}
& \kappa_{\phi}=\frac{-\left(\lambda_{d}+\rho\right)\left(M \gamma_{\phi}+\phi\right)-\lambda_{\phi}}{2\left(\lambda_{d}+\rho\right)}=-\frac{\left(\lambda_{d}+\rho\right)\left(M\left(-\frac{\left(\lambda_{d}+\rho\right)\left(\kappa_{\phi}+\phi\right)+\lambda_{\phi}}{(M+1)\left(\lambda_{d}+\rho\right)}\right)+\phi\right)+\lambda_{\phi}}{2\left(\lambda_{d}+\rho\right)} \\
& \Rightarrow \kappa_{\phi}=-\frac{\left(\lambda_{d}+\rho\right) \phi+\lambda_{\phi}}{(M+2)\left(\lambda_{d}+\rho\right)} \\
& \gamma_{\phi}=-\frac{\left(\lambda_{d}+\rho\right)\left(\kappa_{\phi}+\phi\right)+\lambda_{\phi}}{(M+1)\left(\lambda_{d}+\rho\right)}=-\frac{\left(\lambda_{d}+\rho\right)\left(\frac{-\left(\lambda_{d}+\rho\right)\left(M \gamma_{\phi}+\phi\right)-\lambda_{\phi}}{2\left(\lambda_{d}+\rho\right)}+\phi\right)+\lambda_{\phi}}{(M+1)\left(\lambda_{d}+\rho\right)} \\
& \gamma_{\phi}=-\frac{\left(\lambda_{d}+\rho\right) \phi+\lambda_{\phi}}{(M+2)\left(\lambda_{d}+\rho\right)} \\
& \lambda_{\phi}=-\lambda_{d}\left(\kappa_{\phi}+\phi+M \gamma_{\phi}\right)=-\lambda_{d}\left(\phi-(M+1) \frac{\left(\lambda_{d}+\rho\right) \phi+\lambda_{\phi}}{(M+2)\left(\lambda_{d}+\rho\right)}\right) \\
& \Rightarrow \lambda_{\phi}=\frac{-\lambda_{d}\left(\lambda_{d}+\rho\right) \phi}{\lambda_{d}+(M+2) \rho} \\
& \kappa_{E}=\frac{1-\left(\lambda_{d}+\rho\right) M \gamma_{E}-\lambda_{E}}{2\left(\lambda_{d}+\rho\right)}=\frac{1-\left(\lambda_{d}+\rho\right) M \frac{1-\left(\lambda_{d}+\rho\right) \kappa_{E}-\lambda_{E}}{(M+1)\left(\lambda_{d}+\rho\right)}-\lambda_{E}}{2\left(\lambda_{d}+\rho\right)} \\
& \Rightarrow \kappa_{E}=\frac{1-\lambda_{E}}{(M+2)\left(\lambda_{d}+\rho\right)} \\
& \gamma_{E}=\frac{1-\left(\lambda_{d}+\rho\right) \kappa_{E}-\lambda_{E}}{(M+1)\left(\lambda_{d}+\rho\right)}=\frac{1-\left(\lambda_{d}+\rho\right) \frac{1-\left(\lambda_{d}+\rho\right) M \gamma_{E}-\lambda_{E}}{2\left(\lambda_{d}+\rho\right)}-\lambda_{E}}{(M+1)\left(\lambda_{d}+\rho\right)} \\
& \Rightarrow \gamma_{E}=\frac{1-\lambda_{E}}{(M+2)\left(\lambda_{d}+\rho\right)} \\
& \Rightarrow \lambda_{E}=1-\lambda_{d}\left(\kappa_{E}+M \gamma_{E}\right)=1-\lambda_{d}(M+1) \frac{1-\lambda_{E}}{(M+2)\left(\lambda_{d}+\rho\right)} \\
& \Rightarrow \lambda_{E}=1
\end{aligned}
$$

Returning to the informed investor's demand function,

$$
\kappa_{u}=\frac{(M+1) \alpha-\lambda_{u}}{(M+2)\left(\lambda_{d}+\rho\right)}=\frac{\alpha\left(\lambda_{d}+(M+1) \rho\right)}{\left(\lambda_{d}+\rho\right)\left(\lambda_{d}+(M+2) \rho\right)}
$$




$$
\begin{gathered}
\kappa_{\phi}=-\frac{\left(\lambda_{d}+\rho\right) \phi+\lambda_{\phi}}{(M+2)\left(\lambda_{d}+\rho\right)}=-\frac{\phi \rho}{\lambda_{d}+(M+2) \rho} \\
\kappa_{E}=\frac{1-\lambda_{E}}{3\left(\lambda_{d}+\rho\right)}=0
\end{gathered}
$$

Returning to the rational arbitrageur's demand function,

$$
\begin{gathered}
\gamma_{u}=\frac{-\alpha-\lambda_{u}}{(M+2)\left(\lambda_{d}+\rho\right)}=\frac{-\alpha \rho}{\left(\lambda_{d}+\rho\right)\left(\lambda_{d}+(M+2) \rho\right)} \\
\gamma_{\phi}=-\frac{\left(\lambda_{d}+\rho\right) \phi+\lambda_{\phi}}{(M+2)\left(\lambda_{d}+\rho\right)}=-\frac{\phi \rho}{\lambda_{d}+(M+2) \rho} \\
\gamma_{E}=\frac{1-\lambda_{E}}{(M+2)\left(\lambda_{d}+\rho\right)}=0
\end{gathered}
$$

\section{A.2 Informed investors' viability of trading on redundant information}

Can informed investors who trade on redundant information traders survive in equilibrium? The informed investor in period $t$ trades based on the biased posterior belief $v_{t}+\alpha u_{t-1}+\mathrm{E}\left[\tilde{V} \mid H_{t-1}\right]$, but his expected profits are

$$
\begin{aligned}
& \mathrm{E}\left[\left(v_{t}+\mathrm{E}\left[\tilde{V} \mid H_{t-1}\right]-\mathrm{E}\left[\tilde{P}_{t} \mid s_{t}\right]\right) x_{t}\right] \\
&=\mathrm{E}\left[\left(v_{t}+\mathrm{E}\left[\tilde{V} \mid H_{t-1}\right]-\mathrm{E}\left[\left(\lambda_{d}\left(D_{t}-\mathrm{E}\left[\tilde{D}_{t} \mid H_{t-1}\right]\right)+\mathrm{E}\left[\tilde{V} \mid H_{t-1}\right]+\rho D_{t}\right) \mid s_{t}\right]\right)\right. \\
&\left.\times\left(\frac{1}{2\left(\lambda_{d}+\rho\right)} v_{t}+\frac{\alpha\left(\lambda_{d}+(M+1) \rho\right)}{\left(\lambda_{d}+\rho\right)\left(\lambda_{d}+(M+2) \rho\right)} u_{t-1}-\frac{\phi \rho}{\lambda_{d}+(M+2) \rho} \mathrm{E}\left[\tilde{z}_{t-1} \mid H_{t-1}\right]\right)\right] \\
&= \frac{1}{4\left(\lambda_{d}+\rho\right)} \sigma_{v, t}^{2}-\frac{\rho}{\left(\lambda_{d}+(M+2) \rho\right)^{2}\left(\lambda_{d}+\rho\right)} F(\alpha, \phi)
\end{aligned}
$$

where

$$
\begin{aligned}
F(\alpha, \phi) & \left.=\mathrm{E}\left[\left(\alpha u_{t-1}+\phi \nu_{t-1}\right)\left(\alpha\left(\lambda_{d}+(M+1) \rho\right) u_{t-1}-\phi \rho \nu_{t-1}\right)\right]\right] \\
& =\alpha^{2}\left(\lambda_{d}+(M+1) \rho\right) \mathrm{E}\left[u_{t-1}^{2}\right]+\alpha \phi\left(\lambda_{d}+M \rho\right) \mathrm{E}\left[u_{t-1} \nu_{t-1}\right]-\phi^{2} \rho \mathrm{E}\left[\nu_{t-1}^{2}\right]
\end{aligned}
$$




$$
\begin{gathered}
\mathrm{E}\left[u_{t-1}^{2}\right]=\frac{\lambda_{d}^{2}}{\left(\lambda_{d}+\rho\right)^{2}} \mathrm{E}\left[\eta_{t-1}^{2}\right] \\
\mathrm{E}\left[u_{t-1} \nu_{t-1}\right]=\frac{\lambda_{d}\left(\lambda_{d}+2 \rho\right)}{2\left(\lambda_{d}+\rho\right)^{2}} \mathrm{E}\left[\eta_{t-1}^{2}\right] \\
\mathrm{E}\left[\nu_{t-1}^{2}\right]=\phi^{2} \mathrm{E}\left[\nu_{t-2}^{2}\right]+\frac{\left(\lambda_{d}+2 \rho\right)^{2}}{4\left(\lambda_{d}+\rho\right)^{2}} \mathrm{E}\left[\eta_{t-1}^{2}\right]
\end{gathered}
$$

and

$$
\mathrm{E}\left[\eta_{t-1}^{2}\right]=\frac{1}{4} \sigma_{v, t-1}^{2}+\left(\lambda_{d}+\rho\right)^{2} \sigma_{\zeta, t-1}^{2}
$$

Thus, an informed investor's expected profits increase as $\alpha^{2}$ decreases, $\alpha \phi$ decreases, and $\phi^{2}$ increases. In addition, as $M$ increases, the effect of $\alpha \neq 0$ and $\phi \neq 0$ on an informed investor's expected profits attenuates because rational arbitrageurs lessen the price impact of trading on redundant information.

Although trading on redundant information detracts from an informed investor's expected profits, his expected profits are not necessarily negative. Rather, his expected profits are positive if

$$
0<\mathrm{E}\left[\left(v_{t}+\mathrm{E}\left[V \mid H_{t-1}\right]-\mathrm{E}\left[\tilde{P}_{t} \mid s_{t}\right]\right) x_{t}\right]
$$

I set Equation (A.25) as an equality, and solve it numerically for the break-even level of $\alpha$ over various values of $\rho$, $\bar{\sigma}, \phi$, and $M$. Since an informed investor's expected profits are increasing in $\phi^{2}$, I solve for the minimum break-even level of $\alpha$ by assuming $\mathrm{E}\left[\nu_{t-2}^{2}\right]=0$. Assuming $\sigma_{v, t}^{2}=\sigma_{v, t-1}^{2}$, the informed investor has zero expected profits if

$$
\begin{aligned}
\frac{\left(\lambda_{d}+\rho\right)^{2}\left(\lambda_{d}+(M+2) \rho\right)^{2} \bar{\sigma}}{\rho\left(\frac{1}{4} \bar{\sigma}+\left(\lambda_{d}+\rho\right)^{2}\right)}= & 4 \alpha^{2} \lambda_{d}^{2}\left(\lambda_{d}+(M+1) \rho\right) \\
& +2 \alpha \phi \lambda_{d}\left(\lambda_{d}+M \rho\right)\left(\lambda_{d}+2 \rho\right)-\phi^{2} \rho\left(\lambda_{d}+2 \rho\right)^{2}
\end{aligned}
$$

If $\phi=0$ and $M=0$, and for any $\bar{\sigma} \in[0.01,3]$ and $\rho \in(0,3]$, an informed investor earns positive expected profits if $|\alpha|<2.00$. I plot the (positive) break-even level of $\alpha$ as a function of $\bar{\sigma}$ and $\rho$ with $\phi=0$ and $M=0$ in Figure 2 . As depicted, this break-even level of $\alpha$ is non-monotonic in $\rho$ and $\lambda_{d}$; the breakeven $\alpha$ is decreasing in $\rho$ when $\rho$ is sufficiently low, increasing in $\rho$ when $\rho$ is sufficiently high, increasing in $\bar{\sigma}$ when $\rho$ is sufficiently low, and decreasing in $\bar{\sigma}$ if $\rho$ is sufficiently high. 
As $\phi$ increases or $M$ decreases, the minimum break-even $|\alpha|$ decreases. In Figure 3, I plot the lowest positive breakeven $\alpha$ as a function of $\phi$ and $M$ for any $\bar{\sigma} \in[0.01,3]$ and $\rho \in(0,3]$ (i.e., the minimum point of Figure 2 as a function of $\phi$ and $M$ ). The minimum point on this chart appears when $\phi=1$ and $M=0$. When $\phi=1$ and $M=0$, an informed investor earns positive expected profits as long as $|\alpha|<1.77$.

In summary, although an informed investor might misweight information, he still would earn positive expected profits as long as his non-Bayesian behavior is not too severe.

\section{A.3 Rational arbitrageurs' expected profits}

A rational arbitrageur earns expected profits

$$
\mathrm{E}\left[y_{t}\left(\mathrm{E}\left[\tilde{V}-\tilde{P}_{t} \mid y_{t}, H_{t-1}\right]\right)\right]
$$

Each rational arbitrageur chooses his demand according to

$$
y_{t}=-\frac{\alpha \rho}{\left(\lambda_{d}+\rho\right)\left(\lambda_{d}+(M+2) \rho\right)} u_{t-1}-\frac{\phi \rho}{\lambda_{d}+(M+2) \rho} \mathrm{E}\left[\tilde{z}_{t-1} \mid H_{t-1}\right]
$$

and

$$
\begin{aligned}
\mathrm{E}\left[\tilde{V}-\tilde{P}_{t} \mid y_{t}, H_{t-1}\right] & =-\rho \mathrm{E}\left[\tilde{D}_{t} \mid y_{t}, H_{t-1}\right] \\
& =-\rho\left(\frac{\alpha}{\lambda_{d}+(M+2) \rho} u_{t-1}+\frac{\left(\lambda_{d}+\rho\right) \phi}{\lambda_{d}+(M+2) \rho} \mathrm{E}\left[\tilde{z}_{t-1} \mid H_{t-1}\right]\right)
\end{aligned}
$$

Combining these equations implies that the rational arbitrageur earns expected profits:

$$
\mathrm{E}\left[y_{t}\left(\mathrm{E}\left[\tilde{V}-\tilde{P}_{t} \mid y_{t}, H_{t-1}\right]\right)\right]=\frac{\rho^{2}}{\left(\lambda_{d}+(M+2) \rho\right)^{2}\left(\lambda_{d}+\rho\right)} \mathrm{E}\left[\left(\alpha u_{t-1}+\phi \nu_{t-1}\right)^{2}\right]
$$

where

$$
\mathrm{E}\left[\left(\alpha u_{t-1}+\phi \nu_{t-1}\right)^{2}\right]=\left(\frac{\alpha \lambda_{d}+\phi\left(\frac{1}{2} \lambda_{d}+\rho\right)}{\lambda_{d}+\rho}\right)^{2} \mathrm{E}\left[\eta_{t-1}^{2}\right]+\phi^{4} \mathrm{E}\left[\nu_{t-2}^{2}\right]
$$

and $\mathrm{E}\left[\eta_{t-1}^{2}\right]=\frac{1}{4} \sigma_{v, t-1}^{2}+\left(\lambda_{d}+\rho\right)^{2} \sigma_{\zeta, t-1}^{2}$. 
A rational arbitrageur earns positive expected profits if $\rho \neq 0$ and either $\alpha \neq 0, \phi \neq 0$, or both. His expected profits increase as $\alpha^{2}$ increases, $\phi^{2}$ increases, and $\alpha \phi$ increases. As shown in Figure 4, a rational arbitrageur's expected profits are non-monotonic in information asymmetry, $\bar{\sigma}$, and transaction costs, $\rho$. Over most levels of transaction costs, a rational arbitrageur's expected profits increase as information asymmetry increases. At low levels of transaction costs and high levels of information asymmetry, a rational arbitrageur's expected profits decrease as information asymmetry increases. When $\alpha=0$, a rational arbitrageur's expected profits increase as transaction costs increase. When $\alpha>0$, a rational arbitrageur's expected profits increase as transaction costs increase when transaction costs are low, and a rational arbitrageur's expected profits decrease as transaction costs increase when transaction costs are high. Expected profits for a single rational arbitrageur are decreasing in $M$, but total expected profits for all rational arbitrageurs are increasing in $M$.

\section{A.4 Sensitivity of trading volume to the misweighting of redundant information and expected liquidity trade}

Expected trading volume is

$$
\mathrm{E}\left[\left|x_{t}\right|+M\left|y_{t}\right|+\left|z_{t}\right|\right] \propto \operatorname{Var}\left(x_{t}\right)+M \operatorname{Var}\left(y_{t}\right)+\operatorname{Var}\left(z_{t}\right)
$$

The variance of informed demand is

$$
\begin{aligned}
\operatorname{Var}\left(x_{t}\right)= & \operatorname{Var}\left(\frac{1}{2\left(\lambda_{d}+\rho\right)} v_{t}+\frac{\alpha\left(\lambda_{d}+(M+1) \rho\right)}{\left(\lambda_{d}+\rho\right)\left(\lambda_{d}+(M+2) \rho\right)} u_{t-1}-\frac{\phi \rho}{\lambda_{d}+(M+2) \rho} \mathrm{E}\left[\tilde{z}_{t-1} \mid H_{t-1}\right]\right) \\
= & \frac{1}{4\left(\lambda_{d}+\rho\right)^{2}} \operatorname{Var}\left(v_{t}\right)+\frac{\left(\alpha \lambda_{d}\left(\lambda_{d}+(M+1) \rho\right)-\phi \rho\left(\frac{1}{2} \lambda_{d}+\rho\right)\right)^{2}}{\left(\lambda_{d}+\rho\right)^{4}\left(\lambda_{d}+(M+2) \rho\right)^{2}} \mathrm{E}\left[\eta_{t-1}^{2}\right] \\
& +\frac{\phi^{4} \rho^{2}}{\left(\lambda_{d}+(M+2) \rho\right)^{2}\left(\lambda_{d}+\rho\right)^{2}} \mathrm{E}\left[\nu_{t-2}^{2}\right]
\end{aligned}
$$

Equation (A.34) shows that the variance of informed trade is increasing $\alpha^{2}$, increasing in $\phi^{2}$, and decreasing in $\alpha \phi$.

The variance of rational arbitrage demand is 


$$
\begin{aligned}
\operatorname{Var}\left(y_{t}\right) & =\operatorname{Var}\left(-\frac{\alpha \rho}{\left(\lambda_{d}+\rho\right)\left(\lambda_{d}+(M+2) \rho\right)} u_{t-1}-\frac{\phi \rho}{\lambda_{d}+(M+2) \rho} \mathrm{E}\left[\tilde{z}_{t-1} \mid H_{t-1}\right]\right) \\
& =\frac{\rho^{2}\left(\alpha \lambda_{d}+\phi\left(\lambda_{d}+\rho\right)\right)^{2}}{\left(\lambda_{d}+\rho\right)^{4}\left(\lambda_{d}+(M+2) \rho\right)^{2}} \mathrm{E}\left[\eta_{t-1}^{2}\right]+\frac{\phi^{4} \rho^{2}}{\left(\lambda_{d}+(M+2) \rho\right)^{2}\left(\lambda_{d}+\rho\right)^{2}} \mathrm{E}\left[\nu_{t-2}^{2}\right]
\end{aligned}
$$

Equation (A.35) shows that the variance of rational arbitrage demand is increasing in $\alpha^{2}, \phi^{2}$, and $\alpha \phi$.

If $\sigma_{\zeta, t}^{2}$ is constant over time, the variance of liquidity trade is

$$
\operatorname{Var}\left(z_{t}\right)=\frac{\sigma_{\zeta, t}^{2}}{1-\phi^{2}}
$$

Equation (A.36) shows that the variance of liquidity trade is increasing in $\phi^{2}$.

Since the informed investor and the rational arbitrageurs trade against each other more as $\alpha^{2}$ increases, and the informed investor and the rational arbitrageurs trade against the liquidity trader more as $\phi^{2}$ increases, total trading volume is likely to be increasing in $\alpha^{2}, \phi^{2}$, and $\alpha \phi$.

\section{B Predictability of returns in a sequential Kyle (1985) model with transaction costs}

The following model extends the sequential auction model in Kyle [1985] to allow for transaction costs. The objective of this section is to demonstrate that a Kyle [1985] model with long-lived information and transaction costs cannot give rise to momentum in returns.

\section{B.1 Setup}

I assume that the risky asset has terminal value $\tilde{V} \sim \mathcal{N}\left(0, \sigma_{0}^{2}\right)$. Trading occurs in rounds $t=1,2$. At the end of $t=2$, the risky asset liquidates. The liquidity trader in each period $t$ submits a random market order $\tilde{z}_{t} \sim \mathcal{N}\left(0, \sigma_{z}^{2}\right)$ where $z_{1}$ and $z_{2}$ are independently distributed. The informed investor knows $V$, and demands $x_{t}$ shares in round $t=1,2$ to maximize expected profits over the remaining rounds of trade. 
The market maker sets price in $t=1,2$ by

$$
\begin{gathered}
P_{1}=\mathrm{E}\left[\tilde{V} \mid D_{1}\right]+\rho D_{1} \\
P_{2}=\mathrm{E}\left[\tilde{V} \mid D_{1}, D_{2}\right]+\rho D_{2}
\end{gathered}
$$

where $D_{t}=x_{t}+z_{t}$ and $\rho \geq 0$. Within the context of the present model, the set of public information comprises the history of order flow.

\section{B.2 Equilibrium characterization}

I focus on recursive equilibria, which are equilibria in which price and informed demand are of the following linear forms. Price satisfies

$$
\begin{gathered}
P_{1}=\lambda_{0,1}+\lambda_{d, 1} D_{1}+\rho D_{1} \\
P_{2}=\lambda_{0,2} \mathrm{E}\left[\tilde{V} \mid D_{1}\right]+\lambda_{d, 2} D_{2}+\rho D_{2}
\end{gathered}
$$

Informed demand satisfies

$$
\begin{gathered}
x_{1}=\kappa_{0,1}+\kappa_{V, 1} V \\
x_{2}=\kappa_{0,2} \mathrm{E}\left[\tilde{V} \mid D_{1}\right]+\kappa_{V, 2} V
\end{gathered}
$$

In $t=2$, the informed investor chooses $x_{2}$ by

$$
\begin{gathered}
\max _{x_{2}}\left\{\mathrm{E}\left[x_{2}\left(V-\mathrm{E}\left[\tilde{P}_{2} \mid D_{1}, x_{2}\right]\right)\right]\right\} \\
=\max _{x_{2}}\left\{x_{2}\left(V-\left(\left(\lambda_{d, 2}+\rho\right) x_{2}+\lambda_{0,2} \mathrm{E}\left[\tilde{V} \mid D_{1}\right]\right)\right)\right\} \\
\Rightarrow 0=V-\left(2\left(\lambda_{d, 2}+\rho\right) x_{2}+\lambda_{0,2} \mathrm{E}\left[\tilde{V} \mid D_{1}\right]\right) \\
\Rightarrow x_{2}=\frac{1}{2\left(\lambda_{d, 2}+\rho\right)}\left(V-\lambda_{0,2} \mathrm{E}\left[\tilde{V} \mid D_{1}\right]\right)
\end{gathered}
$$

Anticipating his demand in $t=2$, the informed investor chooses $x_{1}$ by

$$
\max _{x_{1}}\left\{x_{1}\left(V-\mathrm{E}\left[\tilde{P}_{1} \mid x_{1}\right]\right)+\mathrm{E}\left[x_{2}\left(V-\tilde{P}_{2}\right) \mid x_{1}\right]\right\}
$$




$$
\begin{gathered}
=\max _{x_{1}}\left\{x_{1}\left(V-\lambda_{0,1}-\left(\lambda_{d, 1}+\rho\right) x_{1}\right)\right. \\
\left.+\frac{1}{4\left(\lambda_{d, 2}+\rho\right)}\left(V-\lambda_{0,2}\left(\lambda_{0,1}+\lambda_{d, 1} x_{1}\right)\right)^{2}\right\} \\
\Rightarrow 0=V-\lambda_{0,1}-2\left(\lambda_{d, 1}+\rho\right) x_{1}+\frac{-\lambda_{0,2} \lambda_{d, 1}}{2\left(\lambda_{d, 2}+\rho\right)}\left(V-\lambda_{0,2}\left(\lambda_{0,1}+\lambda_{d, 1} x_{1}\right)\right) \\
\Rightarrow x_{1}=-\frac{2\left(\lambda_{d, 2}+\rho\right)-\lambda_{0,2}^{2} \lambda_{d, 1}}{4\left(\lambda_{d, 2}+\rho\right)\left(\lambda_{d, 1}+\rho\right)-\lambda_{0,2}^{2} \lambda_{d, 1}^{2}} \lambda_{0,1}+\frac{2\left(\lambda_{d, 2}+\rho\right)-\lambda_{0,2} \lambda_{d, 1}}{4\left(\lambda_{d, 2}+\rho\right)\left(\lambda_{d, 1}+\rho\right)-\lambda_{0,2}^{2} \lambda_{d, 1}^{2}} V
\end{gathered}
$$

It follows that, in any recursive equilibrium, the coefficients of the informed demand functions must satisfy:

$$
\begin{gathered}
\kappa_{0,2}=\kappa_{V, 2}=\frac{1}{2\left(\lambda_{d, 2}+\rho\right)} \\
\kappa_{V, 1}=\frac{2\left(\lambda_{d, 2}+\rho\right)-\lambda_{0,2} \lambda_{d, 1}}{4\left(\lambda_{d, 2}+\rho\right)\left(\lambda_{d, 1}+\rho\right)-\lambda_{0,2}^{2} \lambda_{d, 1}^{2}} \\
\kappa_{0,1}=-\frac{2\left(\lambda_{d, 2}+\rho\right)-\lambda_{0,2}^{2} \lambda_{d, 1}}{4\left(\lambda_{d, 2}+\rho\right)\left(\lambda_{d, 1}+\rho\right)-\lambda_{0,2}^{2} \lambda_{d, 1}^{2}} \lambda_{0,1}
\end{gathered}
$$

Let $\sigma_{1}^{2} \equiv \operatorname{Var}\left(\tilde{V}-\mathrm{E}\left[\tilde{V} \mid D_{1}\right]\right)$

The market maker sets the market clearing price in $t=2$ to satisfy

$$
\begin{aligned}
P_{2} & =\mathrm{E}\left[\tilde{V} \mid D_{2}, D_{1}\right]+\rho D_{2} \\
& =\frac{\kappa_{V, 2} \sigma_{1}^{2}}{\kappa_{V, 2}^{2} \sigma_{1}^{2}+\sigma_{z}^{2}}\left(D_{2}-\mathrm{E}\left[\tilde{D}_{2} \mid D_{1}\right]\right)+\mathrm{E}\left[\tilde{V} \mid D_{1}\right]+\rho D_{2}
\end{aligned}
$$

The market maker sets the market clearing price in $t=1$ to satisfy

$$
\begin{aligned}
P_{1} & =\mathrm{E}\left[\tilde{V} \mid D_{1}\right]+\rho D_{2} \\
& =\frac{\kappa_{V, 1} \sigma_{0}^{2}}{\kappa_{V, 1}^{2} \sigma_{0}^{2}+\sigma_{z}^{2}} D_{1}+\rho D_{1}
\end{aligned}
$$

It follows that, in any recursive equilibrium, the coefficients of the market maker's pricing functions must satisfy:

$$
\begin{gathered}
\lambda_{d, 2}=\frac{\kappa_{V, 2} \sigma_{1}^{2}}{\kappa_{V, 2}^{2} \sigma_{1}^{2}+\sigma_{z}^{2}} \\
\lambda_{0,2}=1
\end{gathered}
$$




$$
\begin{gathered}
\lambda_{d, 1}=\frac{\kappa_{V, 1} \sigma_{0}^{2}}{\kappa_{V, 1}^{2} \sigma_{0}^{2}+\sigma_{z}^{2}} \\
\lambda_{0,1}=0
\end{gathered}
$$

The unique equilibrium satisfies:

$$
\begin{gathered}
\lambda_{d, 2}=\frac{\left(\frac{1}{2\left(\lambda_{d, 2}+\rho\right)}\right) \sigma_{1}^{2}}{\left(\frac{1}{2\left(\lambda_{d, 2}+\rho\right)}\right)^{2} \sigma_{1}^{2}+\sigma_{z}^{2}} \\
\Rightarrow 0=\lambda_{d, 2}^{3}+2 \rho \lambda_{d, 2}^{2}+\left(\rho^{2}-\frac{\sigma_{1}^{2}}{4 \sigma_{z}^{2}}\right) \lambda_{d, 2}-\frac{\sigma_{1}^{2}}{2 \sigma_{z}^{2}} \rho
\end{gathered}
$$

As before, this polynomial has one real root for $\lambda_{d, 2}$ in which $\lambda_{d, 2} \geq-\rho$ and $\lambda_{d, 2}>0$.

$$
\begin{aligned}
& \lambda_{d, 1}=\frac{\left(\frac{2\left(\lambda_{d, 2}+\rho\right)-\lambda_{0,2} \lambda_{d, 1}}{4\left(\lambda_{d, 2}+\rho\right)\left(\lambda_{d, 1}+\rho\right)-\lambda_{0,2}^{2} \lambda_{d, 1}^{2}}\right) \sigma_{0}^{2}}{\left(\frac{2\left(\lambda_{d, 2}+\rho\right)-\lambda_{0,2} \lambda_{d, 1}}{4\left(\lambda_{d, 2}+\rho\right)\left(\lambda_{d, 1}+\rho\right)-\lambda_{0,2}^{2} \lambda_{d, 1}^{2}}\right)^{2} \sigma_{0}^{2}+\sigma_{z}^{2}} \\
&=\frac{\left(\frac{1}{2\left(\lambda_{d, 1}+\rho\right)}\right) \sigma_{0}^{2}}{\left(\frac{1}{2\left(\lambda_{d, 1}+\rho\right)}\right)^{2} \sigma_{0}^{2}+\sigma_{z}^{2}} \\
& 0=\lambda_{d, 1}^{3}+2 \rho \lambda_{d, 1}^{2}+\left(\rho^{2}-\frac{\sigma_{0}^{2}}{4 \sigma_{z}^{2}}\right) \lambda_{d, 1}-\frac{\sigma_{0}^{2}}{2 \sigma_{z}^{2}} \rho
\end{aligned}
$$

The right hand side of this polynomial is increasing in $\lambda_{d, 1}$. Also, $\lambda_{d, 1}>0$ to satisfy this equation. Thus, this polynomial has one real root for $\lambda_{d, 1}$ in which $\lambda_{d, 1} \geq-\rho$ and $\lambda_{d, 1}>0$.

Given this strategy, informed demand in $t=1$ and $t=2$ is

$$
x_{1}=\frac{1}{2\left(\lambda_{d, 1}+\rho\right)} V
$$

and

$$
x_{2}=\frac{1}{2\left(\lambda_{d, 2}+\rho\right)}\left(V-\mathrm{E}\left[\tilde{V} \mid D_{1}\right]\right)
$$

The variance of the value of the risky asset, conditional on demand in the first period is

$$
\begin{aligned}
\sigma_{1}^{2} & =\operatorname{Var}\left(\tilde{V}-\mathrm{E}\left[\tilde{V} \mid D_{1}\right]\right) \\
& =\frac{\left(\lambda_{d, 1}+2 \rho\right)^{2}}{4\left(\lambda_{d, 1}+\rho\right)^{2}} \sigma_{0}^{2}+\lambda_{d, 1}^{2} \sigma_{z}^{2}
\end{aligned}
$$




\section{B.3 Equilibrium summary}

The market maker sets price using the strategy

$$
\begin{gathered}
P_{1}=\left(\lambda_{d, 1}+\rho\right) D_{1} \\
P_{2}=\left(\lambda_{d, 2}+\rho\right) D_{2}+\mathrm{E}\left[\tilde{V} \mid D_{1}\right]=\left(\lambda_{d, 2}+\rho\right) D_{2}+\lambda_{d, 1} D_{1}
\end{gathered}
$$

where $\lambda_{d, 1}$ and $\lambda_{d, 2}$ satisfy Equations (B.20) and (B.22).

The informed investor chooses his demand according to:

$$
\begin{aligned}
& x_{1}=\frac{2\left(\lambda_{d, 2}+\rho\right)-\lambda_{d, 1}}{4\left(\lambda_{d, 2}+\rho\right)\left(\lambda_{d, 1}+\rho\right)-\lambda_{d, 1}^{2}} V \\
& x_{2}=\frac{1}{2\left(\lambda_{d, 2}+\rho\right)}\left(V-\mathrm{E}\left[\tilde{V} \mid D_{1}\right]\right)
\end{aligned}
$$

\section{B.4 Properties of price changes}

I demonstrate that $\mathrm{E}\left[P_{2}-P_{1} \mid P_{1}\right] \propto-P_{1}$ when $\rho>0$ and $\frac{\partial}{\partial \rho} \mathrm{E}\left[P_{2}-P_{1} \mid P_{1}\right] \propto-P_{1}$. Since the informed investor is assumed to be Bayesian, his demand in each round of trade reflects the remaining information asymmetry between him and the market maker. The informed investor's linear demand functions can be summarized as:

$$
\begin{gathered}
x_{1}=\kappa_{V, 1} V \\
x_{2}=\kappa_{V, 2}\left(V-\mathrm{E}\left[\tilde{V} \mid D_{1}\right]\right)
\end{gathered}
$$

From the market maker's perspective $\mathrm{E}\left[\tilde{x_{2}} \mid D_{1}\right]=\mathrm{E}\left[\kappa_{V, 2}\left(\tilde{V}-\mathrm{E}\left[\tilde{V} \mid D_{1}\right]\right) \mid D_{1}\right]=0$, and $\mathrm{E}\left[\tilde{z}_{2}\right]=0$, so $\mathrm{E}\left[\tilde{D}_{2} \mid D_{1}\right]=$ 0. Given the market maker's pricing functions,

$$
\begin{gathered}
P_{2}-P_{1}=-\rho D_{1}+\left(\lambda_{d, 2}+\rho\right) D_{2} \\
\Rightarrow \mathrm{E}\left[P_{2}-P_{1} \mid P_{1}\right]=\mathrm{E}\left[-\rho D_{1}+\left(\lambda_{d, 2}+\rho\right) D_{2} \mid P_{1}\right]=-\frac{\rho}{\lambda_{d, 1}+\rho} P_{1}
\end{gathered}
$$

and

$$
\frac{\partial}{\partial \rho} \mathrm{E}\left[P_{2}-P_{1} \mid P_{1}\right]=-\frac{\lambda_{d, 1}}{\left(\lambda_{d, 1}+\rho\right)^{2}} P_{1}
$$


Thus, a sequential auction Kyle [1985] model with transaction costs predicts mean reversion in returns and cannot give rise to momentum. 